University of South Florida

DIGITAL COMMONS Digital Commons @ University of @ UNIVERSITY OF SOUTH FLORIDA South Florida

3-1-2010

\title{
Evaluation of Camera Based Systems to Reduce Transit Bus Side Collisions
}

CUTR

Follow this and additional works at: https://digitalcommons.usf.edu/cutr_nctr

\section{Recommended Citation}

"Evaluation of Camera Based Systems to Reduce Transit Bus Side Collisions," National Center for Transit Research (NCTR) Report No. CUTR-NCTR-RR-2009-07, Center for Urban Transportation Research, University of South Florida, 2010.

DOI: https://doi.org/10.5038/CUTR-NCTR-RR-2009-07

Available at: https://scholarcommons.usf.edu/cutr_nctr/143

This Technical Report is brought to you for free and open access by the National Center for Transit Research (NCTR) Archive (2000-2020) at Digital Commons @ University of South Florida. It has been accepted for inclusion in Research Reports by an authorized administrator of Digital Commons @ University of South Florida. For more information, please contact digitalcommons@usf.edu. 


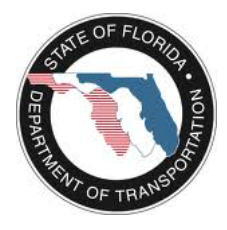

Florida Department of Transportation

\section{Final Report}

BDK85 Two 977-08

\section{Evaluation of Camera-Based Systems to Reduce Transit Bus Side Collisions}

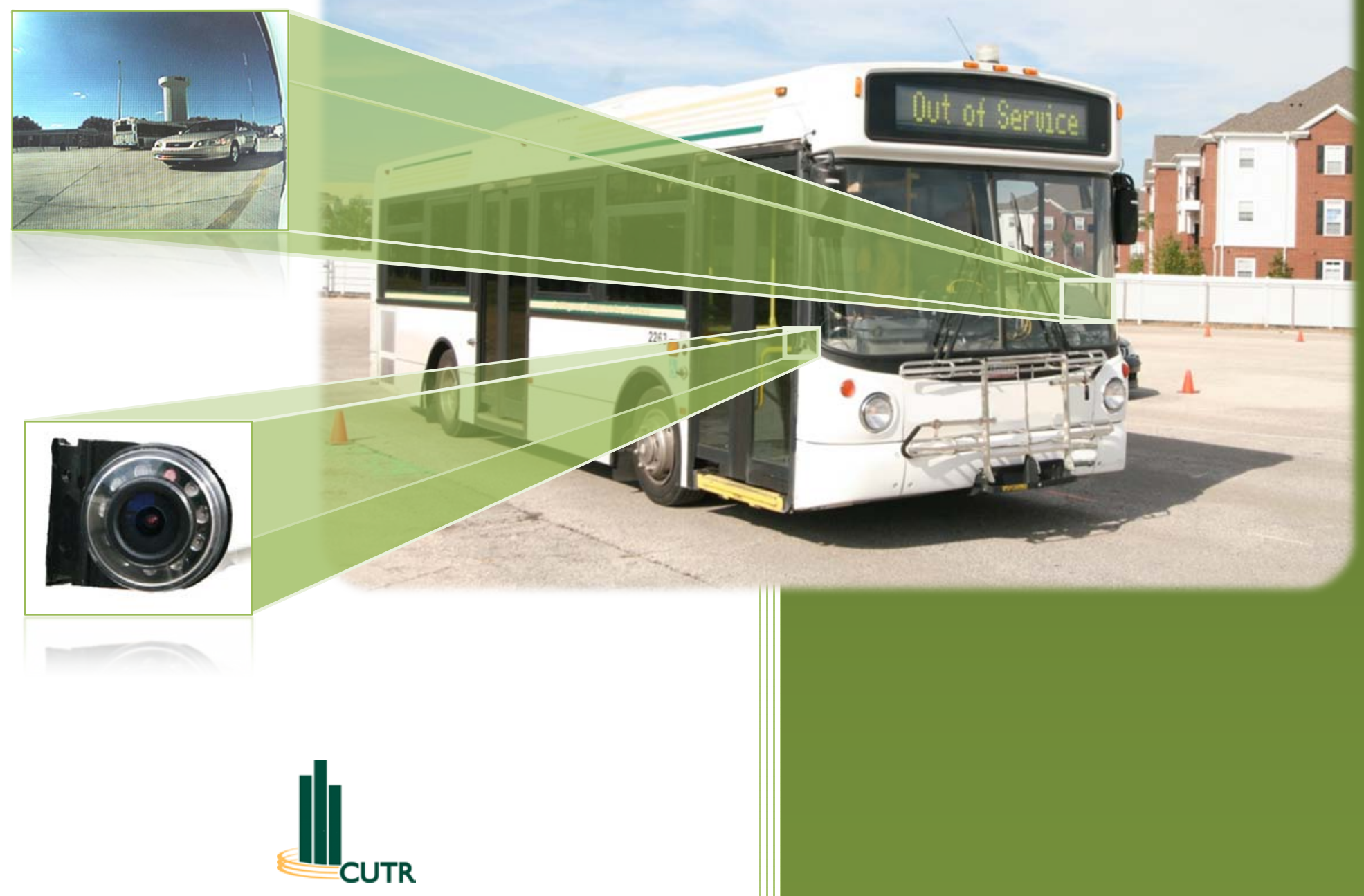

Center for Urban Transportation Research

March 2010 


\title{
Evaluation of Camera-Based Systems to Reduce Transit Bus Side Collisions
}

BDK85 Two 977-08

\author{
Final Report
}

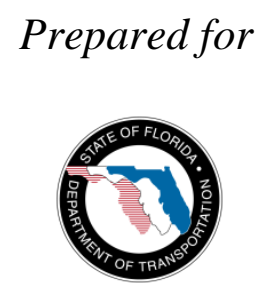

Florida Department of Transportation

Research Center

605 Suwannee Street, MS 30

Tallahassee FL 32399-0450

\section{Prepared by}

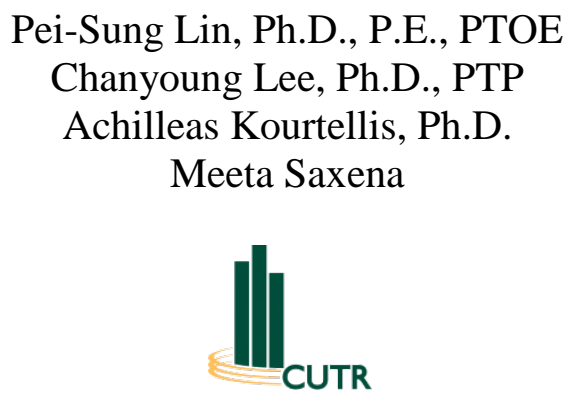

Center for Urban Transportation Research (CUTR) University of South Florida 4202 E. Fowler Ave. CUT100 Tampa, Florida, 33620-5375

March 31, 2010 


\section{Disclaimer}

The contents of this report reflect the views of the authors, who are responsible for the facts and the accuracy of the information presented herein. This document is disseminated under the sponsorship of the Department of Transportation University Transportation Centers Program and the Florida Department of Transportation, in the interest of information exchange. The U.S. Government and the Florida DOT assumes no liability for the contents or use thereof. 


\section{Metric Conversion Table \\ SI* (MODERN METRIC) CONVERSION FACTORS \\ APPROXIMATE CONVERSIONS TO SI UNITS}

\begin{tabular}{|c|c|c|c|c|}
\hline SYMBOL & WHEN YOU KNOW & MULTIPLY BY & TO FIND & SYMBOL \\
\hline in & inches & 25.4 & millimeters & $\mathrm{mm}$ \\
\hline $\mathrm{ft}$ & feet & 0.305 & meters & $\mathrm{m}$ \\
\hline $\mathrm{yd}$ & yards & 0.914 & meters & $\mathrm{m}$ \\
\hline $\mathrm{mi}$ & miles & 1.61 & kilometers & $\mathrm{km}$ \\
\hline $\mathrm{in}^{2}$ & square inches & 645.2 & square millimeters & $\mathrm{mm}^{2}$ \\
\hline $\mathrm{ft}^{2}$ & square feet & 0.093 & square meters & $\mathrm{m}^{2}$ \\
\hline $\mathrm{ft}^{3}$ & cubic feet & 0.028 & cubic meters & $\mathrm{m}^{3}$ \\
\hline $\mathrm{lb}$ & pounds & 0.454 & kilograms & $\mathrm{kg}$ \\
\hline
\end{tabular}

*SI is the symbol for the International System of Units. Appropriate rounding should be made to comply with Section 4 of ASTM E380. 


\section{Technical Report Documentation Page}

\begin{tabular}{|c|c|c|c|}
\hline \multirow{3}{*}{\multicolumn{2}{|c|}{\begin{tabular}{l|l} 
1. Report No. & 2. Government Accession No. \\
4. Title and Subtitle \\
Evaluation of Camera-Based Systems to Reduce Transit Bus Side \\
Collisions
\end{tabular}}} & \multicolumn{2}{|c|}{ 3. Recipient's Catalog No. } \\
\hline & & \multicolumn{2}{|l|}{$\begin{array}{l}\text { 5. Report Date } \\
\text { 3/31/2010 }\end{array}$} \\
\hline & & \multicolumn{2}{|c|}{ 6. Performing Organization Code } \\
\hline \multicolumn{2}{|c|}{$\begin{array}{l}\text { 7. Author(s) } \\
\text { Pei-Sung Lin, Chanyoung Lee, Achilleas Kourtellis, Meeta Saxena }\end{array}$} & \multicolumn{2}{|c|}{ 8. Performing Organization Report No. } \\
\hline \multirow{2}{*}{\multicolumn{2}{|c|}{$\begin{array}{l}\text { 9. Performing Organization Name and Address } \\
\text { Center for Urban Transportation Research } \\
\text { 4202 E. Fowler Avenue, CUT100 } \\
\text { Tampa FL 33620-5735 }\end{array}$}} & \multicolumn{2}{|c|}{ 10. Work Unit No. (TRAIS) } \\
\hline & & \multicolumn{2}{|c|}{$\begin{array}{l}\text { 11. Contract or Grant No. } \\
\text { BDK85 - Task Order TWO 977-08 } \\
\text { DTRT07-G-0059 }\end{array}$} \\
\hline \multirow{2}{*}{\multicolumn{2}{|c|}{$\begin{array}{l}\text { 12. Sponsoring Agency Name and Address } \\
\text { Research Center } \\
\text { Florida Department of Transportation } \\
605 \text { Suwannee St., MS } 30 \\
\text { Tallahassee, FL 32399-0450 } \\
\\
\text { Research and Innovative Technology Administration } \\
\text { U.S. Department of Transportation } \\
\text { Mail Code RDT-30 } \\
\text { 1200 New Jersey Ave, SE, Room E33 } \\
\text { Washington, D.C. 20590-0001 }\end{array}$}} & \multicolumn{2}{|c|}{$\begin{array}{l}\text { 13. Type of Report and Period Covered } \\
\text { Final Report } \\
01 / 22 / 09-04 / 30 / 10\end{array}$} \\
\hline & & \multicolumn{2}{|c|}{ 14. Sponsoring Agency Code } \\
\hline \multicolumn{4}{|l|}{ 15. Supplementary Notes } \\
\hline \multicolumn{4}{|c|}{$\begin{array}{l}\text { 16. Abstract } \\
\text { The camera-based system has great potential to reduce transit bus side crashes. This study reviewed and compared mirror- } \\
\text { based, sensor-based, and camera-based systems for side collision avoidance. It evaluated the effectiveness of camera-based } \\
\text { systems to reduce transit bus side crashes through measuring the reduction of blind zones and analyzing the results of } \\
\text { controlled driving tests and driver surveys using sideview video systems. The result from measurements of blind zone } \\
\text { reduction showed that the camera-based system with a regular angle lens (no distorted image) can reduce about } 64 \text { percent of } \\
\text { the blind zones of a flat mirror system. It can reduce about } 43 \text { percent of blind zones of a common combined flat and convex } \\
\text { mirror system. Using a wide-angle lens, the blind zones on the both sides of transit buses can be completely eliminated. The } \\
\text { result of the controlled driving test from } 28 \text { bus drivers was positive on distance/depth perception and lane change } \\
\text { maneuvers using sideview video systems. Most bus drivers were able to adapt to the sideview video system and quickly } \\
\text { learn how to use the system to drive without mirrors. While using the video system, the bus drivers could perceive distance } \\
\text { similar to the mirrors while the bus was in motion. By using the sideview system, bus drivers could still see the vehicle in } \\
\text { the blind zone of mirrors. The driver survey results confirmed that bus drivers participating in the study valued the benefits } \\
\text { of sideview video systems, with some reservations about system reliability due to unfamiliarity with the new system. It was } \\
\text { recommended that the sideview video system in this study be further enhanced for evaluation through actual deployments to } \\
\text { ensure its reliability and effectiveness. }\end{array}$} \\
\hline \multicolumn{2}{|c|}{$\begin{array}{l}\text { 17. Key Word } \\
\text { Transit bus side crash, camera-based system, sideview, video, side blind } \\
\text { zone, object detection, controlled driving test }\end{array}$} & \multicolumn{2}{|c|}{ 18. Distribution Statement } \\
\hline $\begin{array}{l}\text { 19. Security Classif. (of this report) } \\
\text { Unclassified }\end{array}$ & $\begin{array}{l}\text { 20. Security Classif. (of this page) } \\
\text { Unclassified }\end{array}$ & $\begin{array}{l}\text { 21. No. of Pages } \\
89\end{array}$ & 22. Price \\
\hline
\end{tabular}

Form DOT F 1700.7 (8-72) Reproduction of completed page authorized 


\section{Acknowledgements}

The authors would like to sincerely thank the project's manager, Ms. Erin K. Schepers, Florida TRIPS Manager at the Florida Department of Transportation Transit Office, for her guidance and support throughout the project. The authors would also like to thank the FDOT project panel, Mr. Victor Wiley and Mr. Jerry Hicks for their valuable input, as well as Mr. Hank Cusack and Ms. Deborah Sapper from the Transit Training and Technical Assistance Program at CUTR for their help and support. The authors also wish to express their appreciation to Mr. Jankristof DeVastey of Traffic Operations, Florida Department of Transportation-District VI, for providing transit crash data for analysis, and Mr. Rick Fallin, Director of USF's Bullrunner Transportation and Mr. Brian Abrams, Bullrunner training coordinator for their assistance and cooperation with use of their department's facilities, buses, and drivers for the controlled driving test. 


\section{Executive Summary}

One of the major reasons that side crashes occur if the bus drivers are at fault is that the drivers cannot see other vehicles or objects in the blind zones of the mirrors of the bus. This brings the bus driver into situations where he/she cannot see vehicles approaching from the side, especially during lane changing maneuvers. The camera-based system has great potential to significantly reduce or eliminate the blind zone of mirrors, thus reducing transit bus side crashes.

The primary objective of this study was to evaluate the effectiveness of camera-based systems to reduce transit bus side crashes in a controlled environment. The camera-based system for transit buses under evaluation through this study was a system that incorporates video cameras installed on the outside walls of the bus, aimed at the left and right rear sides of the bus, and two monitors connected inside the bus to provide the driver with an image from the cameras. This study evaluated the effectiveness of camera-based systems to reduce transit bus side crashes through measuring the reduction of blind zones and analyzing the results of controlled driving tests and driver surveys using sideview video systems.

Previous research on this matter included sensor-based systems covering all areas around the bus. These systems use proximity sensors to scan the area adjacent to the bus and provide the driver with an audible warning for eminent hazard. These sensor systems were deployed with transit agencies and tested, with some success. A major issue was that the sensors were not reliable the entire time, i.e., they did not perform continuous detection or missed objects. In addition, the sensor systems tested provided false alarms to an uncomfortable level, rendering the systems unusable by drivers.

The comparison of mirrors and camera systems from this study showed that the side blind zones that exist due to the mirrors' inability to cover the area were greatly reduced or eliminated when using the sideview video system with wide angle cameras. The result from volumetric measurements of blind zone reduction from this study showed that the camera-based system with a regular-angle lens (no distorted image) can reduce about $64 \%$ of the blind zones of a flat mirror system. It can reduce about $43 \%$ of blind zones of a common combined flat and convex mirror system. Using a wide-angle lens, the blind zones on the both sides of transit buses can be completely eliminated.

The camera-based technology for transit buses to reduce blind zones is fairly new, so there is no crash data associated with the implementation of the technology. The approach selected in this study was to closely evaluate the aftermarket sideview video system using a controlled driving test that simulated reality scenarios. The participating bus drivers performed the controlled driving tests with and without using the sideview video system. The controlled driving test had two parts: the first was to provide the drivers with a maneuver test to establish if the drivers 
could drive using the video system instead of the mirrors and to determine if they value the benefits of having such a system. The second part was to obtain feedback from the drivers about possible setup locations and monitor size and orientation, as well as enhancements to make the sideview video system more attractive for use through a driver survey taken before and after the driving test.

The result of the controlled driving test from 28 bus drivers was positive on distance/depth perception and lane change maneuvers with sideview video systems. Drivers were able to adapt to the sideview video system and quickly learn how to use the system to drive. While using the video system, the drivers could perceive distances similar to the mirrors while the bus was in motion. By using the sideview system, bus drivers could see vehicles in the blind zone of the mirrors. The bus drivers could see at least two lanes next to the bus, providing them the opportunity to avoid situations where a lane change maneuver would potentially result in a sideswipe crash.

The result of the driver survey confirmed that the majority of bus drivers participating in the controlled driving test liked the sideview video system and valued the benefits of the system, with some reservations about system reliability due to unfamiliarity with the new system. The majority of bus drivers agreed that the mirrors become less effective during rainy weather and that it is difficult to identify a person with them at night. The majority of bus drivers agreed that the sideview video system can be useful in helping them observe vehicles in the next lanes during lane changing maneuvers and see passengers better, and that the system can minimize or eliminate the side blind zones of the bus.

This study verified that the sideview video system could perform better than the mirrors in dark conditions due to infrared sensors as well as in rain. Also, the wide field of view provided the drivers with a much better sideview, thus creating great potential to avoid vehicles during lane changing maneuvers.

The sideview video systems used in the controlled driving test had minor limitations under certain lighting conditions, which can be further improved in the future. In addition, the size and location of the monitors can vary, providing an optimum viewing experience. It is important to note that the systems tested are available as aftermarket systems designed and manufactured to provide additional side views of the vehicle, but are not perfect and were not designed to be used in place of mirrors. Therefore, the sideview video system used in this study has great potential to be enhanced for use in the field to replace mirrors.

The result of the study shows very promising potential for the sideview video system to help bus drivers reduce side crashes caused by the side blind zones of mirrors. It demonstrated, via a controlled driving test, that a sideview video system can provide perceptions of distance and 
depth of other vehicles similar to those of mirrors. It also confirmed that most bus drivers can use a sideview video system to drive without issues. Most of the 28 bus drivers participating in the controlled driving test were able to quickly adapt to the sideview video system and learn how to use it to drive without mirrors. The study concluded that the sideview video system can significantly increase the safe operation of buses, especially for lane change maneuvers. It was recommended that the sideview video system in this study can be further enhanced for evaluation through field actual deployments to ensure its reliability and effectiveness. 


\section{Table of Contents}

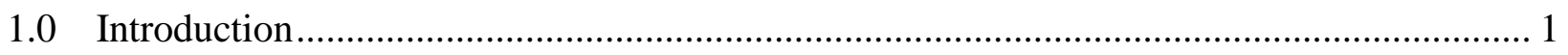

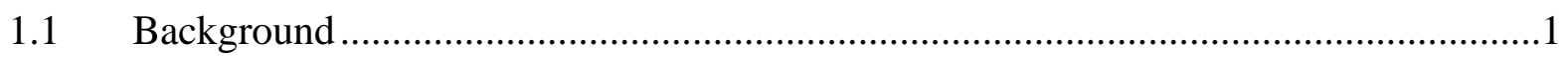

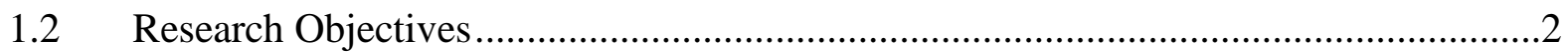

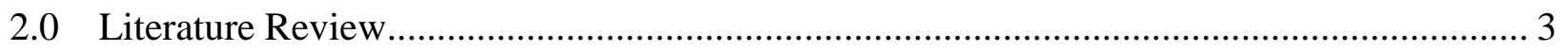

2.1 Common Transit Bus Side and Other Collisions Causes and Remedies .........................3

$2.2 \quad$ Review of Existing Mirror-Based Systems...............................................................6

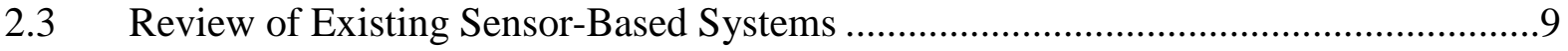

2.4 Review of Existing Camera-Based Systems..............................................................13

2.5 Comparison of Mirror-, Sensor-, and Camera-Based Systems for Side Collision Avoidance ...........................................................................................................17

3.0 Blind Zone Reductions for Transit Buses using Available Camera-Based Systems ........... 19

3.1 Blind Zones for Transit Buses ..............................................................................19

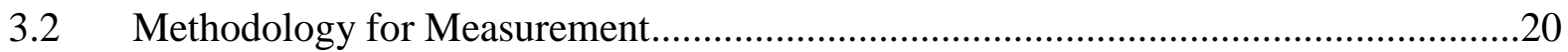

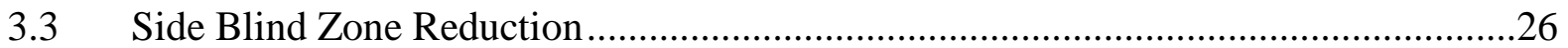

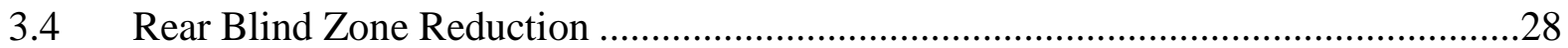

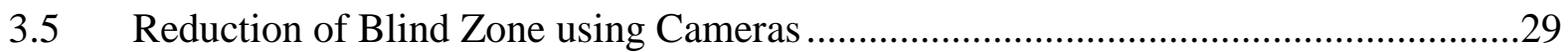

4.0 Controlled Driving Test with Sideview Video System................................................. 30

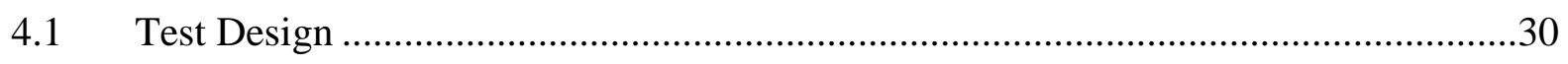

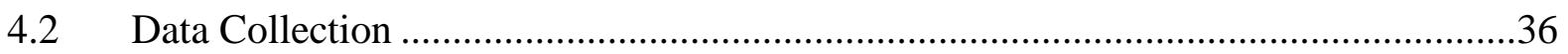

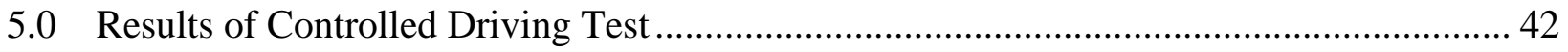

5.1 Distance/Depth Perception under Static Conditions.....................................................42

5.2 Distance/Depth Perception under Dynamic Conditions ..................................................43

5.3 Field of View under Dynamic Conditions ...............................................................45

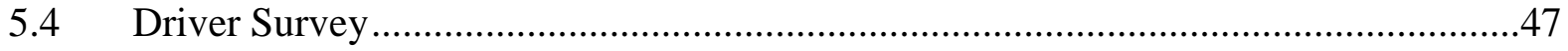

$5.5 \quad$ Sideview Video System Benefits...................................................................................6

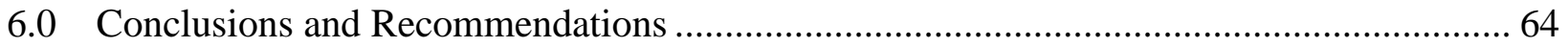

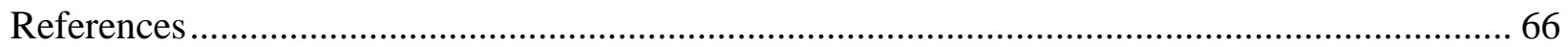

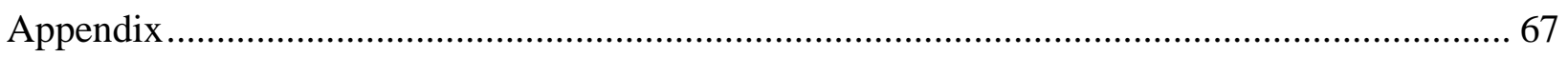




\section{List of Tables}

Table 2-1. Percentages of crashes with initial point of impact ................................................... 3

Table 2-2. Mix of collisions by type for transit buses vs. other modes (2005) ............................. 3

Table 2-3. Classification of bus at-fault crashes by first harmful event......................................... 4

Table 2-4. Contributing cause in bus at-fault lane change crashes .............................................. 4

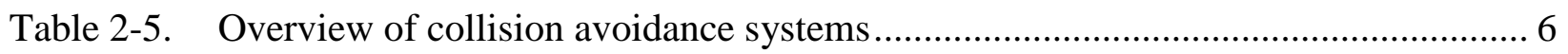

Table 2-6. Percent of collisions judged "avoidable" by type of collision ..................................... 6

Table 2-7. Summary of detection technologies........................................................................... 12

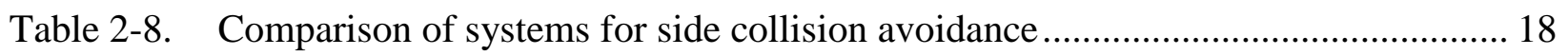

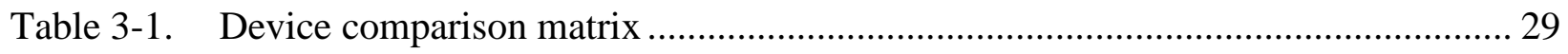

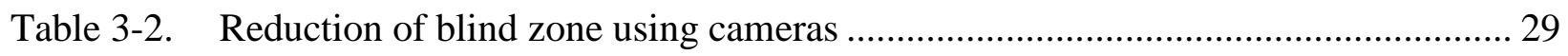

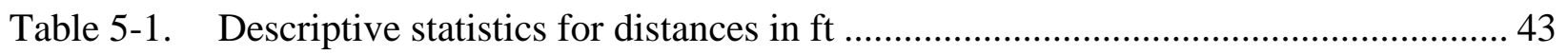

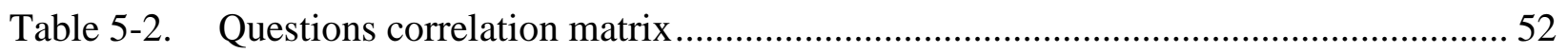

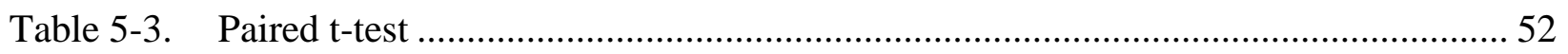

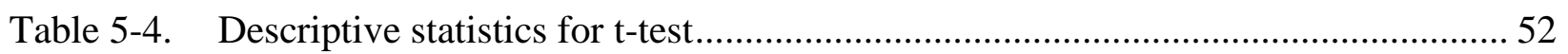

\section{List of Figures}

Figure 2-1. Field of view of flat and convex mirrors on low floor bus....................................

Figure 2-2. Modern housing for both flat and convex mirrors .................................................

Figure 2-3. Different types of mirror-based systems ...............................................................

Figure 2-4. Convex mirror capable of covering 70ft next to the vehicle ......................................

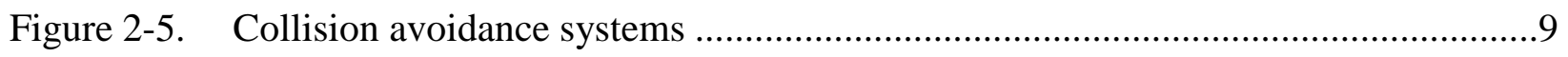

Figure 2-6. Sensor coverage along the length of the bus .....................................................12

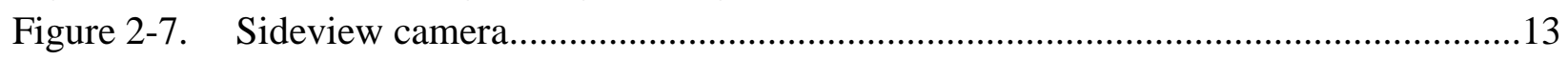

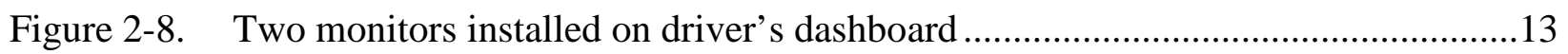

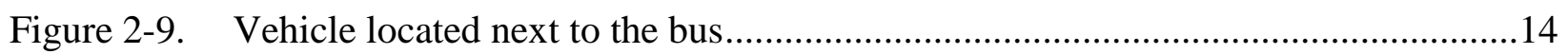

Figure 2-10. Mirror and monitor (portrait orientation) view of the vehicle...................................14

Figure 2-11. Monitor view in landscape orientation ................................................................15

Figure 2-12. Vehicle located behind the length of the bus ......................................................... 15

Figure 2-13. Mirror views for vehicle located behind the length of the bus................................16

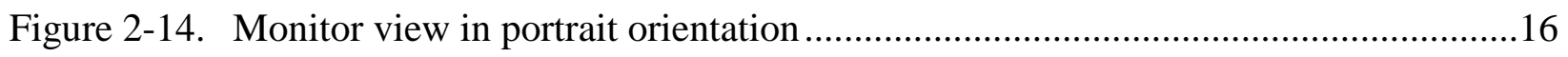

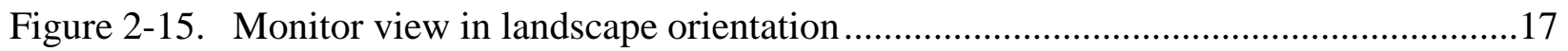

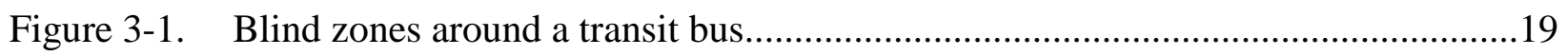

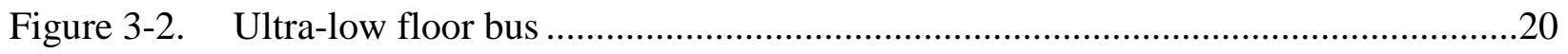

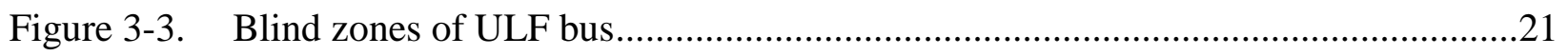

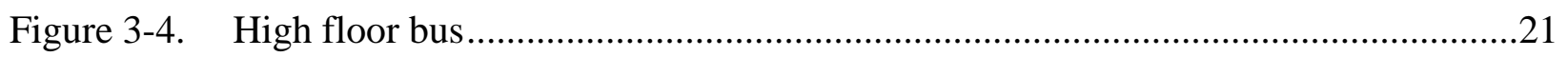

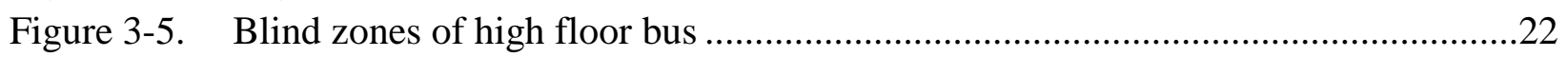

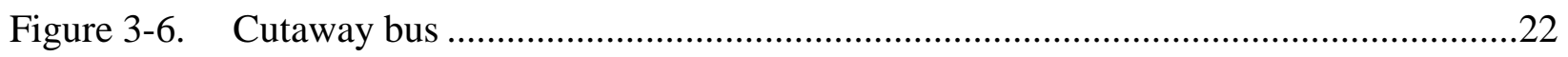




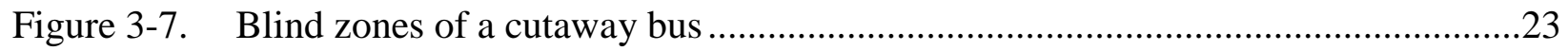

Figure 3-8. Plan and isometric view of blind zones for a bus.............................................23

Figure 3-9. Views of a transit bus with mirror blind zones ................................................25

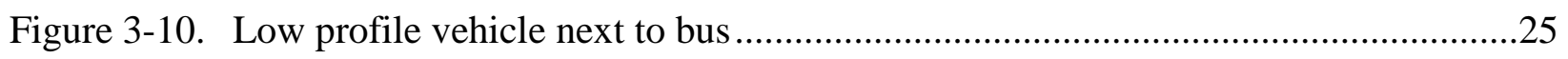

Figure 3-11. Blind zones of bus in road ............................................................................26

Figure 3-12. Field of view of mirrors and cameras.............................................................27

Figure 3-13. Progressive blind zone reduction using sideview video system...........................27

Figure 3-14. Rear blind zone covered by rearview camera ...................................................28

Figure 4-1. Closed course used during test ....................................................................31

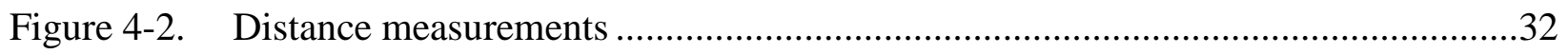

Figure 4-3. Lane change maneuver with vehicle in adjacent lane .......................................33

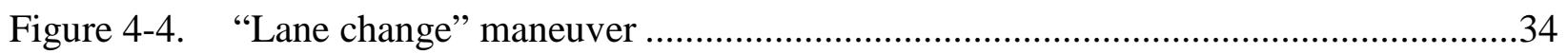

Figure 4-5. Lane change maneuver with vehicle in next to adjacent lane ..............................34

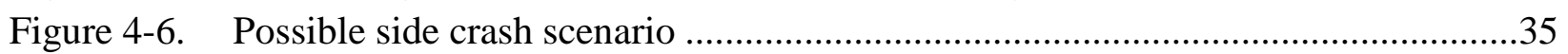

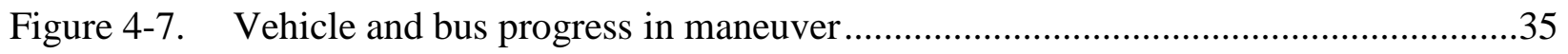

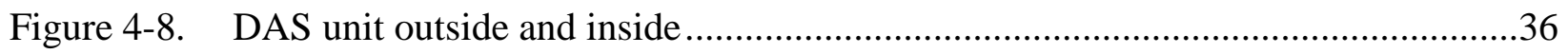

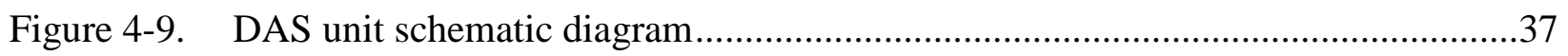

Figure 4-10. Left (1) and right (2) side cameras, left and right side monitors, DAS unit and

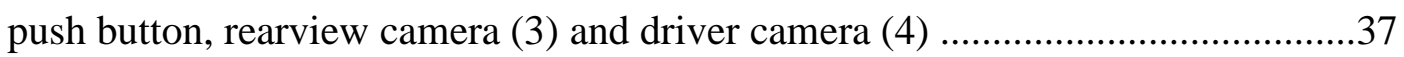

Figure 4-11. Camera locations and fields of view ..............................................................38

Figure 4-12. Screenshot from the software used for video analysis ........................................39

Figure 4-13. The actual scale used for distance measurement ...............................................39

Figure 4-14. Scale placement behind the bus.......................................................................40

Figure 4-15. Virtual scale used to measure distance ...............................................................40

Figure 4-16. Distance measurement during "lane change” maneuver .......................................41

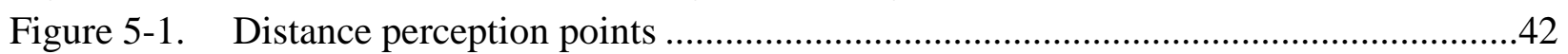

Figure 5-2. Distance measurements for lane change with mirrors.......................................44

Figure 5-3. Distance measurement for lane change with sideview video system....................44

Figure 5-4. Vehicle visible with video system but not with mirrors......................................45

Figure 5-5. Maneuver diagram and location of other vehicle ..............................................46

Figure 5-6. Left-and right-side camera images ...............................................................46

Figure 5-7. Driver age distribution...........................................................................4

Figure 5-8. Driver responses on survey question: Do you agree that the side mirrors become less effective during rainy weather due to water droplets on the window glass and mirrors?

Figure 5-9. Driver responses on survey question: Do you agree that it is difficult to identify an object/person with the side mirrors during nighttime?

Figure 5-10. Driver responses to survey question: With the sideview video system, the side blind spots are reduced/eliminated compared to conventional mirrors 
Figure 5-11. Driver responses to survey question: The sideview video system can help drivers to reduce side crashes (sideswipe, turns, angle crashes) by providing a better view

Figure 5-12. Driver responses to survey question: In general, the sideview video system can improve bus safety .... .50

Figure 5-13. Driver responses to survey question: The use of the sideview video system is easy and can be adopted quickly ....

Figure 5-14. Driver responses to survey question: Would you agree to replace the mirrors with the sideview video system?....

Figure 5-15. Driver responses to survey question: Do you agree that with the sideview video system you can observe the boarding and late arriving passengers better than with the mirror?

Figure 5-16. Driver responses to survey question: The sideview video system provides a better side view than the mirrors ....

Figure 5-17. Driver responses to survey question: Do you agree that you can comfortably driver the bus with the sideview video system alone (without mirrors)?................54

Figure 5-18. Driver responses to survey question: Would you like to have the sideview video system in the bus you driver every day?

Figure 5-19. Driver responses to survey question: With the sideview video system, you felt comfortable performing a lane change maneuver.

Figure 5-20. Driver responses to survey question: The sideview video system has the potential to help reduce side crashes during a lane change maneuver

Figure 5-21. Driver responses to survey question: The sideview video system can minimize or eliminate the side blind zones of the bus 56

Figure 5-22. Monitor orientation.....................................................................................56

Figure 5-23. Driver responses to survey question: How would you prefer to have the monitors oriented - portrait or landscape? 57

Figure 5-24. Left and right monitor installed next to mirror in portrait orientation ...................58

Figure 5-25. Driver responses to survey question about setup scenario .................................59

Figure 5-26. Driver responses to survey question about monitor size ......................................59

Figure 5-27. Image from camera-based system during nighttime ........................................60

Figure 5-28. Image from mirror during nighttime ........................................................61

Figure 5-29. Image from mirror through driver's window while raining ...............................61

Figure 5-30. Image from sideview while raining...........................................................62

Figure 5-31. Mirror views for vehicle located behind the length of the bus ..............................62

Figure 5-32. Side camera location on cutaway bus.........................................................63 


\subsection{Introduction}

\subsection{Background}

Transit bus side crashes occur for a number of reasons. Some of them include driver misjudgment, driver inattention, side blind zones, and other drivers' actions. According to the Federal Motor Vehicle Safety Standards No. 111: Rearview Mirrors, every vehicle, including transit buses, is required to have an inside mirror and two outside mirrors that extend the driver's rear view. These mirrors are called rearview mirrors because they provide the rear view. For this report, the outside mirrors will be called sideview mirrors. Transit buses, as well as most commercial vehicles, do not have an inside rearview mirror because they usually do not have a rear window or the rear window is too far to provide the driver with useful view information. The primary use of the sideview mirrors is to help the driver with surveillance of the surroundings of the vehicle while driving, especially in lane change and parking maneuvers.

Mirror-based systems have evolved over the years because of the need to provide a better view to the driver and now include more than one mirror with different magnifications. However, current mirror-based systems have several limitations. First, they do not cover the whole side area of the vehicle, thus leaving what are referred to as "blind zones." Second, they are less effective during adverse weather, such as rain or fog. And finally, they are required to be large in size and extend out of the vehicle perimeter in order to provide the necessary view to the driver. However, since transit buses come very close to the edge of the pavement to pick up standing pedestrians and passengers, a mirror that extends out of the bus footprint is not desirable. There have been reported cases where a pedestrian was struck by the mirror from a passing bus.

In addition to the small number of crashes, research has shown that up to 94 percent of sideswipe and mirror crashes are not reported in Florida's state crash database because there is no police report [1]. This shows a large under-representation of less severe crashes.

Research has been conducted in previous years on systems to help address the issues of mirrors and side crashes. Different technologically-advanced systems have been proposed to help the driver detect and avoid objects next to the bus. This research is shown in the following chapter, Literature Review. 


\subsection{Research Objectives}

This project has five primary objectives:

1) Compare available systems, including mirror-, sensor-, and camera-based technologies, to reduce transit bus side and other collisions.

2) Measure blind zone reductions on the side of common types of transit buses using camera-based systems.

3) Conduct and analyze transit bus driving tests with and without camera-based systems in a controlled environment.

4) Conduct and analyze transit bus driver surveys on driver satisfaction for using camera-based systems on lane changes.

5) Provide major findings and recommendations. 


\subsection{Literature Review}

\subsection{Common Transit Bus Side and Other Collisions Causes and Remedies}

According to data obtained from the Federal Transit Administration's (FTA) 2002 National Transit Database (NTD), nearly 46 percent of bus accidents occur on the left or right side of the bus, compared to 25 percent occurring at the front of the bus and 19 percent occurring at the rear of the bus [2]. Table 2-1 shows the percentage of fatal or injury-related crashes per location. According to the Traffic Safety Facts reports from 1999-2003, an average of 40 fatalities and 18,430 injuries of bus occupants occurred per year [3]. The majority of fatal crashes involving buses result from frontal crashes. Bus occupant injuries are evenly distributed to crashes on all sides of the bus. Reported property damage costs range from \$3,660 per incident for sideswipe collisions to nearly $\$ 13,085$ for collisions with fixed objects. These collisions impact the availability of buses for revenue operations, add to the cost of providing transit services, and can have a negative effect on public perception of transit. For these reasons, FTA began working with the transit industry, researchers, and private vendors in 1998 to support the development and study of a Side Object Detection System (SODS) for transit buses.

Table 2-1. Percentages of crashes with initial point of impact

\begin{tabular}{|l|c|c|c|}
\hline \multicolumn{1}{|c|}{ Initial Point of Impact } & Total & Fatal & Injury \\
\hline Front & $25 \%$ & $64 \%$ & $37 \%$ \\
\hline Side (Left or Right) & $46 \%$ & $14 \%$ & $36 \%$ \\
\hline Rear & $19 \%$ & $16 \%$ & $25 \%$ \\
\hline
\end{tabular}

According to Dunn et al., the sideswipe collisions of transit buses with other vehicles account for 33 percent of total crashes [4]. As shown in Table 2-2, angle and sideswipe crashes caused a total of 44 percent of crashes.

Table 2-2. Mix of collisions by type for transit buses vs. other modes (2005) ${ }^{1}$

\begin{tabular}{|l|c|c|c|c|c|c|}
\hline \multirow{2}{*}{ Mode } & \multicolumn{3}{|c|}{ Collisions with vehicles } & Other/non- & Pedestrian & $\begin{array}{c}\text { Object } \\
\text { collision }\end{array}$ \\
\cline { 2 - 7 } & Front/rear & Angle & Sideswipe & collision & collion \\
\hline Transit Bus & $30 \%$ & $11 \%$ & $33 \%$ & $13 \%$ & $2 \%$ & $10 \%$ \\
\hline All Roadway Modes & $30 \%$ & $29 \%$ & $8 \%$ & $4 \%$ & $2 \%$ & $27 \%$ \\
\hline
\end{tabular}

The data from the Florida Crash Analysis Reporting (CAR) System were analyzed for the time period 2003-2006 with the purpose of studying bus lane changing maneuvers and characteristics. The crashes where the bus was at fault have remained consistent over the years, with an average

\footnotetext{
${ }^{1}$ The figures in this table corresponding to the "transit bus" mode are based on analysis of data from NTD and collision records provided by six transit agencies participating in this study. The values shown for "all roadway modes” are based on General Estimates System (GES) data.

${ }^{2}$ Includes, for example, road departure crashes, rollovers, and other accidents not otherwise classified.
} 
of 2,489 annual bus at-fault crashes. Side collisions include many categories of crashes. It was identified that side crashes with the potential to be avoided included mainly lane change maneuvers and turning maneuvers. Sideview mirrors are used by drivers mainly while changing lanes and making turns. Specifically, drivers perform lane changing maneuvers primarily based on the information obtained from both sideview mirrors. A review of bus at-fault crashes by their first harmful event is shown in Table 2-3. It can be seen that sideswipe crashes are on the rise, mostly due to improper lane changes. One of the major causes of improper lane change crashes is the side blind zone caused by the mirror's limited view. In addition, some rear end, turn, and angle crashes are caused by the blind zone.

Table 2-3. Classification of bus at-fault crashes by first harmful event

\begin{tabular}{|l|c|c|c|c|c|}
\hline \multicolumn{1}{|c|}{ First Harmful Event } & $\mathbf{2 0 0 3}$ & $\mathbf{2 0 0 4}$ & $\mathbf{2 0 0 5}$ & $\mathbf{2 0 0 6}$ & Total \\
\hline Rear End & $17.01 \%$ & $17.19 \%$ & $17.37 \%$ & $16.35 \%$ & $16.98 \%$ \\
\hline Angle & $13.09 \%$ & $11.08 \%$ & $11.48 \%$ & $11.11 \%$ & $11.67 \%$ \\
\hline Left Turn & $7.13 \%$ & $6.07 \%$ & $7.36 \%$ & $6.58 \%$ & $6.79 \%$ \\
\hline Right Turn & $2.49 \%$ & $3.38 \%$ & $3.62 \%$ & $4.45 \%$ & $3.50 \%$ \\
\hline Sideswipe & $16.93 \%$ & $17.72 \%$ & $18.49 \%$ & $18.79 \%$ & $18.00 \%$ \\
\hline Backed Into & $6.04 \%$ & $6.40 \%$ & $4.78 \%$ & $5.91 \%$ & $5.76 \%$ \\
\hline Collision with Parked Car & $9.08 \%$ & $8.43 \%$ & $7.59 \%$ & $9.18 \%$ & $8.56 \%$ \\
\hline Collision with Moving Vehicle on Roadway & $1.60 \%$ & $1.67 \%$ & $1.58 \%$ & $1.69 \%$ & $1.64 \%$ \\
\hline Collision with Pedestrian & $1.90 \%$ & $1.47 \%$ & $2.00 \%$ & $1.89 \%$ & $1.82 \%$ \\
\hline Hit Utility/Light Pole & $1.65 \%$ & $1.43 \%$ & $1.23 \%$ & $1.26 \%$ & $1.39 \%$ \\
\hline Hit Fence & $1.14 \%$ & $0.45 \%$ & $0.85 \%$ & $0.39 \%$ & $0.70 \%$ \\
\hline Hit Tree/Shrubbery & $1.18 \%$ & $1.38 \%$ & $1.27 \%$ & $0.91 \%$ & $1.18 \%$ \\
\hline Collision with Fixed Object above Road & $1.52 \%$ & $0.08 \%$ & $2.39 \%$ & $1.65 \%$ & $1.43 \%$ \\
\hline Hit Other Fixed Object & $2.20 \%$ & $1.67 \%$ & $2.58 \%$ & $2.01 \%$ & $2.12 \%$ \\
\hline All Other & $17.01 \%$ & $21.59 \%$ & $17.41 \%$ & $17.84 \%$ & $12.17 \%$ \\
\hline Total & $100.00 \%$ & $100.00 \%$ & $100.00 \%$ & $100.00 \%$ & $100.00 \%$ \\
\hline
\end{tabular}

Table 2-4 shows that improper lane changing was a major contributing cause and accounted for about 65 percent of lane change crashes.

Table 2-4. Contributing cause in bus at-fault lane change crashes

\begin{tabular}{|l|c|c|c|c|c|}
\hline \multicolumn{1}{|c|}{ Contributing Cause } & $\mathbf{2 0 0 3}$ & $\mathbf{2 0 0 4}$ & $\mathbf{2 0 0 5}$ & $\mathbf{2 0 0 6}$ & Total \\
\hline No Improper Driving/Act & $2.17 \%$ & $1.75 \%$ & $3.57 \%$ & $2.41 \%$ & $2.54 \%$ \\
\hline Careless Driving & $15.22 \%$ & $12.28 \%$ & $18.57 \%$ & $15.66 \%$ & $15.63 \%$ \\
\hline Failed to Yield & $6.52 \%$ & $7.02 \%$ & $6.43 \%$ & $6.63 \%$ & $6.64 \%$ \\
\hline Improper Lane Change & $66.30 \%$ & $65.79 \%$ & $64.29 \%$ & $63.25 \%$ & $64.65 \%$ \\
\hline Improper Passing & $2.17 \%$ & $0.00 \%$ & $0.71 \%$ & $1.81 \%$ & $1.17 \%$ \\
\hline All Other & $7.61 \%$ & $13.16 \%$ & $6.43 \%$ & $10.24 \%$ & $9.38 \%$ \\
\hline Total & $100.00 \%$ & $100.00 \%$ & $100.00 \%$ & $100.00 \%$ & $100.00 \%$ \\
\hline
\end{tabular}


Sideswipe crashes with no associated lane changing maneuver typically involved damage to the bus side mirror. This damage to the mirror was due to the mirror hitting other vehicles' mirrors or the mirror hitting a pole or, in some cases, pedestrians.

Based on the descriptions in the long form reports, there are two kinds of limited view situations. One is that the driver did not see the other vehicle/object because it was located in the blind zone. The other is when the driver did not have the complete view due to weather conditions such as moisture on glass, rain, fog, and darkness, or being careless in noticing a bicyclist driving around the bus.

"Bus hitting an object due to human error" accounts for the majority of all bus crashes. Although no driver would deliberately hit another vehicle or object, human error and misjudgment appear to be the number one cause of bus crashes. The majority of the descriptions of bus crashes mention the driver hitting a parked car, losing control and hitting road signs, not turning on time or misjudging clearance, taking wide turns, failing to move around stationary objects, and not braking on time. A very common pattern in human error was a bus driver hitting mailboxes and road signs.

Crashes associated with lane changing maneuvers are increasing every year. The lane changing maneuver involves the use of sideview mirrors to assess surrounding traffic and a proper judgment in a timely manner. To enhance the safety of lane changing maneuvers, it is desirable to have a system that can address the blind spot issue and also help drivers make proper assessments and judgments during the maneuver. The camera-based system proposed in this study holds great potential to aid or even replace bus side mirrors to provide drivers with a clear view of both sides of the bus. It is, therefore, prudent to test the performance of camera-based systems in respect to blind spot reduction and perception of distance by drivers.

A number of in-vehicle technologies have been developed to mitigate transit bus collisions of all types. Table 2-5 below shows the technologies available in 2008 for transit buses. One of the causes of side crashes of transit buses is the side blind spot. When the bus operator cannot see far enough next to the vehicle, it can cause collisions, especially during turning and lane changing maneuvers. Since the technologies are fairly new and have no history of use, their effectiveness can only be estimated. The same study showed investigation of the potential of the technologies in avoiding collisions. Expert panels were created to review a number of documented crash reports and ranked which of the systems they thought could help the avoidance of a crash. 
Table 2-5. Overview of collision avoidance systems

\begin{tabular}{|c|l|l|l|}
\hline $\begin{array}{c}\text { Collision Avoidance } \\
\text { Systems }\end{array}$ & $\begin{array}{c}\text { Sensor } \\
\text { Technology }\end{array}$ & $\begin{array}{c}\text { System } \\
\text { Manufacturer }\end{array}$ & \multicolumn{1}{|c|}{ System Availability } \\
\hline \multirow{2}{*}{ FCWS } & Video & Mobileye & Commercialized \\
\cline { 2 - 4 } & Lidar/Radar & PATH & Prototype \\
\hline \multirow{2}{*}{ RCWS } & Lidar & AATA/UMTRI & Prototype \\
\hline \multirow{2}{*}{ FODS } & Ultrasonic & Clever Devices & Commercialized \\
\cline { 2 - 4 } & Video & Mobileye & Under Development \\
\hline \multirow{2}{*}{ RODS } & Ultrasonic & Clever Devices & Commercialized \\
\hline \multirow{2}{*}{ LDWS } & Ultrasonic & Clever Devices & Under Development \\
\cline { 2 - 4 } & Video & Mobileye & Under Development \\
\hline \multirow{2}{*}{ PDS } & Video & Mobileye & Commercialized \\
\cline { 2 - 4 } & Video & Iteris & Commercialized-trucks only \\
\cline { 2 - 4 } & Video & Assistware & Commercialized-trucks only \\
\hline & Video & Mobileye & Application only \\
\hline
\end{tabular}

The panel of experts reviewed 58 documented cases. Table 2-6 shows the percentage of collisions deemed avoidable by the panel [4].

Table 2-6. Percent of collisions judged “avoidable” by type of collision [3]

\begin{tabular}{|c|c|c|c|c|c|c|c|}
\hline \multicolumn{5}{|c|}{ With vehicle } & \multirow{2}{*}{$\begin{array}{c}\text { With } \\
\text { pedestrian }\end{array}$} & \multirow{2}{*}{$\begin{array}{c}\text { With } \\
\text { object }\end{array}$} & \multirow{2}{*}{$\begin{array}{c}\text { All } \\
\text { collisions }\end{array}$} \\
\hline Front & Rear & Angle & Sideswipe & Other & & & \\
\hline $28 \%$ & $16 \%$ & $14 \%$ & $18 \%$ & $32 \%$ & $35 \%$ & $90 \%$ & $29 \%$ \\
\hline
\end{tabular}

The following sections show the available mirror-based systems, the available sensor-based systems, the available camera-based systems, and a comparison of all the systems.

\subsection{Review of Existing Mirror-Based Systems}

Mirror-based systems are the traditional means used by drivers for visual surveillance of the vehicle's surroundings. This section presents a review of existing mirror-based systems available for transit buses. Each side of the vehicle has either one or two mirrors to help the driver see next to the vehicle. Figure 2-1 shows the coverage of the mirrors.

Flat surface (West Coast) mirrors provide views directly along the side of the vehicle, reaching $5 \mathrm{ft}$ wide near the rear end of the bus.

Convex surface mirrors provide extended views from the traditional flat surface mirror up to $15 \mathrm{ft}$ wide near the rear end of the bus. The convex mirror covers the flat mirror field of view (FOV) as well. 

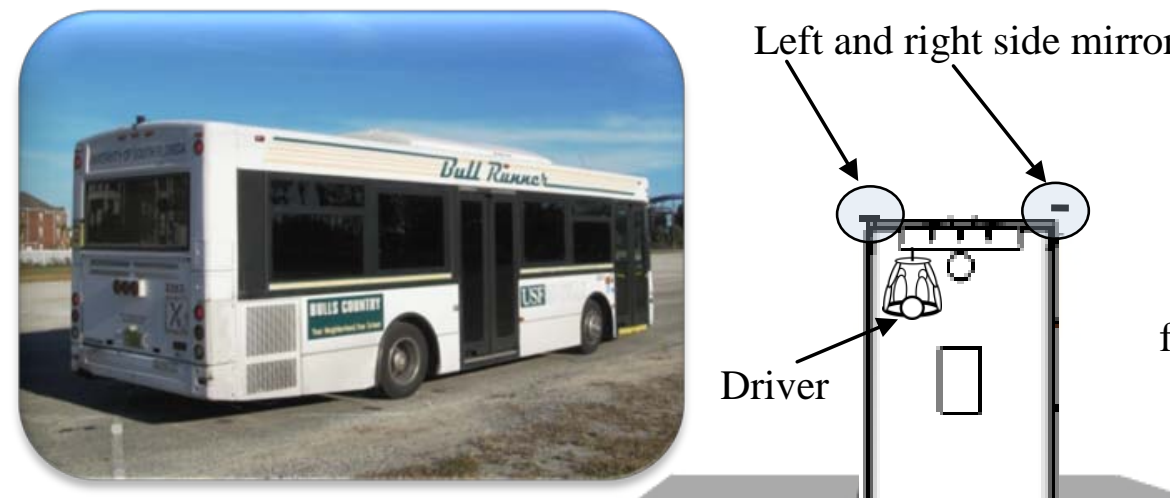

Flat mirror

field of view

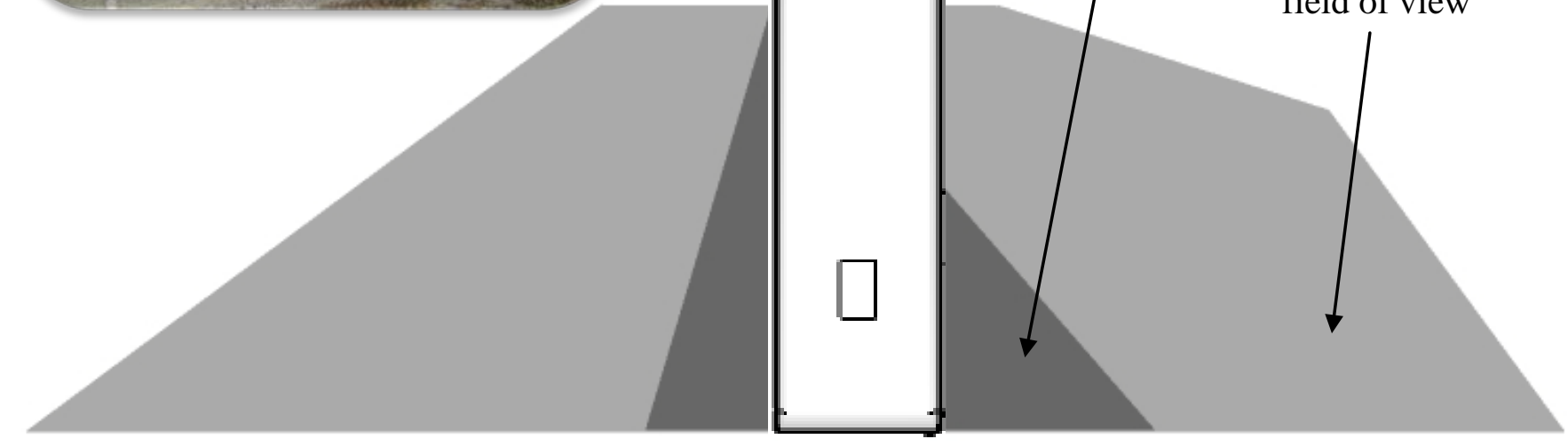

(The field of view is drawn in scale to the bus size)

Figure 2-1. Field of view of flat and convex mirrors on low floor bus

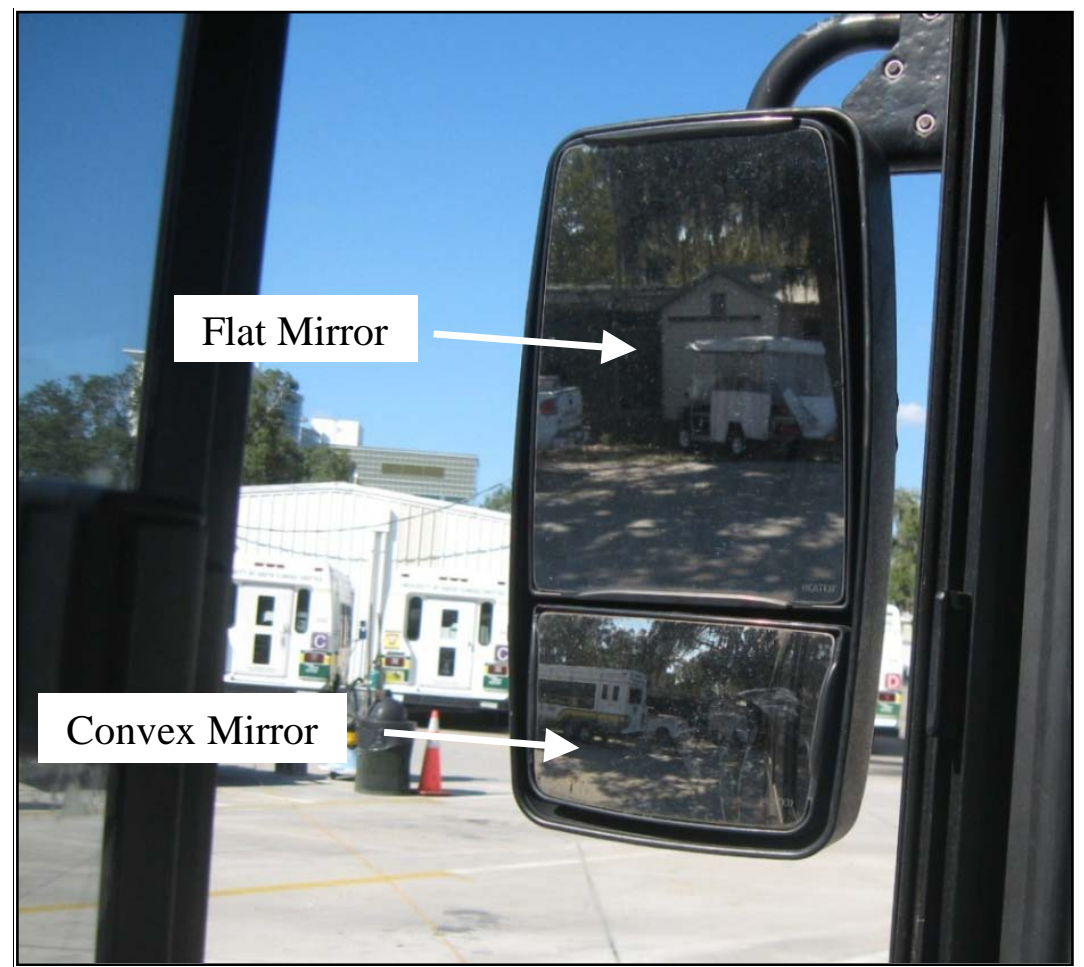

Figure 2-2. Modern housing for both flat and convex mirrors 
Over the years, convex mirrors have been used more frequently to cover the viewing needs of large vehicles. The area a convex mirror can cover relates to the angle of curvature of the surface. A mirror with a larger angle of curvature can obviously provide a wider FOV. The problem it creates, however, is that the view is as deformed as the mirror itself, so the objects cannot be identified as easily as on a flat surface mirror. In recent years, different designs of convex mirrors have improved visibility without experiencing the distortion of the traditional convex mirrors. Two different mirror-based systems are shown in Figure 2-3. In the literature review, it was found that a company has produced a convex mirror capable of covering $70 \mathrm{ft}$ next to the vehicle (shown in Figure 2-4), as opposed to the $18 \mathrm{ft}$ of visibility with the traditional mirror.
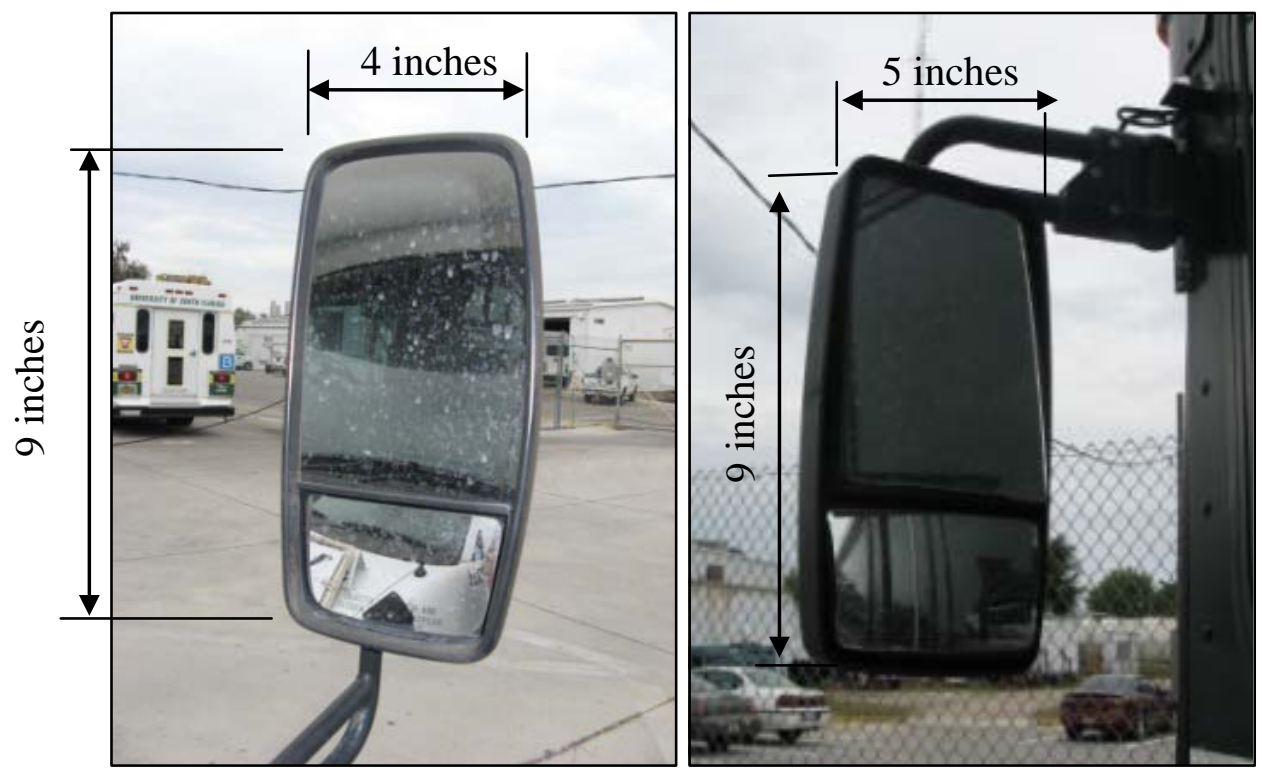

Figure 2-3. Different types of mirror-based systems

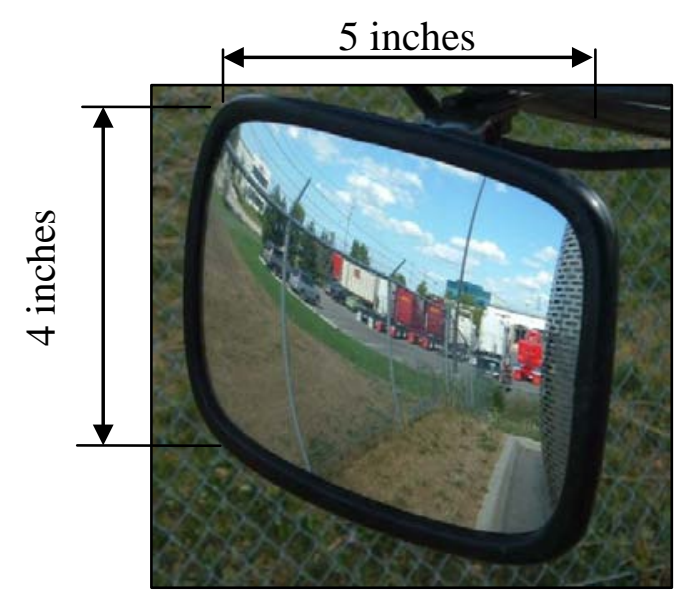

Figure 2-4. Convex mirror capable of covering $70 \mathrm{ft}$ next to the vehicle 


\subsection{Review of Existing Sensor-Based Systems}

In the last decade, sensor systems have been used more frequently in systems designed to warn the driver of objects in close proximity to the vehicle. These systems are categorized as either Object Detection Systems (ODS) or collision warning systems. According to Dunn et al., the ODS shown in Figure 2-5 are intended to monitor the area within close proximity of the vehicle (e.g., up to 10ft) and provide a visual or audible warning when an object is detected near the vehicle [4]. Given this small proximity, ODS are sometimes considered an "enhancement" to the driver's mirror. These systems can detect the presence of an object but not its distance or relative speed. In Figure 2-5, ODS are represented by the circular shaped areas. They are defined as follows:

Forward Object Detection Systems (FODS) monitor the area in front of a vertical plane intersecting the front bus wheels (the area within the forward view of the driver).

Side Object Detection Systems (SODS) monitor the area behind the vertical plane intersecting the front bus wheels. It does not include the area behind the vehicle, only the area from the front wheels, down the side of the bus, to the rear bumper.

Rear Object Detection Systems (RODS) monitor the area directly behind the vehicle.

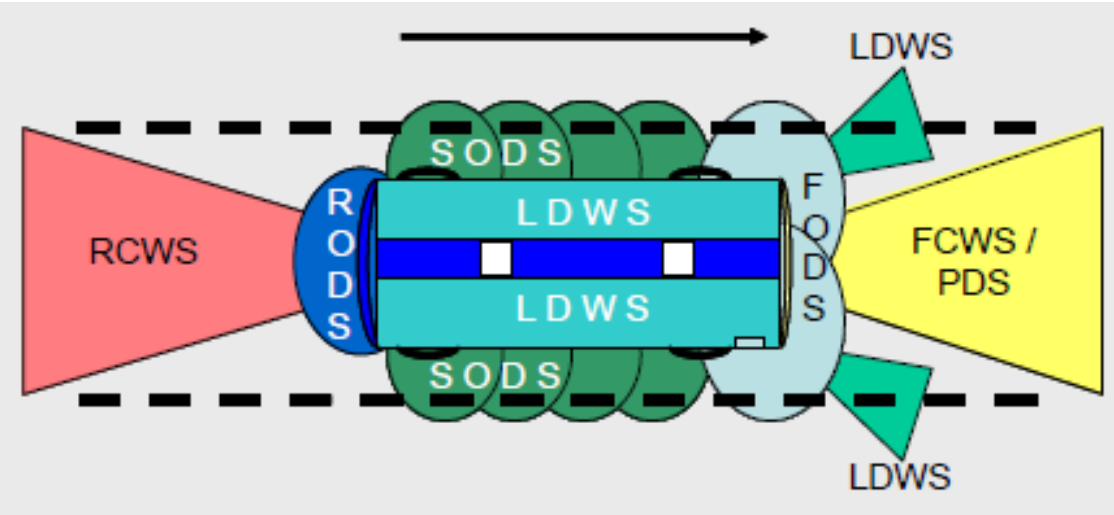

O FCWS / PDS O RCWS O FODS O SODS O RODS OLDWS

Figure 2-5. Collision avoidance systems [4]

Collision Warning Systems (CWS) monitor distances further away from the vehicle (up to $500 \mathrm{ft}$ ) and warn the driver of impending collisions. Algorithms use distance and relative speed information supplied by the detection sensors to calculate the time to contact of a detected object, and then provide the driver with visual or audible warnings that increase in intensity as the time to contact approaches zero. The systems will provide warnings to the driver as vehicles/objects enter the field of view or as the vehicle approaches a fixed object. Figure 2-5 illustrates the different type of CWS with triangular shapes. They include the following: 
Forward Collision Warning Systems (FCWS) use forward-looking sensors and warn the driver of the "time to contact" with a vehicle in the driver's lane. Forward sensors are situated in the front of a vehicle with a widening view as they scan farther ahead.

Rear Collision Warning Systems (RCWS) warn the driver of an approaching vehicle of a rearend collision. The warning is an external indicator on the back of the equipped bus that alerts the driver in the approaching vehicle (The driver of the equipped vehicle is not alerted of the impending collision).

Lane Departure Warning Systems (LDWS) are camera-based systems that monitor lane markings. Together with object recognition software and algorithms that compute closing distance, LDWS provide warnings when a lane or road edge departure is imminent via visual, audible, or tactile warning signals.

Each collision avoidance system relies on at least one of the following four underlying detection technologies:

- Lidar - radar-like systems that function at near-infrared wavelengths

- Traditional radar-based systems

- Ultrasonic-based sensors

- Computer vision systems

The role of these technologies is to provide information on the presence of objects near a vehicle, the proximity of those objects, and, for some technologies, the differences in the relative speeds of the bus and the detected object. The selection of which specific detection technology to use in developing any given collision avoidance system depends directly on the system's intended application, the desired performance characteristics, and the supplier's design philosophy. The following are brief descriptions of each of these detection methods.

\section{Lidar-Based Systems}

Lidar-based systems transmit a light beam to the area surrounding the vehicle and then detect the presence of nearby objects through the reflected signal. In addition to direction, Lidar systems can determine an object's distance and relative speed. The ideal operation range for Lidar is $6 \mathrm{ft}$ to $100 \mathrm{ft}$, between which this technology provides excellent angle resolution. Lidar systems are susceptible to weather conditions (e.g., being able to "see" through fog or heavy precipitation). In general, if an object is not detectable by the naked eye, then it is unlikely that a Lidar-based system will provide an adequate warning of the impending collision. Therefore, during times of fog, heavy rain, or heavy snow, the system will become inoperable. Given these characteristics, Lidar-based systems are preferred by those that believe a collision avoidance system should not extend beyond the driver's view. This position is based, in part, on the concern that systems that extend the driver's view beyond what is visible with the naked eye may encourage reckless 
driving, particularly in poor weather conditions. Lidar sensors have a high cost of implementation, and the output power level must be limited to meet eye safety constraints due to the light beam operating in the near-infrared range.

\section{Radar-Based Systems}

In contrast to Lidar, the performance of radar-based systems is not adversely affected by poor weather conditions. Hence, this technology is favored by those who believe collision avoidance systems offer their greatest benefits during adverse weather. Radar-based systems are capable of detecting objects out to 500ft but suffer from low angular resolution, poor detection at medium range (i.e., $100 \mathrm{ft}$ to $200 \mathrm{ft}$ ), and generally inferior resolution to Lidar. As with Lidar, radar sensors have a high cost of implementation.

\section{Ultrasonic-Based Sensors}

Ultrasonic-based sensors are reliable and inexpensive. They operate at a high frequency (20 kHz to $200 \mathrm{kHz}$ ) and are similar to the back-up sensors installed on passenger vehicles. The sensors emit an ultrasonic signal that is capable of traveling $10 \mathrm{ft}$ to $12 \mathrm{ft}$. The system detects the object when a recognizable echo is reflected from it and the system can measure the detected object's distance and relative speed. Sensors provide a clear signal for detection algorithms and are less influenced by interference than radar and Lidar systems. Their disadvantage is the limited detection range; they cannot detect objects beyond a small area around the vehicle. In addition, they are only capable of providing a recognizable echo from solid objects with reflective surfaces, i.e., metal. Therefore, they should not be used for "soft object" detection (e.g., pedestrians wearing clothing). The latest side object detection system in use for transit buses was evaluated in Side Object Detection Evaluation [2]. As shown in Figure 2-6, the side object detection system uses ultrasonic sensors that cover a small area directly next to the bus.

\section{Computer Vision Systems}

Computer vision systems have been used primarily for FCWS and RCWS. A forward-looking camera is used for detection of objects. A pixel-based recognition algorithm identifies objects that may be of concern to the driver. The use of pixel-based recognition can distinguish pedestrians from other objects, a form of detection that is not possible with Lidar, radar, or ultrasonic-based systems. With the low cost of the camera, video-based sensors have a low cost of implementation. Video-based sensors rely on ideal lighting conditions for detection. Therefore, in situations where the driver's field of vision is impaired, the system will not function well; this includes adverse weather conditions, direct sunlight, and evening. In most of the video systems reviewed, the video-based systems are supplemented with infrared sensors to ensure object detection under a greater range of conditions than that permitted by a video-based system alone. This allows for the image to be illuminated and the cameras to work even in absolute darkness (night vision mode). These camera-based systems are passive and, therefore, 
cannot issue a warning to the driver. They have to be used as a sensor for an algorithm to detect, identify, and issue a warning for a specific purpose. Therefore, this is called computer vision.

Sensor-based systems were designed to supplement the view provided by the mirrors of the vehicle to reduce side crashes. The systems have a number of different modes to help with false alarms and ensure better tolerance by the drivers who seem to be very sensitive about such systems. It is clear that the mirrors alone do not provide the driver with the view needed for 100 percent collision-free operation. A brief comparison of the sensor-based detection technologies is shown in Table 2-7.

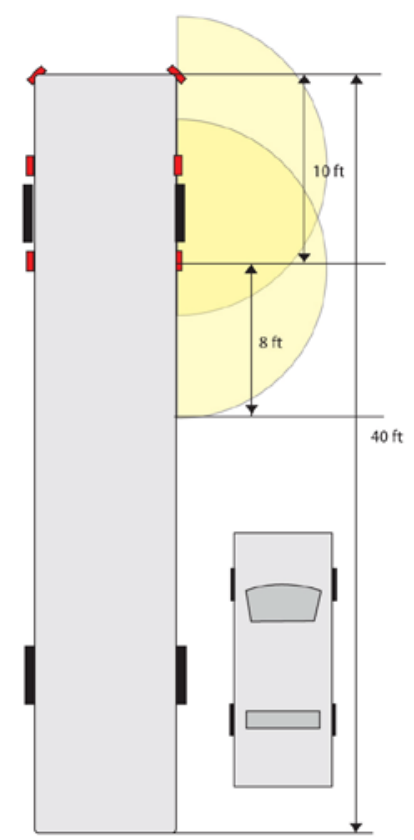

Figure 2-6. Sensor coverage along the length of the bus

Table 2-7. Summary of detection technologies [2]

\begin{tabular}{|c|c|c|c|c|}
\hline \multirow{2}{*}{ Strengths } & Ultrasonic & Radar & Infrared Laser & Computer Vision \\
\cline { 2 - 5 } & Accuracy, price & $\begin{array}{c}\text { Accuracy, } \\
\text { environmental } \\
\text { tolerance, low } \\
\text { profile installation }\end{array}$ & Accuracy & $\begin{array}{c}\text { Ability to distinguish } \\
\text { pedestrians from other } \\
\text { objects }\end{array}$ \\
\hline Weaknesses & $\begin{array}{c}\text { Weather, irregular } \\
\text { surfaces, limited range, } \\
\text { does not reliably detect } \\
\text { pedestrians* }\end{array}$ & N/A & $\begin{array}{c}\text { Weather, } \\
\text { required } \\
\text { processing } \\
\text { power }\end{array}$ & $\begin{array}{c}\text { Weather, required } \\
\text { processing power, } \\
\text { several frames required } \\
\text { for identification }\end{array}$ \\
\hline
\end{tabular}

*Although ultrasonic sensors may sometimes detect pedestrians, they do not do so reliably since the detection is dependent on factors such as the clothing the pedestrian is wearing. For example, if the pedestrian is wearing clothing made of a synthetic fiber such as nylon, they might be detected, but if the pedestrian is wearing clothing made of a natural fiber such as cotton, they may not be detected. 


\subsection{Review of Existing Camera-Based Systems}

Existing camera-based systems are either used as vision sensors or as vision aids. Using cameras installed at strategic locations on the vehicle, the systems present the cameras' image to the driver just as a mirror would. The camera can be installed at any location that is blind to the driver. Usually, these areas include the rear of large vehicles and the sides beyond the mirror FOV. The cameras have a very small physical size compared to the mirrors, and the monitors can be placed anywhere in the driver's cockpit. Figure 2-7 shows a sideview camera installed temporarily on the side of a bus. Figure 2-8 shows two monitors installed on the driver's dashboard for the two sideview cameras (left and right).

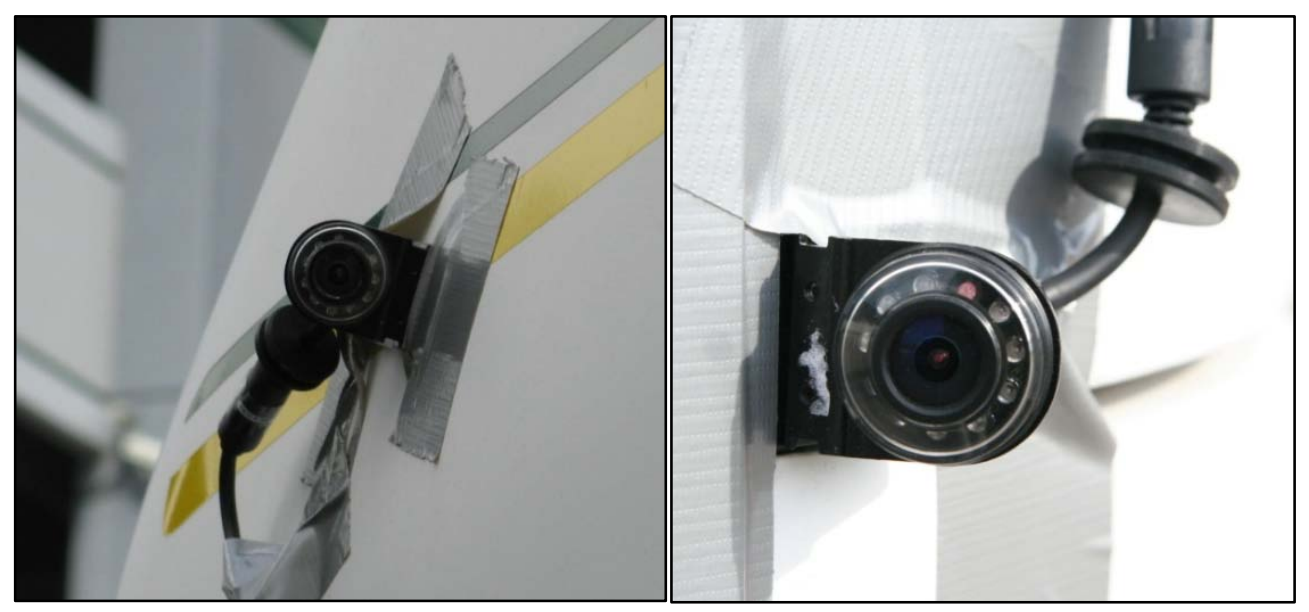

Figure 2-7. Sideview camera

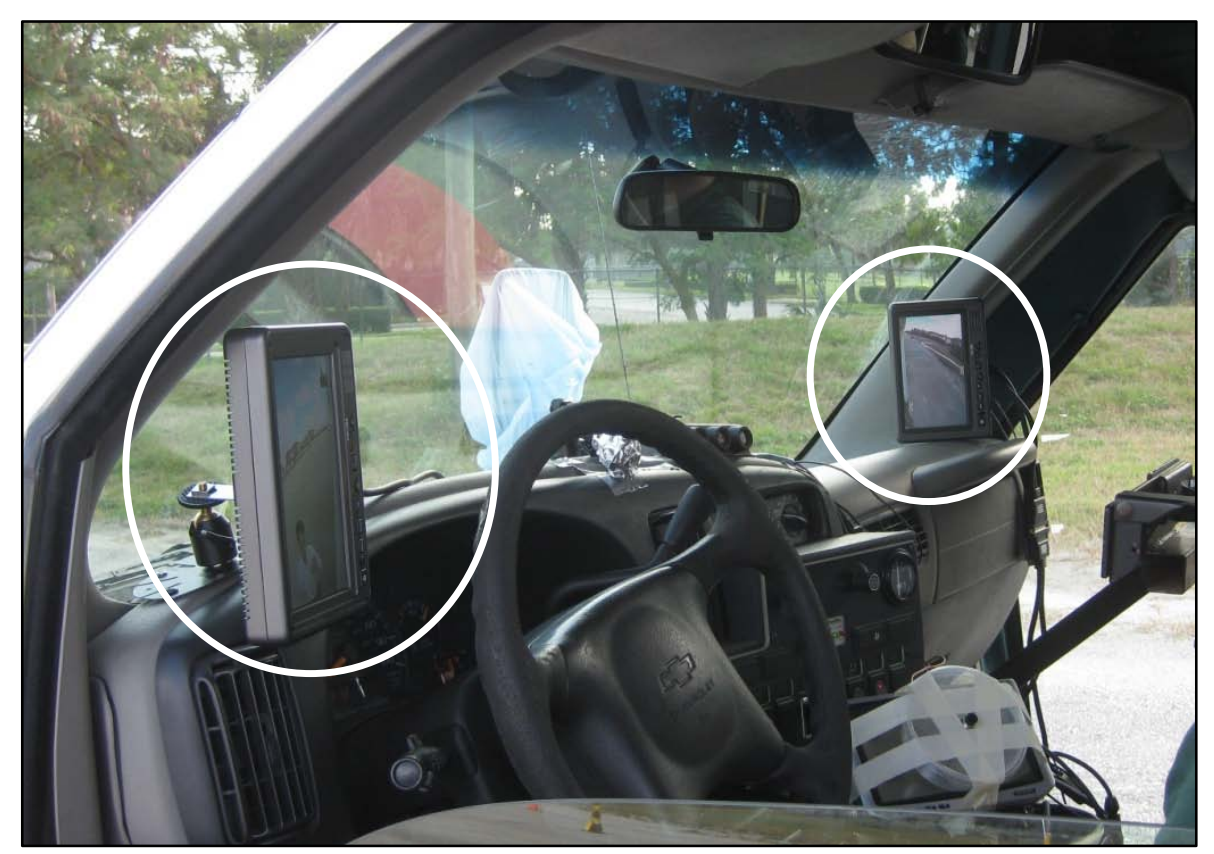

Figure 2-8. Two monitors installed on driver's dashboard 
Figure 2-9 shows a vehicle next to a bus, just as a vehicle would be in the adjacent lane while driving. Figure 2-10 shows how the vehicle would be seen in the mirrors and in the monitor of the sideview video system in portrait orientation. Figure 2-11 shows the same vehicle view but with the monitor in landscape orientation.

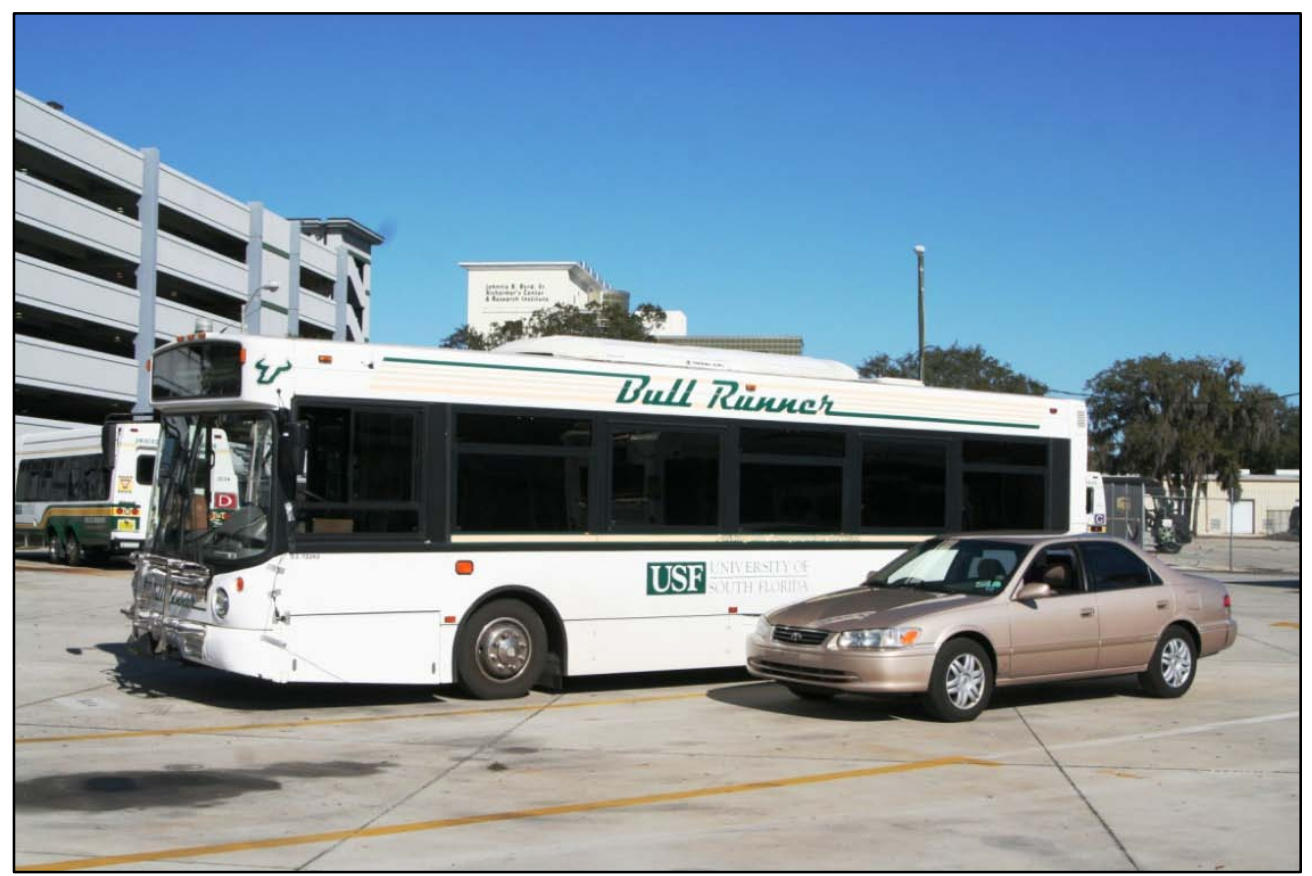

Figure 2-9. Vehicle located next to the bus
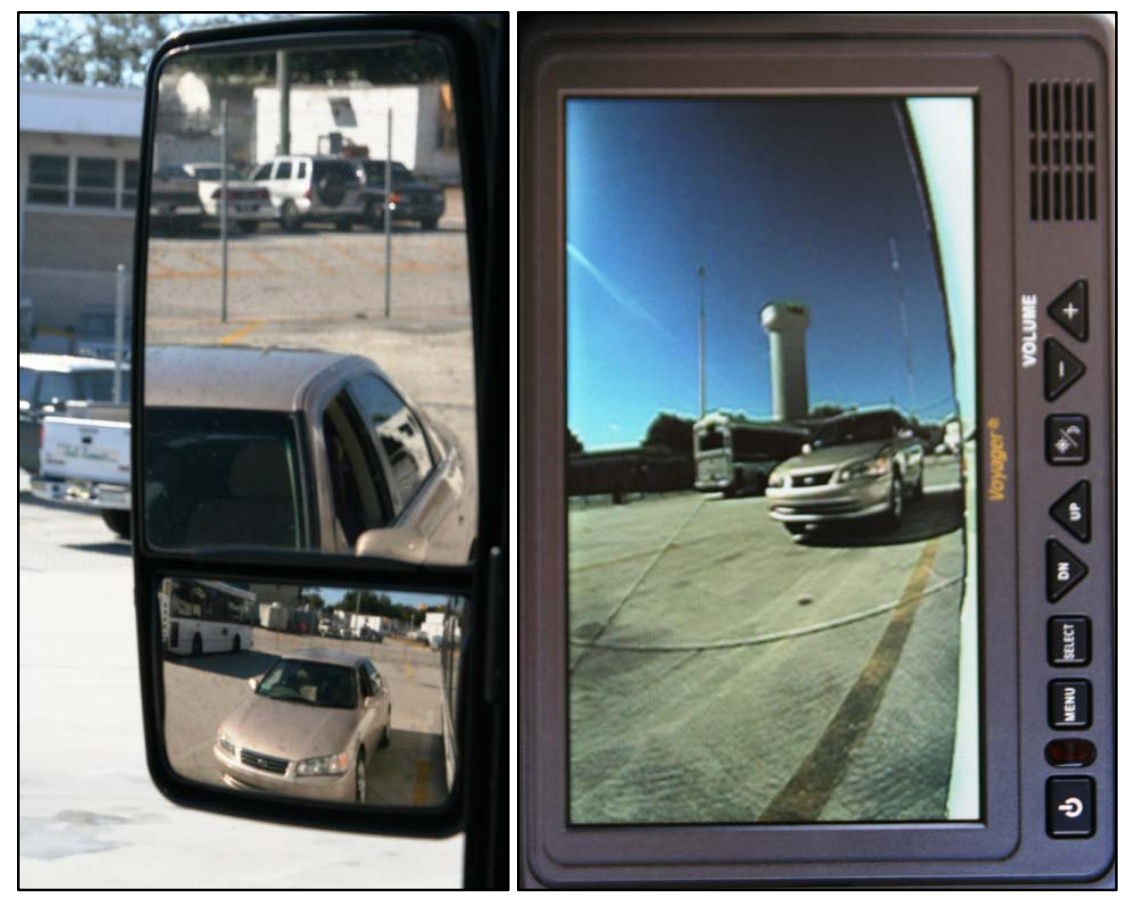

Figure 2-10. Mirror and monitor (portrait orientation) view of the vehicle 


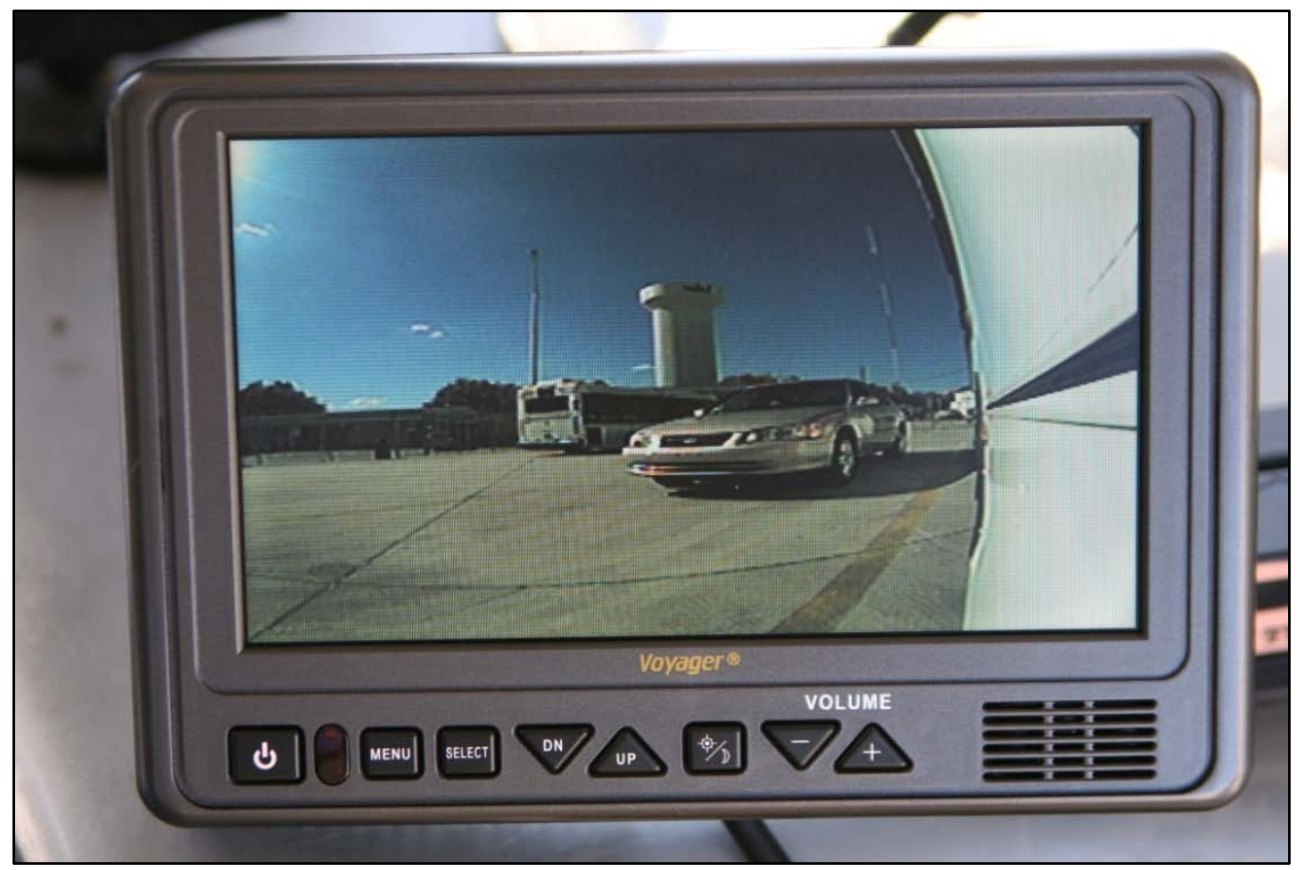

Figure 2-11. Monitor view in landscape orientation

When a vehicle is located behind the bus in the adjacent lane (Figure 2-12), the vehicle can be seen in the mirrors. However, different drivers may have different views using a mirror because of adjustment angles and height of the driver (Figure 2-13). For most drivers, mirror adjustment is necessary. With the sideview video system, there is no adjustment necessary since the FOV of the camera, once set, is the same for all drivers.

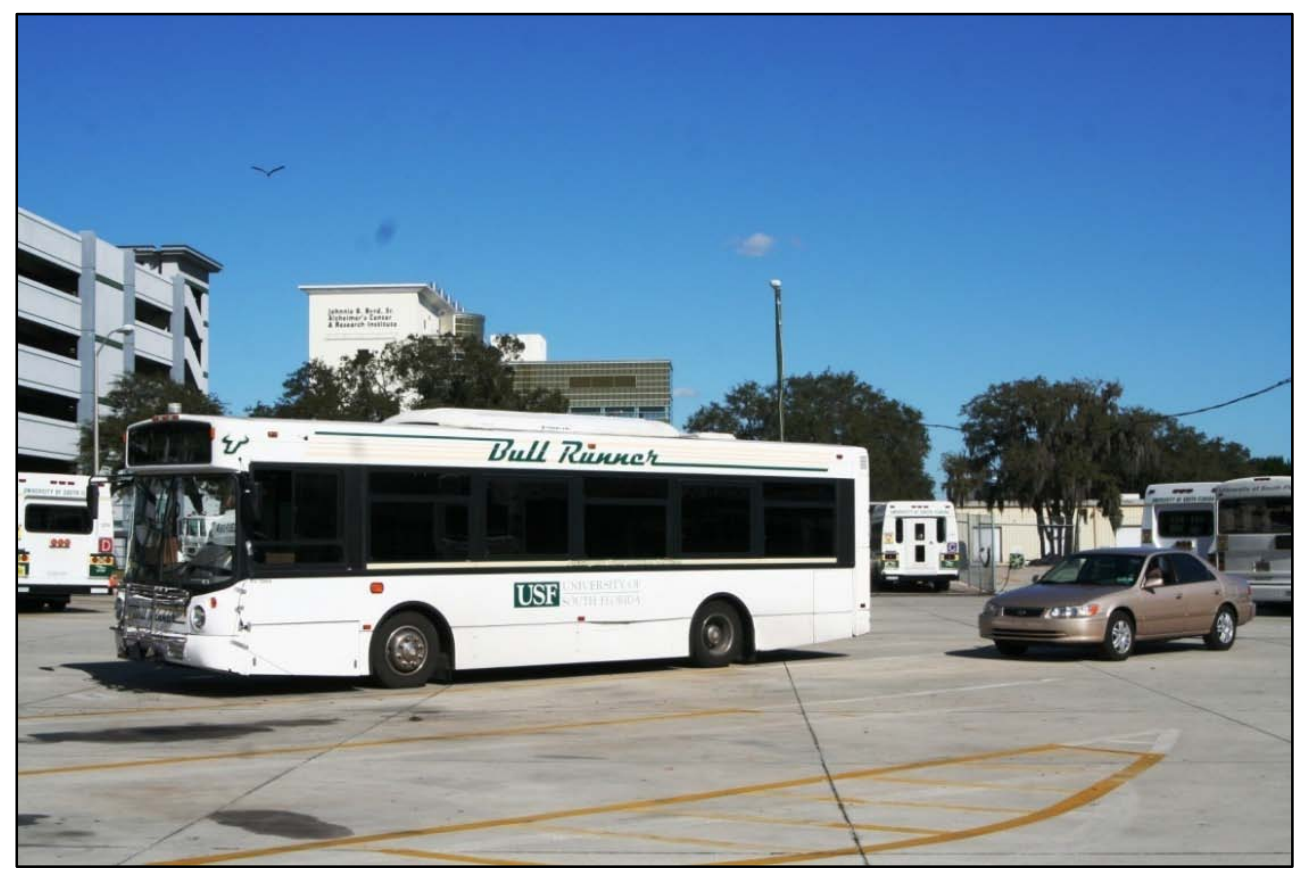

Figure 2-12. Vehicle located behind the length of the bus 


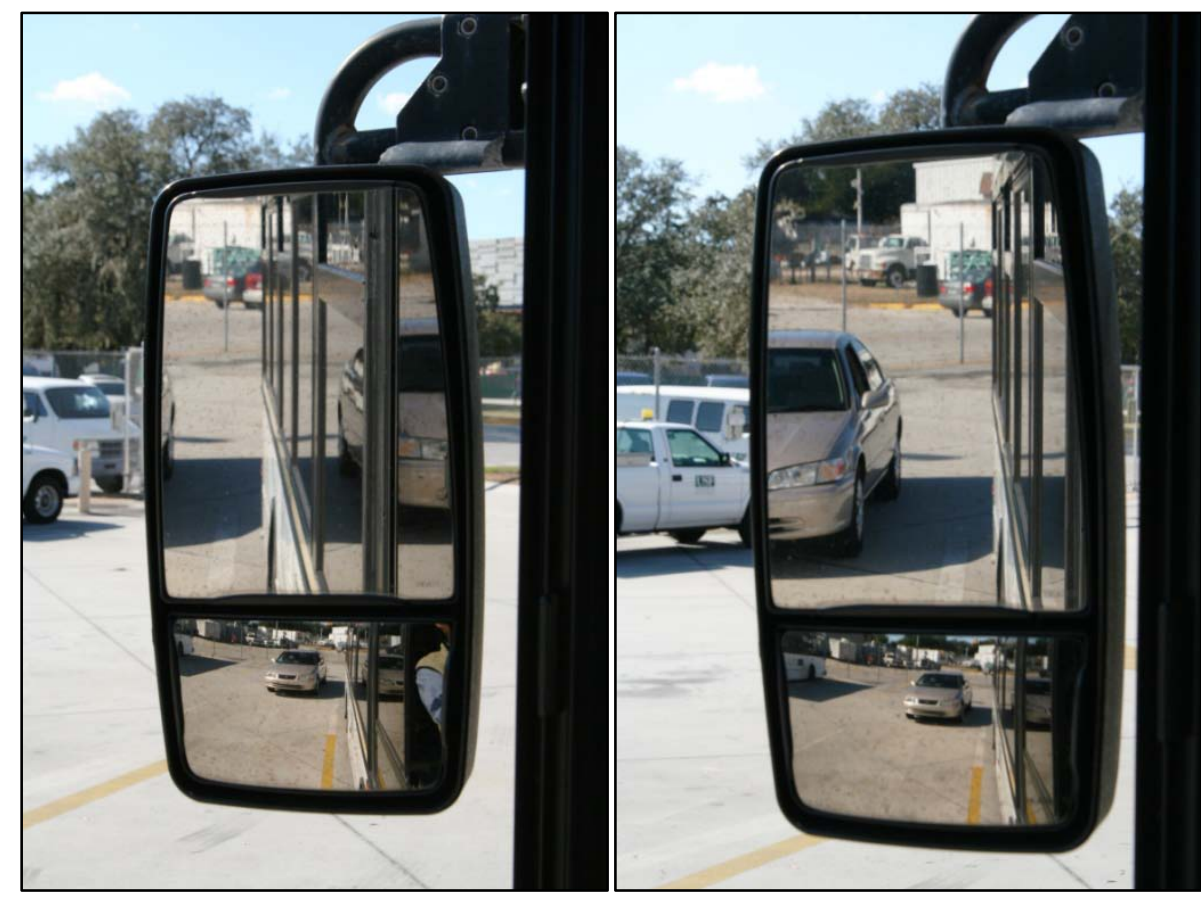

Figure 2-13. Mirror views for vehicle located behind the length of the bus

Figure 2-14 shows the monitor view of the same vehicle in portrait orientation, and Figure 2-15 shows the monitor view in landscape orientation.

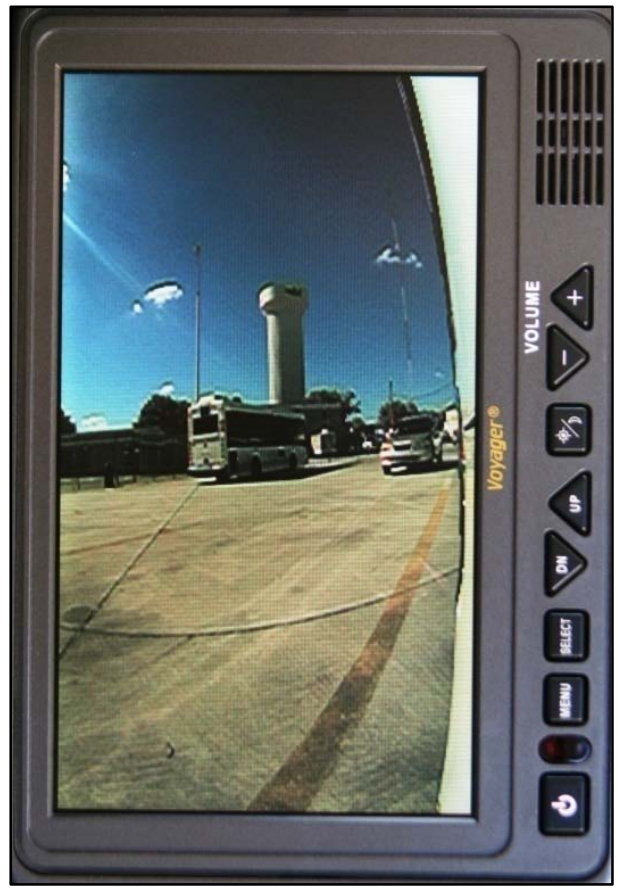

Figure 2-14. Monitor view in portrait orientation 


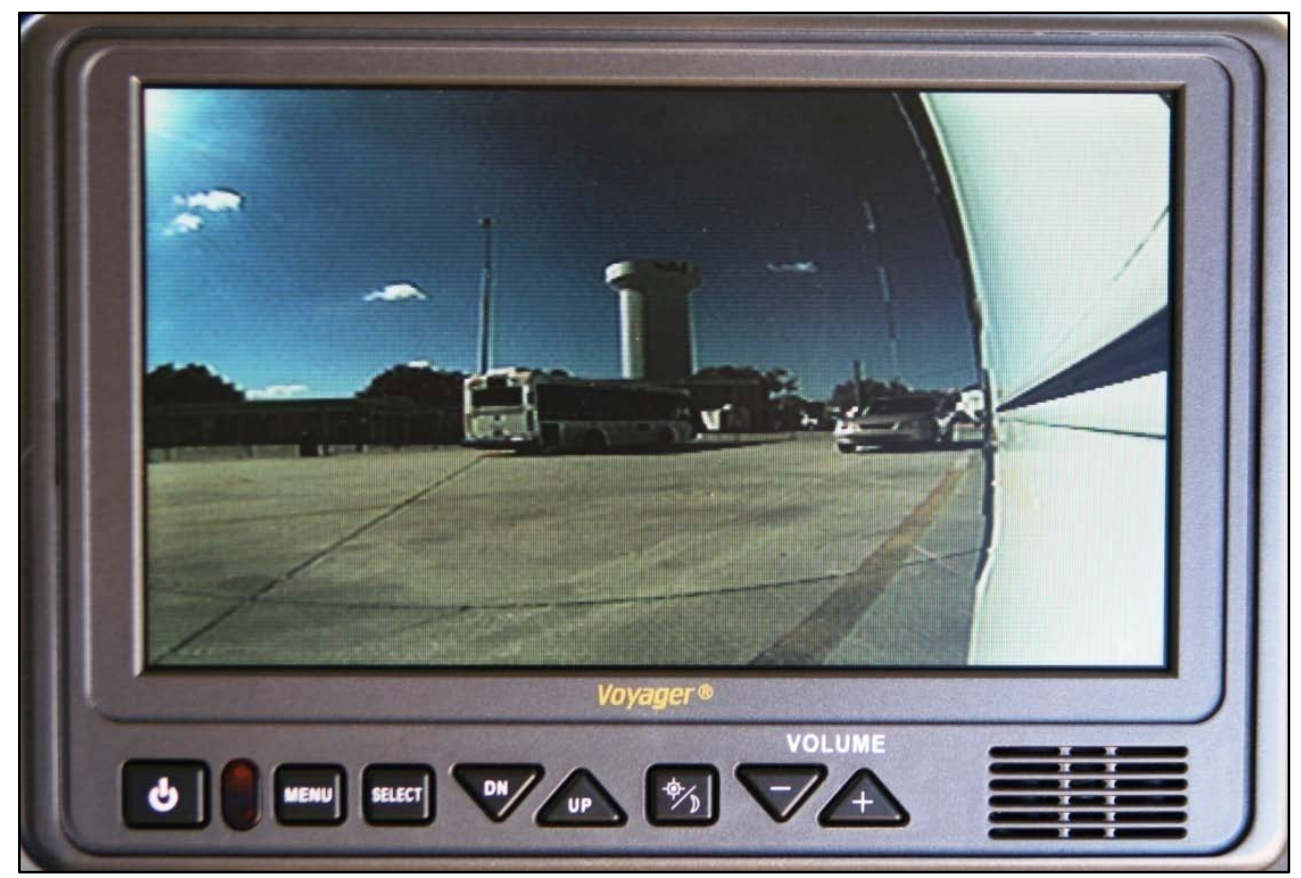

Figure 2-15. Monitor view in landscape orientation

Some research conducted for heavy trucks has shown that rearview camera-based systems provide a rearview image to the driver and thus help in backing collisions. These cameras traditionally have been used on recreational vehicles (RV) and box trucks. Recent research conducted by the National Highway Traffic Safety Administration (NHTSA) and the Federal Motor Carrier Safety Administration (FMCSA) has shown the potential of camera-based systems to aid and even replace mirrors; in many cases, this is due to the fact that they work exactly as the mirrors do, providing visual images to the drivers and thus making the transition from mirrors to cameras much smoother. Video systems were evaluated in a recent study [5] for their use on heavy trucks. The coverage area and angles required, as well as specifications of the cameras and monitors, were evaluated, showing that the potential use of these systems is great because of their capabilities.

\subsection{Comparison of Mirror-, Sensor-, and Camera-Based Systems for Side Collision Avoidance}

The comparison of the three systems is not easy, as it entails very different aspects. The mirrors have been the default device used for indirect vision since vehicles were manufactured. All drivers are used to the mirrors and rely on them. Unfortunately, the mirrors have a great limitation: they cannot cover all blind zones. For passenger vehicles, that is not a big problem, but the size of the blind zone becomes larger as the size of vehicle increases. Through the years, researchers and manufacturers have tried to find countermeasures and have found that sensor systems work somewhat satisfactorily. The problem, however, is that even though the systems work, the drivers still do not trust them or do not like them very much because the sensor-based 
systems can only detect an obstacle and provide warning to the driver. The driver still needs to use the mirror to see what or where the object is. The sensor systems also fail to detect objects and pedestrians or may provide many false alarms, thus hindering the drivers' trust in them [4]. Visualization is the biggest advantage of the camera-based systems; in this aspect, they work the same way that the mirrors do. In fact, the camera-based systems are better than the mirrors because they cover much more area, leaving virtually no blind zones. The measurement of the reduction of the blind zone using camera-based systems is one of the main objectives of this research project. Table 2-8 shows a comparison of the three mentioned systems.

Table 2-8. Comparison of systems for side collision avoidance

\begin{tabular}{|c|l|l|}
\hline System & \multicolumn{1}{|c|}{ Advantages } & \multicolumn{1}{c|}{ Disadvantages } \\
\hline Mirror-Based & $\begin{array}{l}\text { Used since beginning of vehicle } \\
\text { manufacturing. Default device on all } \\
\text { vehicles. Trusted by drivers. Does not } \\
\text { malfunction except if removed. } \\
\text { Relatively inexpensive. }\end{array}$ & $\begin{array}{l}\text { Does not cover the necessary area on } \\
\text { the side to help drivers avoid all } \\
\text { potential collisions. Passive devices } \\
\text { (require driver attention to work). } \\
\text { Weather deteriorates their effectiveness. }\end{array}$ \\
\hline $\begin{array}{c}\text { Sensor-Based } \\
\text { (ultrasonic, Lidar, } \\
\text { radar, infrared, } \\
\text { computer vision) }\end{array}$ & $\begin{array}{l}\text { Relatively accurate, active devices that } \\
\text { provide the driver with audio/visual } \\
\text { warning on eminent hazard. Long } \\
\text { range, cover all blind zones. Used for a } \\
\text { decade on vehicles. Beginning to gain } \\
\text { driver’s trust. }\end{array}$ & $\begin{array}{l}\text { Expensive. Prone to damage easily. Can } \\
\text { malfunction. Maintenance required. } \\
\text { Some environmental conditions } \\
\text { required to work. Shown to not work } \\
\text { 100\% of the time. Does not provide } \\
\text { visual image. }\end{array}$ \\
\hline \multirow{3}{*}{ Camera-Based } & $\begin{array}{l}\text { Used to add views in blind zones. } \\
\text { Relatively expensive. Provide a visual } \\
\text { image, similar to the mirrors. Can cover } \\
\text { a very large area covering all blind } \\
\text { zones. }\end{array}$ & $\begin{array}{l}\text { Passive devices like mirrors. Fog } \\
\text { deteriorates their effectiveness. More } \\
\text { expensive than mirrors. Not widespread } \\
\text { use yet. Can malfunction. Require } \\
\text { maintenance. }\end{array}$ \\
\hline
\end{tabular}




\subsection{Blind Zone Reductions for Transit Buses using Available Camera-Based Systems}

Crashes of transit buses, commercial trucks, and motor carriers often are caused by the presence of large blind zones, commonly known as the "blind zone" or "no zone," where the driver has virtually no visibility. The major objective of this task is to measure the blind zone reductions for transit buses using camera-based systems. The researchers physically measured the blind zone areas on the side and rear of each common type of transit bus based on the uses of mirror and camera-based systems. The percentage of reduction of blind zones on the side and rear of each common type of transit bus via the use of the camera-based system was computed and documented. The result of this task provides clear insight into the effectiveness of using camerabased systems to reduce blind zones of transit buses.

\subsection{Blind Zones for Transit Buses}

Blind zones are areas where the driver cannot see directly or indirectly with the aid of a mirror. Transit buses have many blind zones, with the main blind zones to the left and right side and to the rear and front of the vehicle. The rear blind zone can reach a few hundred feet behind the bus. Transit buses do not usually back up in public areas, except in the case of an emergency. This minimizes the number of backing crashes with transit buses involved. As shown in Figure $3-1$, the transit bus has several blind zones due to the devices being installed in the bus or the vehicle structure itself.

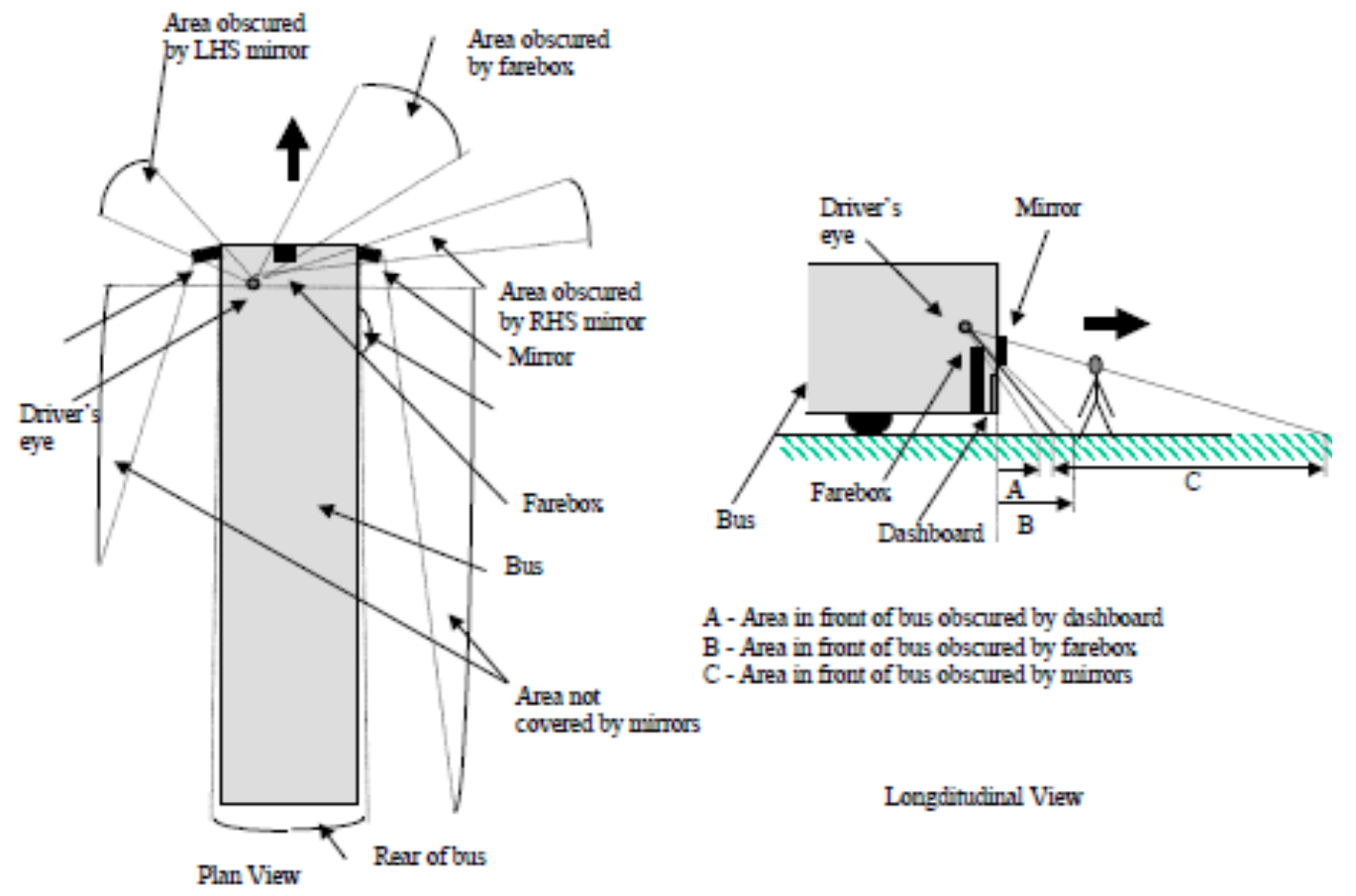

Figure 3-1. Blind zones around a transit bus [6] 


\subsection{Methodology for Measurement}

The methodology used for measuring the blind zones of the buses was straightforward. A bus driver of average height $\left(5^{\prime} 10^{\prime \prime}\right)$ sat in the driver's seat and adjusted the mirrors for his height. A team member located outside of the bus carried a white plastic pole, and the two coordinated with two-way radios. The team member located outside walked along the sides of the bus until the driver could not see the plastic pole any longer. The location of this point in regards to the bus was recorded. The same procedure was performed for all types of buses and side blind zones.

The research team measured the side blind zones for three types of buses. The first is a commonly-used type of bus called the Ultra-Low Floor (ULF) Bus. This bus is used by many transit agencies. The bus used for the measurements was $30 \mathrm{ft}$ long and $8 \mathrm{ft}$ wide and can be longer if needed. The bus is shown in Figure 3-2, and the blind zones are shown in Figure 3-3.

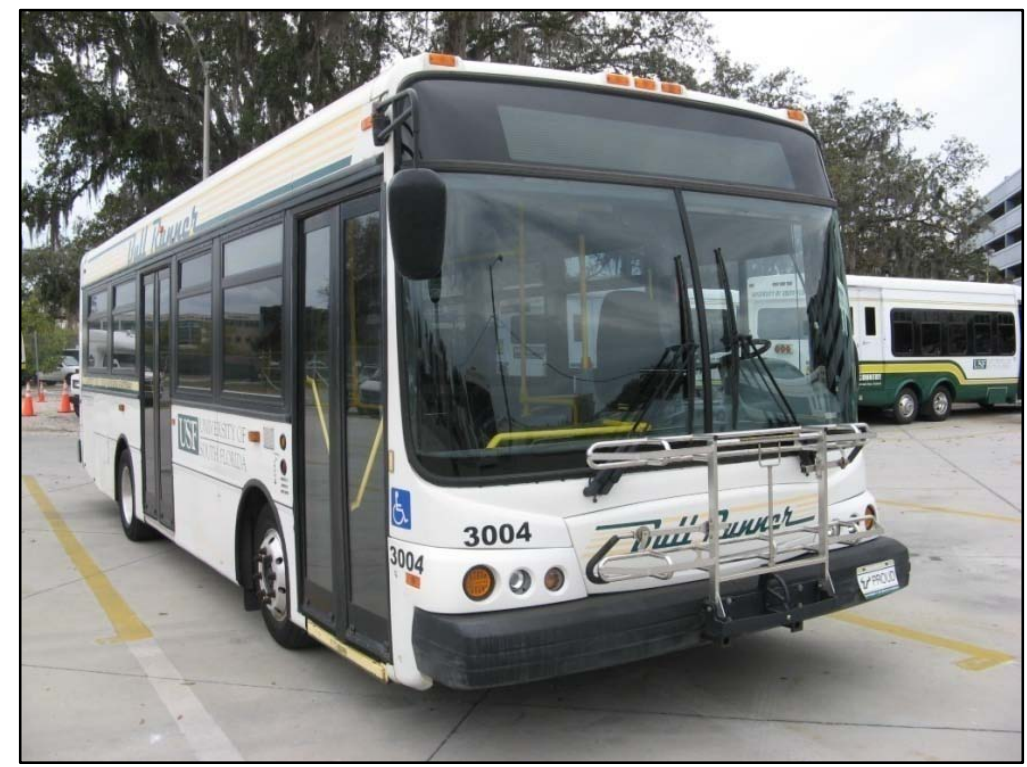

Figure 3-2. Ultra-low floor bus 


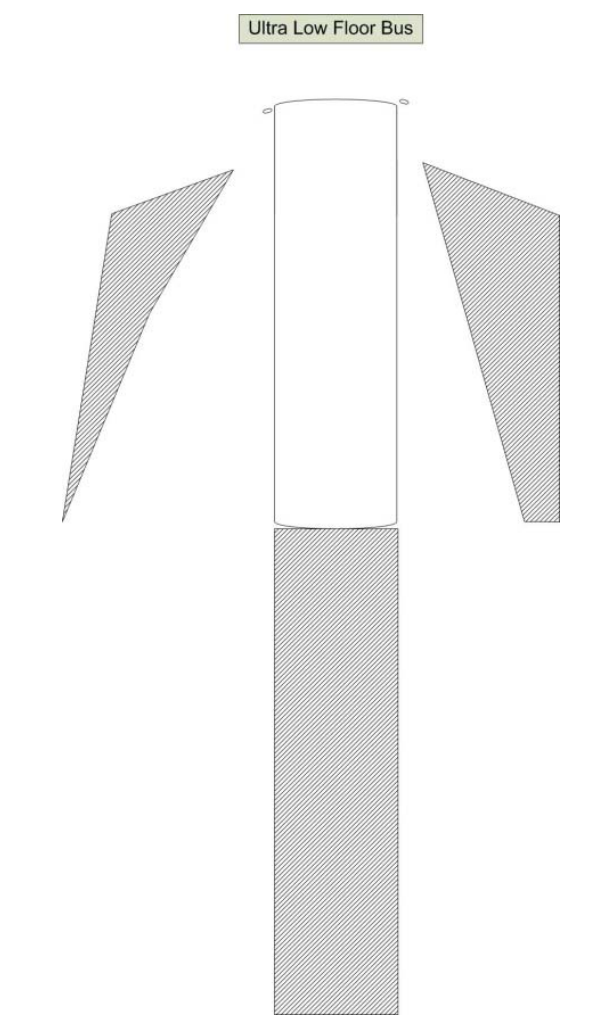

Figure 3-3. Blind zones of ULF bus

The second type of bus is a high floor bus that has four steps at the entrance and elevated passenger and driver floors. Most school buses and smaller transit agency buses are of this type. This bus was 25ft long and 8ft wide and is shown in Figure 3-4. The blind zones are shown in Figure 3-5.

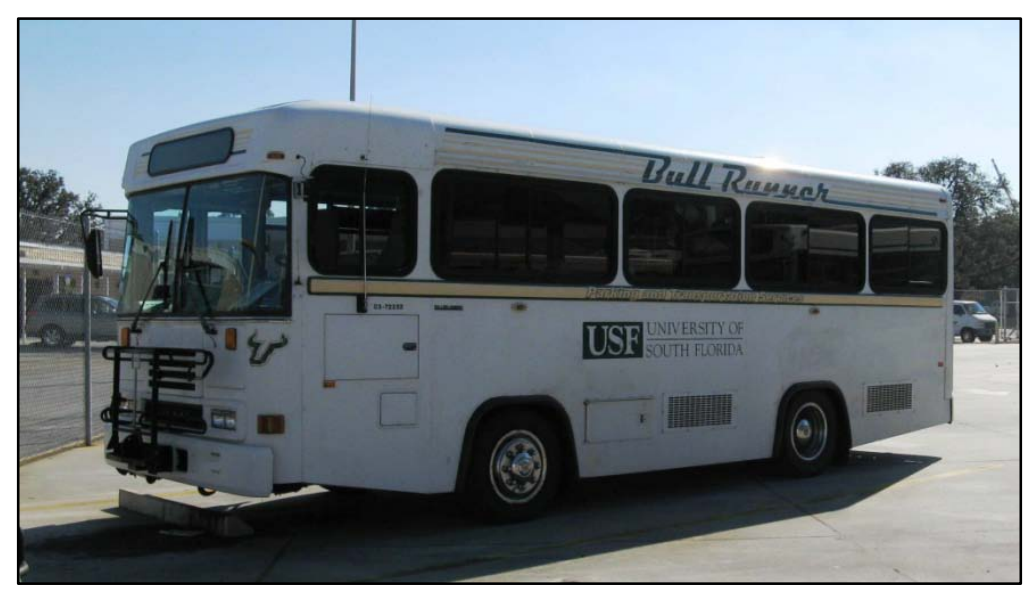

Figure 3-4. High floor bus 


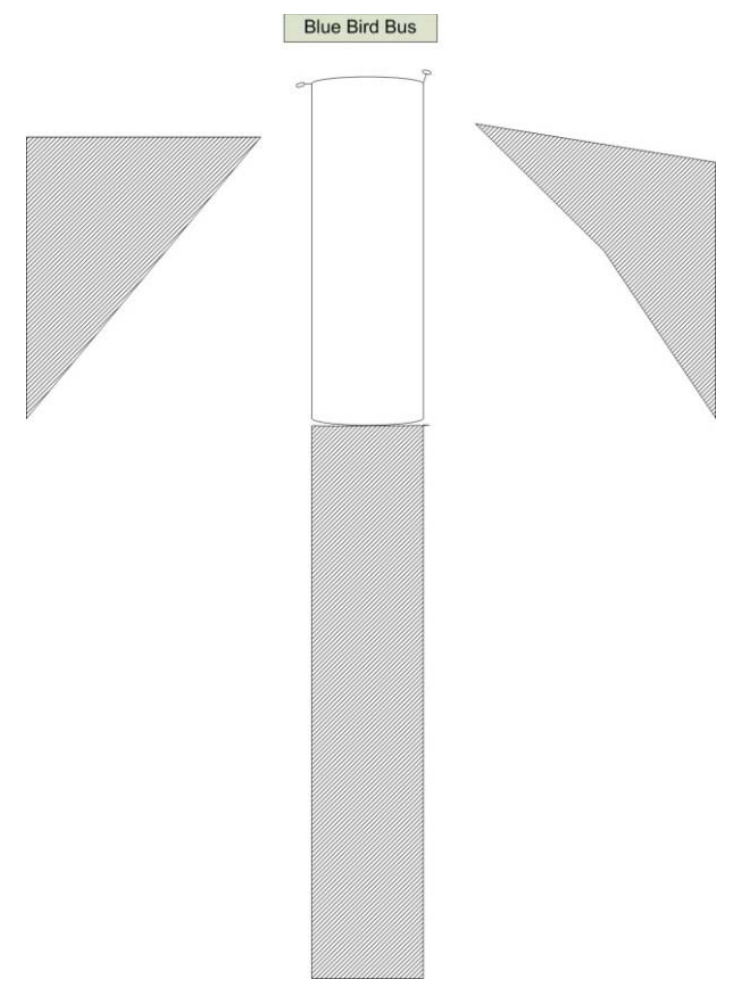

Figure 3-5. Blind zones of high floor bus

The third type of bus is a cutaway bus that is not specifically designed as a bus; the chassis is built for many utility services. A passenger compartment is secured onto the chassis to create a small shuttle. This type of buses is commonly used for shuttle or paratransit services. It measures $28 \mathrm{ft}$ long and $8 \mathrm{ft}$ wide at the passenger compartment, as shown in Figure 3-6. The blind zones are shown in Figure 3-7.

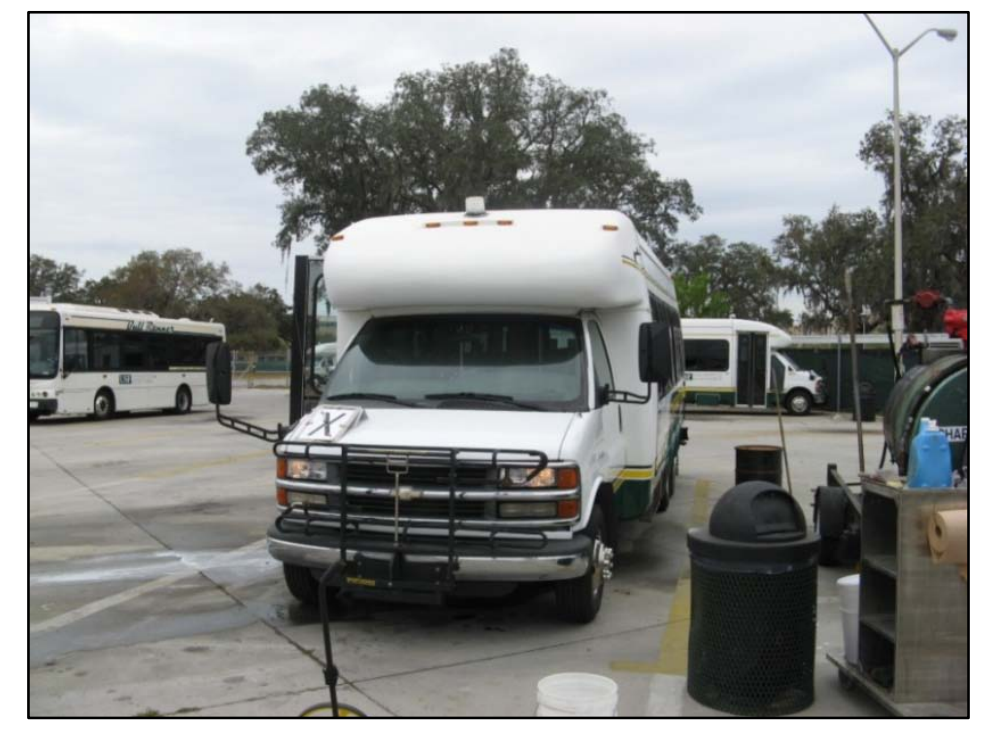

Figure 3-6. Cutaway bus 


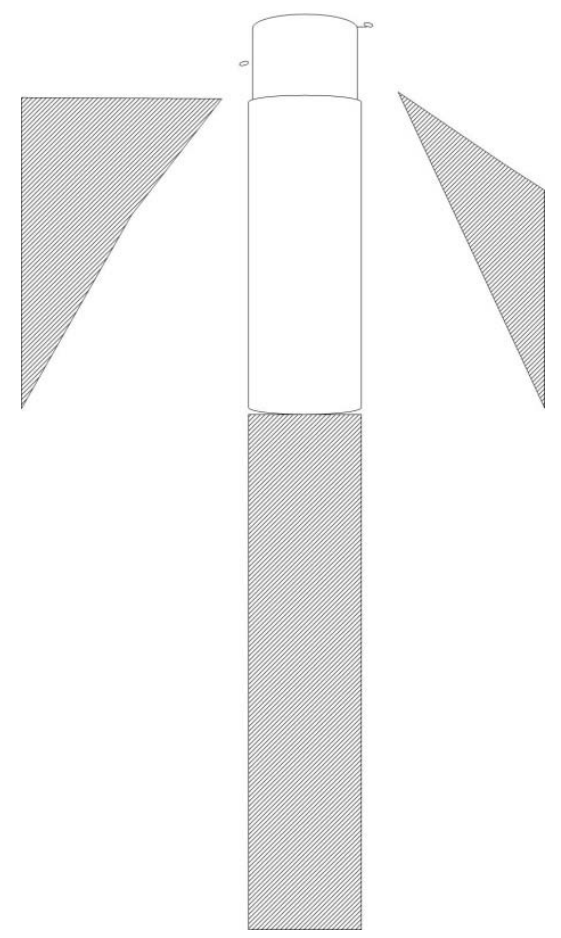

Figure 3-7. Blind zones of a cutaway bus

The problem with this type of bus is that the blind zones are only two-dimensional and, therefore, can be shown only from the top view. Figures 3-3, 3-5, and 3-7 show the twodimensional top view of the blind zones of different bus types. Figure 3-8 shows the isometric view of the blind zones. The shaded area on the ground shows the blind zone.

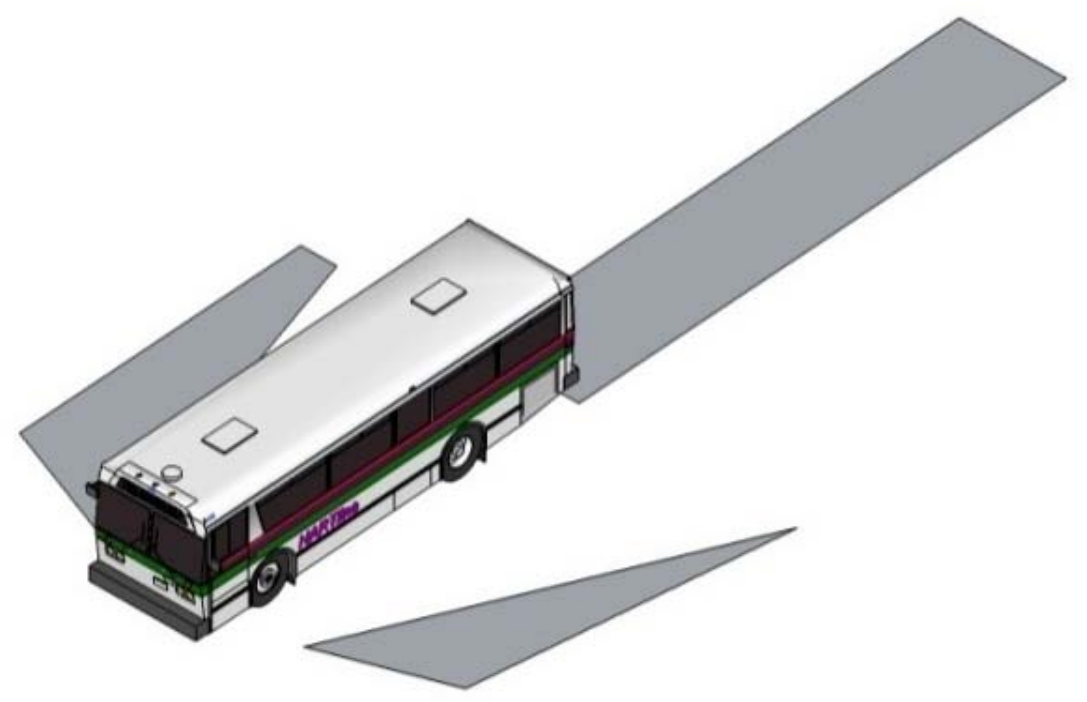

Figure 3-8. Plan and isometric view of blind zones for a bus 
As described earlier, these figures do not show the complete picture. Figure 3-9 shows a transit bus ULF type in all views. Figure 3-9(a) shows the front view with the two zones; the square pattern on the figure is the area covered by the mirrors and the checkered pattern is the area that still remains blind to the driver. Figure 3-9(b) shows the rear of the bus with the same two zones. Figure 3-9(c) shows the driver side of the bus with the same two zones. Figure 3-9(d) shows the passenger side of the bus with the two zones. Figure 3-9(e) shows the top view and blind zones together with the visible zones. Finally, Figure 3-9(f) shows the isometric view of a bus with the three areas. As seen in Figures 3-9(c) and 3-9(d), the driver has low blind zones next to the vehicle. For example, a sports car can virtually "disappear" in this zone, so the bus driver will not know it is there until it is too late, as shown in Figure 3-10. These are the issues caused by mirrors and related blind zones. This research focuses on minimizing or eliminating the blind zones, thus reducing crashes.

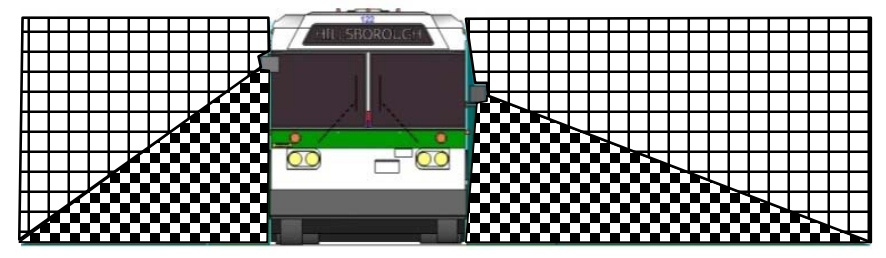

(a) Front view

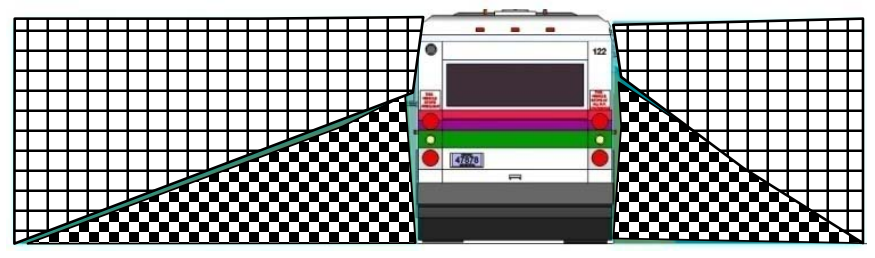

(b) Rear view

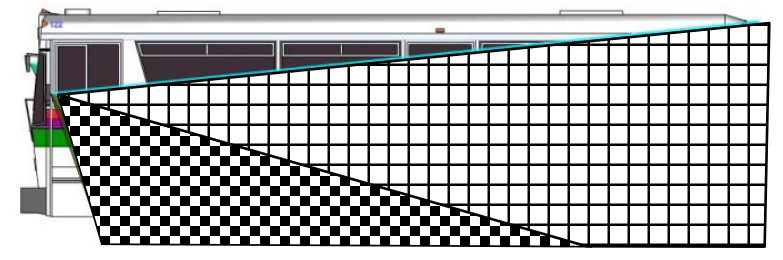

(c) Driver side view

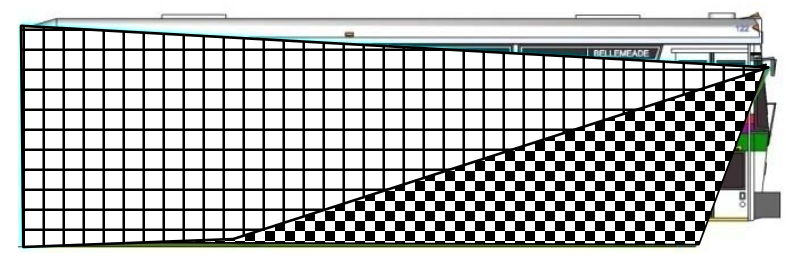

(d) Passenger side view 


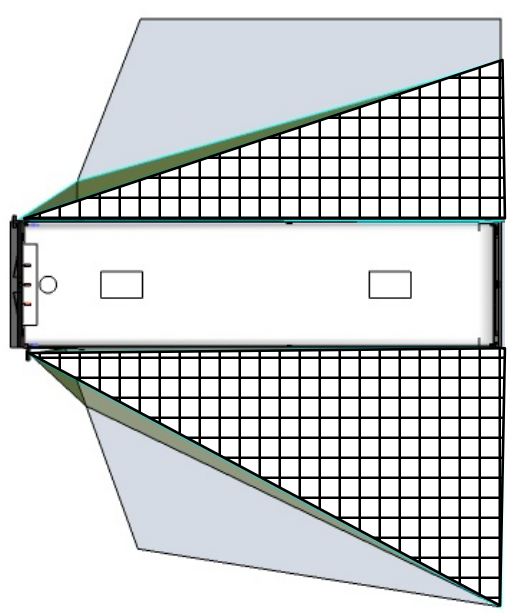

(e) Top view

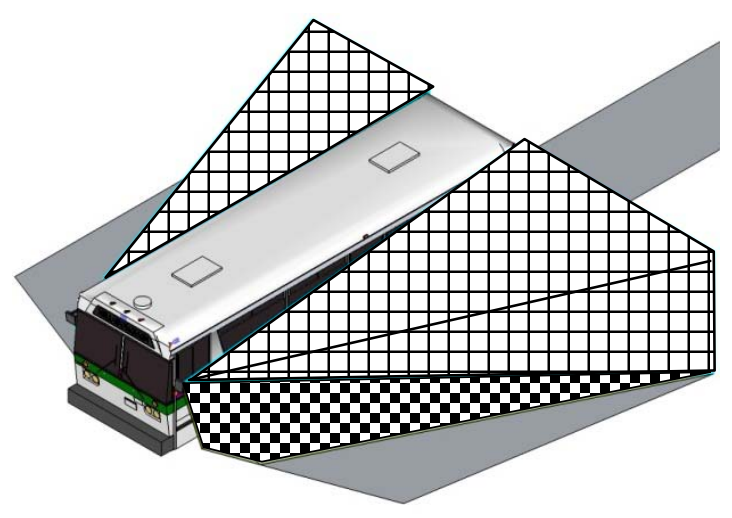

(f) Isometric view

Figure 3-9. Views of a transit bus with mirror blind zones

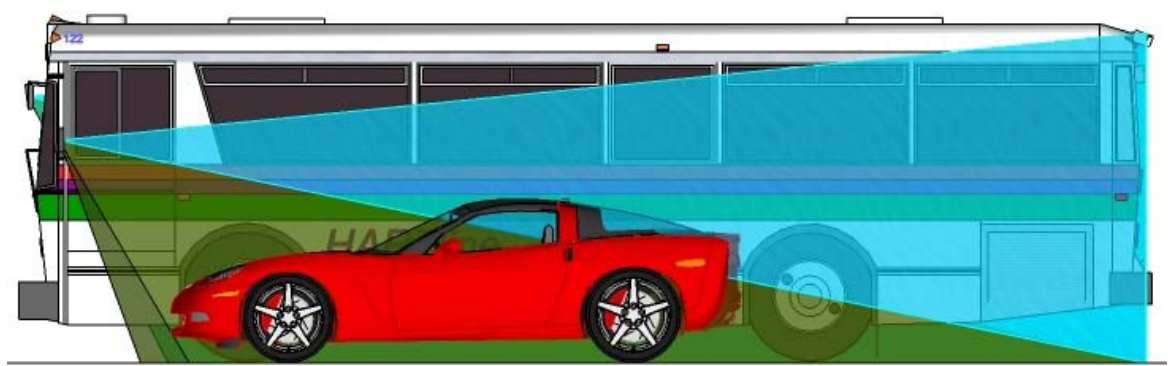

Figure 3-10. Low profile vehicle next to bus

It is extremely important for drivers to be able to see the blind zones of a bus in a road environment. With the bus located in the center lane of a three-lane road section, the driver has considerable blind zones next to the vehicle covering the two adjacent lanes (see Figure 3-11). In this situation, the rear blind zone extends more than the length of the bus. 


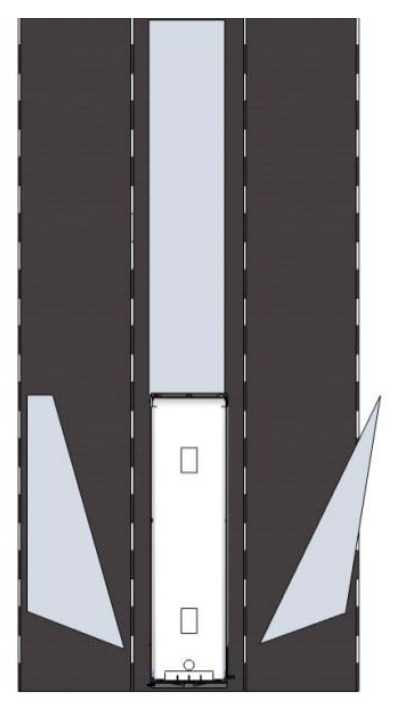

Figure 3-11. Blind zones of bus in road

\subsection{Side Blind Zone Reduction}

As shown in the previous section, the transit bus has blind zones on the side when both flat and convex side mirrors are used. The major difference between the two mirrors is that the flat surface mirror provides an undistorted image of the object. Depending on its radius of curvature, a convex mirror typically provides an image that is distorted. Camera-based systems can be used to cover the same or a wider area than both mirrors do, but with one major difference: the image of the camera is clear and larger and surpasses the convex mirror's image. Depending on the lens angle, the cameras are capable of much wider views than regular mirrors. A normal camera with $\mathrm{f} / 1.4$ has a view similar to a convex mirror. This lens can be found in regular consumer camcorders. Figure 3-12 shows the coverage of the two mirrors that are standard on all buses, the FOV of a regular-lens camera, and the FOV of a wide-angle camera. Convex mirror and camera fields of view cover the flat mirror FOV. The cameras also cover the FOV of the mirrors. The cameras were located at a height of 44" on the side of the bus, next to the side marker lights and angled so that the boundary of the FOV starts along the side of the bus. It is apparent that these cameras have the potential to cover as much area as the mirrors do and can provide much more coverage if necessary. The cameras are installed at the same location on each side of the bus, unlike the mirrors that require different brackets for the left and right mirrors. 


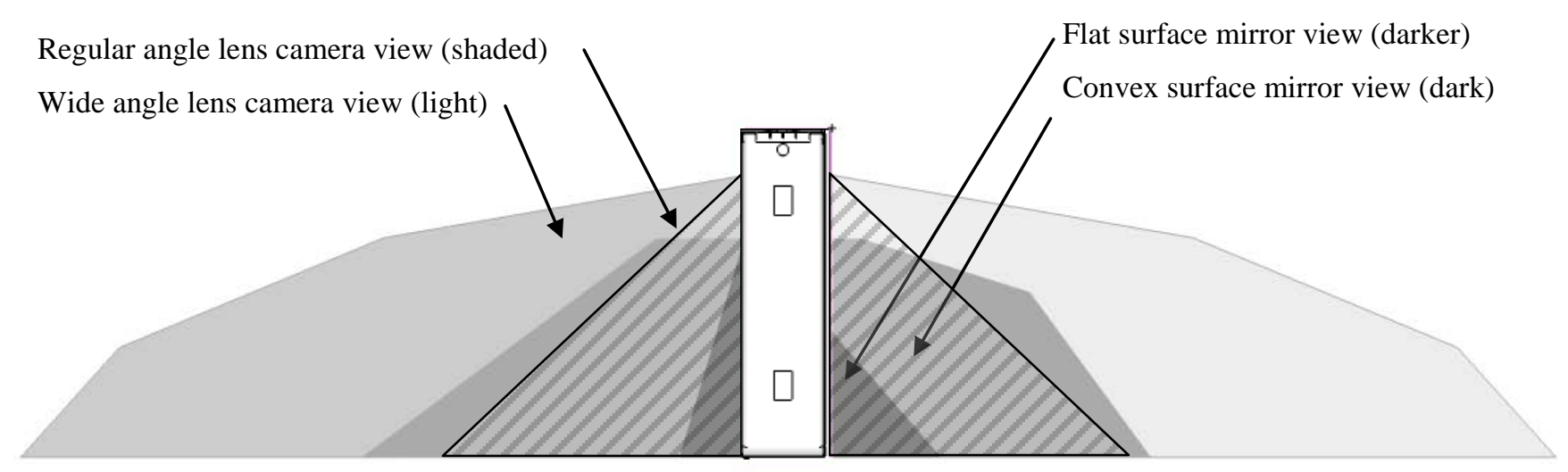

Figure 3-12. Field of view of mirrors and cameras

The regular-lens camera covers a slightly larger area than the flat and convex mirrors, but with more clarity than convex mirror. Figure 3-13(b) shows the regular-lens camera covering the mirror on the vertical axis, leaving a small portion next to the driver's window. A wide-angle camera shown in Figure 3-13(c) covers the blind zone completely.

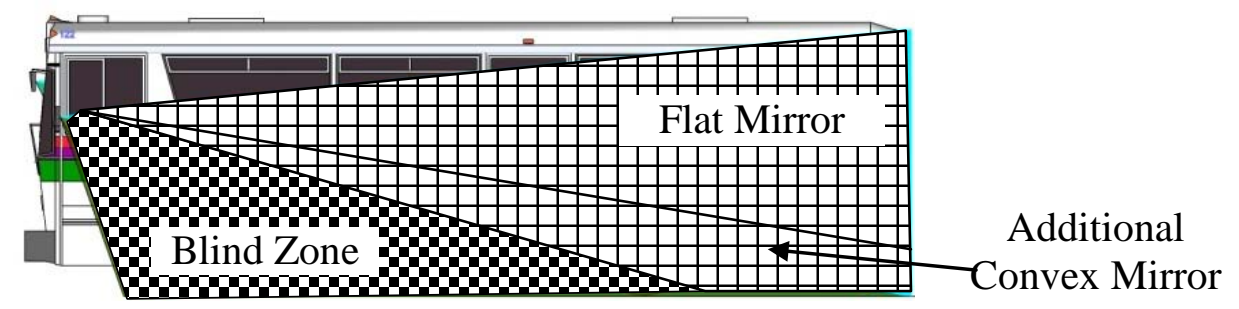

(a) Mirror view and blind zone on side of bus

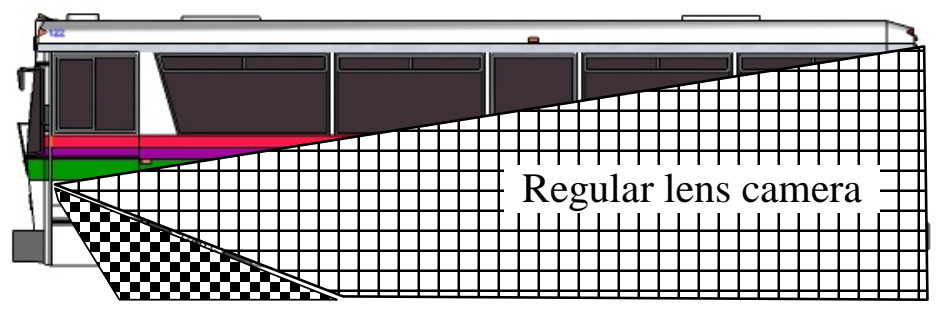

(b) Blind zone reduction with regular lens

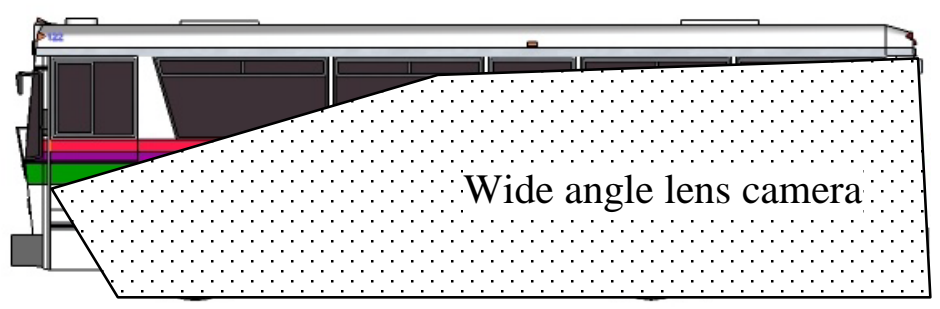

(c) No blind zone with wide angle lens

Figure 3-13. Progressive blind zone reduction using sideview video system 


\subsection{Rear Blind Zone Reduction}

Since the rear of transit buses usually has no windows, the driver is unable to have a rear view. Even if there were a window, the driver would not be able to see due to passenger traffic and the length of the vehicle. One of the policies of many transit agencies is for their buses not to reverse in public areas for safety reasons. This is the main reason for backing crashes being rare. A view of the rear of the vehicle, however, is not useful just during backing maneuvers. The driver can use the rear view on many other occasions besides backing. There are many benefits to having a rear view while driving forward in a congested area. Since direct visibility is not possible, indirect visibility is the only option for this implementation. To date, the cross-view mirror has been the only mirror offered as a possible solution. This mirror is installed at the top corner of the vehicle, and the driver looking through the side mirror must see through this 12 " convex mirror and obtain information for the rear of the vehicle. It has been used extensively on straight (one-unit) box trucks. One of this system's many limitations is the length of the vehicle; this mirror cannot be used on regular transit buses exceeding 20ft [7].

A rearview camera, however, can be used to provide a rear view of the vehicle on a monitor on the driver's dashboard. Figure 3-14 shows that the rear blind zone (angled lines) is covered (square lines) using a camera looking towards the rear of the vehicle installed at the top of the bus rear side.

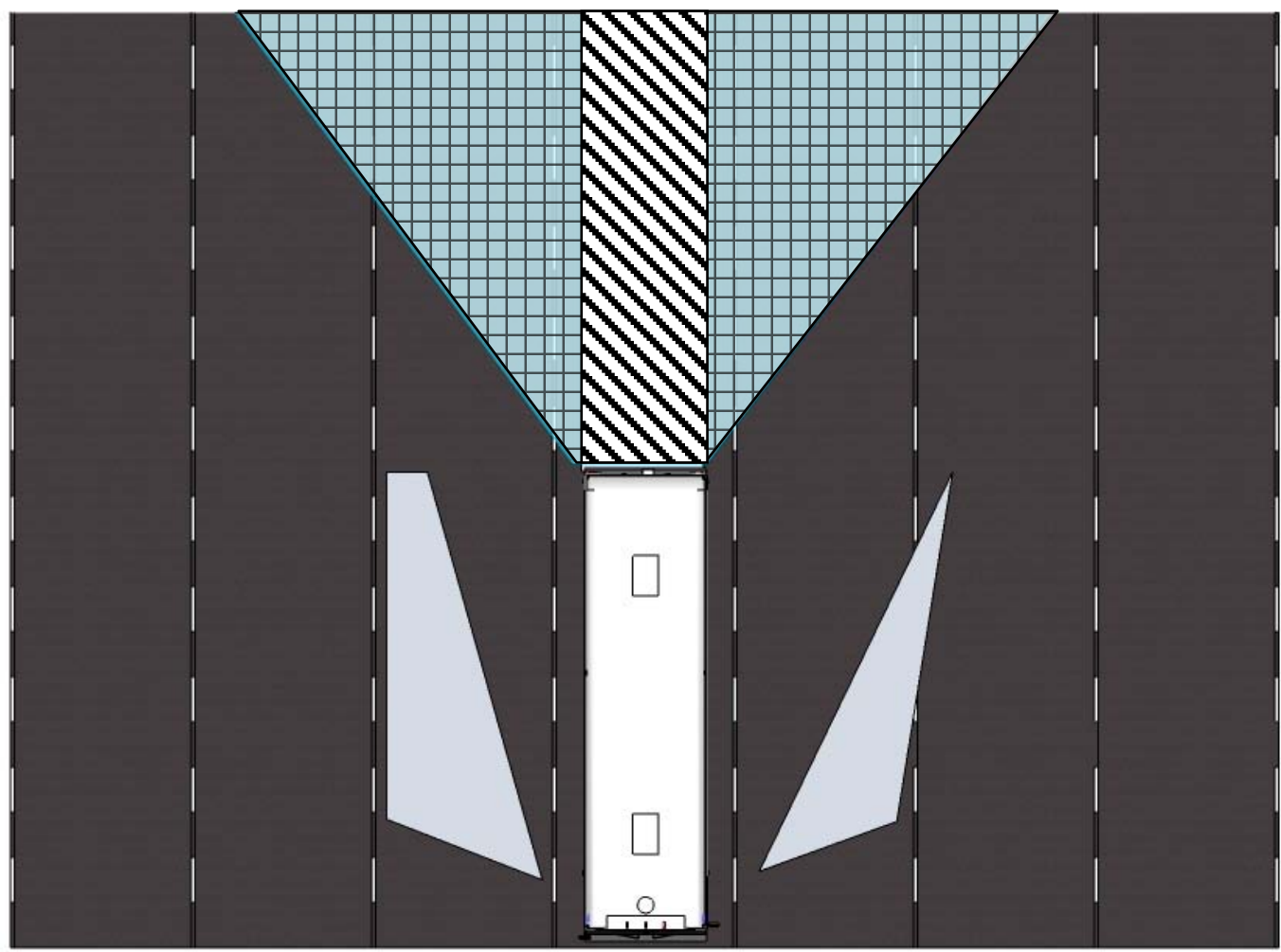

Figure 3-14. Rear blind zone covered by rearview camera 


\subsection{Reduction of Blind Zone using Cameras}

By using video cameras, the side and rear blind zones of a transit bus can be seen, thus reducing the cause of side collisions. The feasibility, implementation, and use of this system by transit drivers will be investigated at a later time. It appears that these camera-based systems have a great likelihood of solving the problem of blind zones. This study also investigates other benefits they might have, as well as the best possible setup of the system inside the driver's compartment, so that the maximum potential of the system can be achieved. Table 3-1 shows a basic comparison of the four devices reviewed earlier.

Table 3-1. Device comparison matrix

\begin{tabular}{|c|c|c|c|}
\hline Device & $\begin{array}{c}\text { Side blind zone } \\
\text { (lane width) } \\
\text { covered? }\end{array}$ & $\begin{array}{c}\text { Provides additional view to } \\
\text { the side of the vehicle? }\end{array}$ & Image \\
\hline Flat mirror & No & Yes & Undistorted \\
\hline Convex mirror & Yes & Yes & Distorted \\
\hline Regular lens camera & Yes & Yes & Undistorted \\
\hline Wide lens camera & Yes & Yes & Distorted \\
\hline
\end{tabular}

The reduction was measured in percentages for total blind zone volume (3 dimensions) in $\mathrm{ft}^{3}$. The reduction percentages are shown in Table 3-2. The percentages were calculated for the two axes looking at the bus from the top (horizontal, as in Figure 3-12) and from the side (vertical, as in Figure 3-13). The calculations were made taking the blind zones of the flat mirror view as the basis and adding the coverage by the convex mirror, regular lens camera, and wide angle camera, respectively.

Table 3-2. Reduction of blind zone using cameras

\begin{tabular}{|c|c|c|c|c|c|c|}
\hline \multicolumn{7}{|c|}{ Volume (ft ${ }^{3}$ ) } \\
\hline Device & $\begin{array}{c}\text { Left Side } \\
\text { Volume } \\
\left(\mathrm{ft}^{3}\right)\end{array}$ & $\begin{array}{c}\text { Right Side } \\
\text { Volume } \\
\left(\mathrm{ft}^{3}\right)\end{array}$ & $\begin{array}{c}\text { Blind Zone } \\
\text { Volume } \\
\text { Left }\left(\mathrm{ft}^{3}\right)\end{array}$ & $\begin{array}{c}\text { Blind Zone } \\
\text { Volume } \\
\text { Right }\left(\mathrm{ft}^{3}\right)\end{array}$ & $\begin{array}{c}\text { Reduction } \\
\text { Left } \\
\%\end{array}$ & $\begin{array}{c}\text { Reduction } \\
\text { Right } \\
\%\end{array}$ \\
\hline Flat Mirror & 150 & 150 & 1690 & 1690 & 0.0 & 0.0 \\
\hline Convex Mirror & 689 & 592 & 1001 & 1098 & 40.8 & 35.1 \\
\hline Regular Angle Lens & 1089 & 1089 & 601 & 601 & 64.4 & 64.4 \\
\hline Wide Angle Lens & 1840 & 1840 & 0 & 0 & 100.0 & 100.0 \\
\hline
\end{tabular}

The resulting blind zone measurements, as shown in Table 3-2, indicate that the camera-based video system can further reduce the blind zones of transit buses by using the combination of flat and convex mirror systems. The camera-based system with a regular-angle lens (no distorted image) can reduce about 64 percent of the blind zones of a flat mirror system along. It can reduce about 43 percent of blind zones of a common combined flat and convex mirror system. Using the wide-angle lens, the blind zones on the both sides of transit buses can be completely eliminated. 


\subsection{Controlled Driving Test with Sideview Video System}

One of the methods used to evaluate a safety enhancement device is to perform a driver test under controlled conditions, in order to collect certain data pertaining to the use of the system by drivers and its effectiveness on the safety aspect tested. A driver test requires drivers from the relevant population (in this case, transit bus drivers) driving a bus equipped with the safety enhancement device (in this case, the sideview video system) performing certain maneuvers designed to test different aspects of the system.

To determine if the drivers can drive the bus with the proposed sideview video system, a controlled driving test was used to assess if the drivers could adapt to the system and perform basic maneuvers required in everyday driving. Also, the test was used to assure that the drivers could use such a video system and perceive distance and depth relatively correctly (the main functions of the mirrors). In addition, the test was used to obtain feedback from the drivers on the system's effectiveness and to aid the driver in identifying potentially hazardous situations they cannot identify with the mirrors.

\subsection{Test Design}

The test consisted of three parts:

1. Pre-maneuver driving course

2. Distance/depth perception exercise under static conditions

3. Driving maneuvers under dynamic conditions

The three parts were designed to address the objectives outlined earlier. The materials given to the drivers can be found in the Appendix. A description of each part follows.

\section{Pre-Maneuver Driving Course}

A closed loop driving course was designed. Drivers were provided with a limited time to experience the sideview video system and use it before they performed the driving maneuvers. This allowed for some learning and exposure time. The course consisted of some left and right turns and a lane change maneuver (shown in Figure 4-1).

Before the drivers drove the course, they were advised to use the sideview video system as they would have used their side mirrors in order to follow the course and make sure not to hit any traffic cones. The turns had a tight radius, so that the drivers had to be very careful when passing through. After the drivers drove the bus around the closed course two times, they proceeded to perform the next part of the test unless they felt they needed more time to get familiar with the system. 

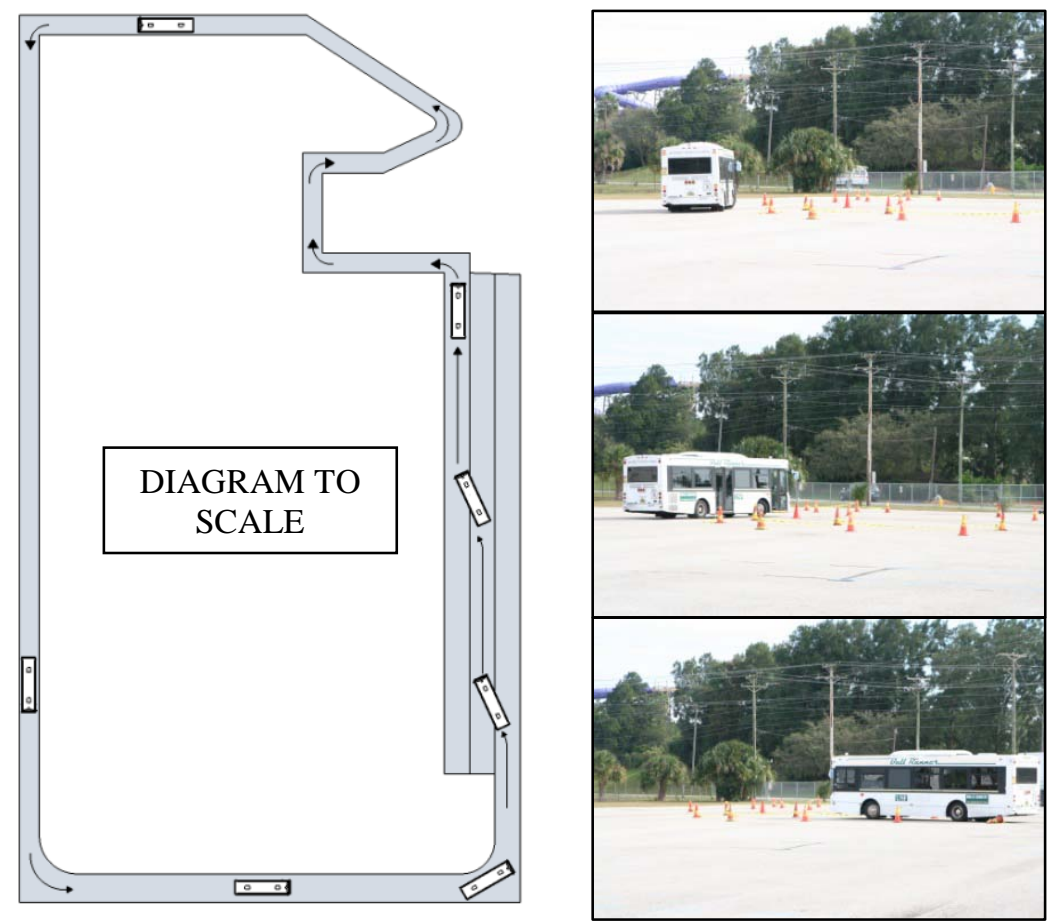

Figure 4-1. Closed course used during test

\section{Distance/Depth Perception under Static Conditions}

In order to drive a bus and maneuver in its surroundings, a bus driver needs to be able to use the mirrors to see around and perceive relatively correctly where things are positioned and where the bus is located. The view provided with a video system is not exactly the same as the image provided by mirrors. Depth and distance change as the magnification used changes. Flat mirrors have a magnification of one. Convex mirrors and cameras have less magnification that varies. A scene that is otherwise much larger can be recorded at a specific ratio using cameras.

A test was performed to obtain distance and depth perception information using the video system with a static object. Perceiving the distances correctly is the key to ensuring safe operation of the vehicle. The drivers were asked to estimate how far a person was standing to the left rear or right rear of the bus. They were required to provide two distances: the distance to the left of the bus (or right) and the distance to the rear, as shown in Figure 4-2. The test hypothesis was that the drivers will identify similar distances for the person's position using the mirrors and the sideview video system. The results show that the drivers did perceive the person at similar locations with the mirrors and the sideview video system. More details are found in the results chapter. 


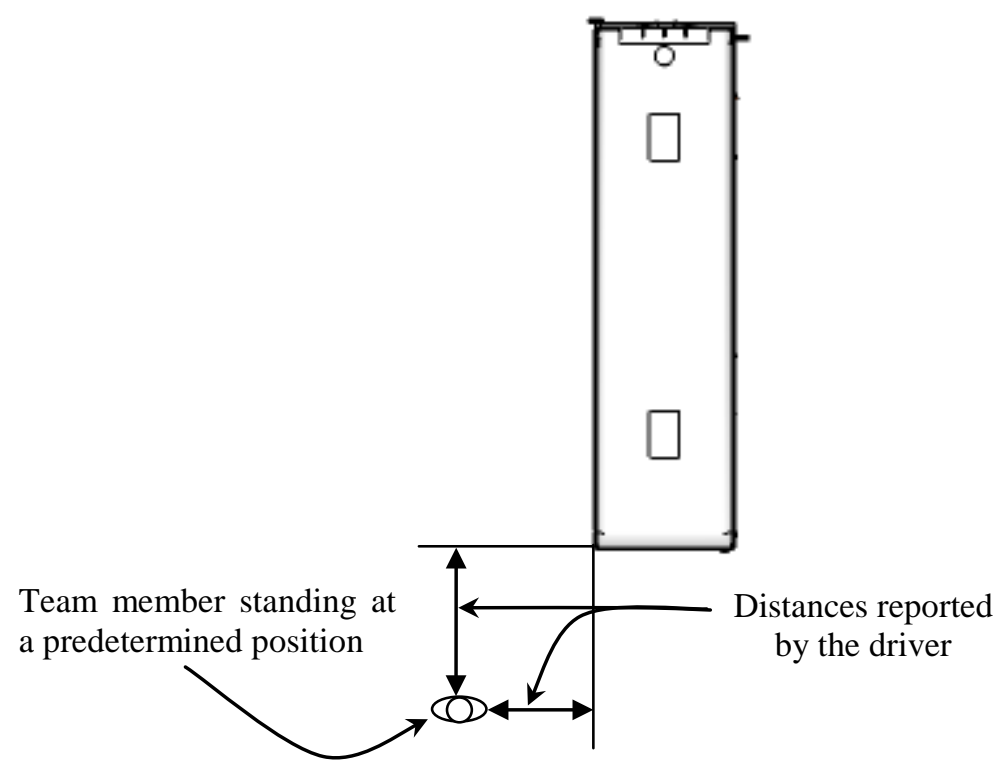

Figure 4-2. Distance measurements

\section{Driving Maneuvers under Dynamic Conditions}

Although distance perception was tested and proven accurate in the previous test, perceptions can change under dynamic conditions. The same concept was tested as in the static test, but with the bus moving and a vehicle instead of a person used for the target. These maneuvers were called "lane change maneuvers" but did not actually require the drivers to change lanes. They were designed to test how well the drivers can perceive distances using a video system instead of mirrors. As described in the driver packet given to the drivers, two different maneuvers were used. The first was a maneuver capturing the minimum distance between bus and vehicle in an eminent lane change, and the second was a maneuver to show the limitations of the FOV of the mirrors and the advantage of the FOV of the sideview video system.

\section{Distance Perception under Dynamic Conditions}

The hypothesis of this test was that the drivers can perceive the location of the other vehicle similarly using mirrors or a sideview video system. This was tested by asking the drivers to indicate at what point was the last moment they would change lanes in front of an oncoming vehicle. This created a scenario where the drivers needed to indicate when they would change lanes safely; thus, the minimum distance between the bus and the vehicle was obtained using a method explained in a following section.

This maneuver required the drivers to bring the bus into the center lane of the three-lane section shown in Figure 4-1. This section was 300ft long and deemed adequate for the test. The drivers were advised to bring the bus to $15 \mathrm{mph}$ and continue cruising at a constant speed. A second vehicle started from the same position as the bus and slowly accelerated to approach the bus 
from the rear to the adjacent lane, as shown in Figure 4-3. Figure 4-3(a) shows the vehicle on the left side of the bus, and Figure 4-3(b) shows the vehicle on the right side of the bus.

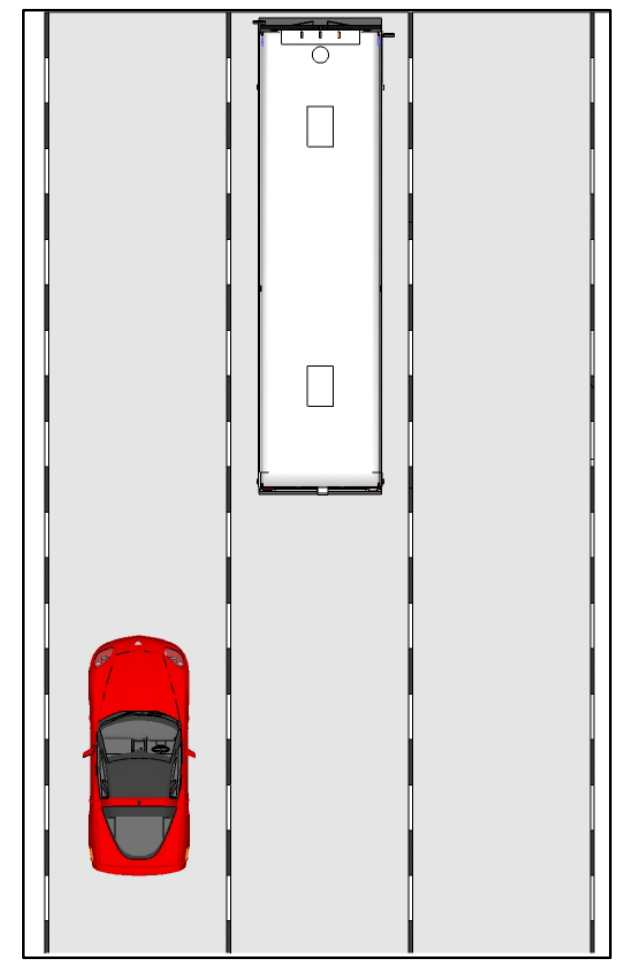

(a)

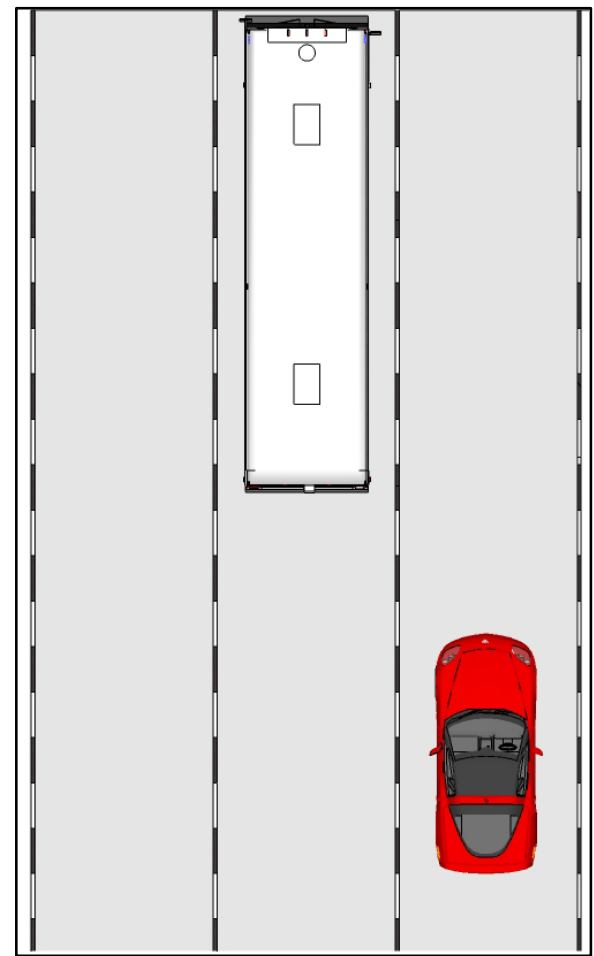

(b)

Figure 4-3. Lane change maneuver with vehicle in adjacent lane

The objective of this maneuver was to determine the minimum perceived distance for a safe lane change between the bus and the vehicle. The drivers were asked to push a sensor button when they thought it was the last moment they could safely change lanes in front of the oncoming vehicle while driving the bus at the requested speed. For safety purposes, none of the drivers actually changed lanes. Instead of changing lanes, the drivers pushed the sensor button that recorded the event on video. The details of this method are described in the Data Collection section. This maneuver was performed four times in random order for each driver:

1. Vehicle to right of the bus using mirror

2. Vehicle to right of the bus using sideview video system

3. Vehicle to the left of the bus using mirror

4. Vehicle to the left of the bus using sideview video system

A photograph of the maneuver is shown in Figure 4-4. 


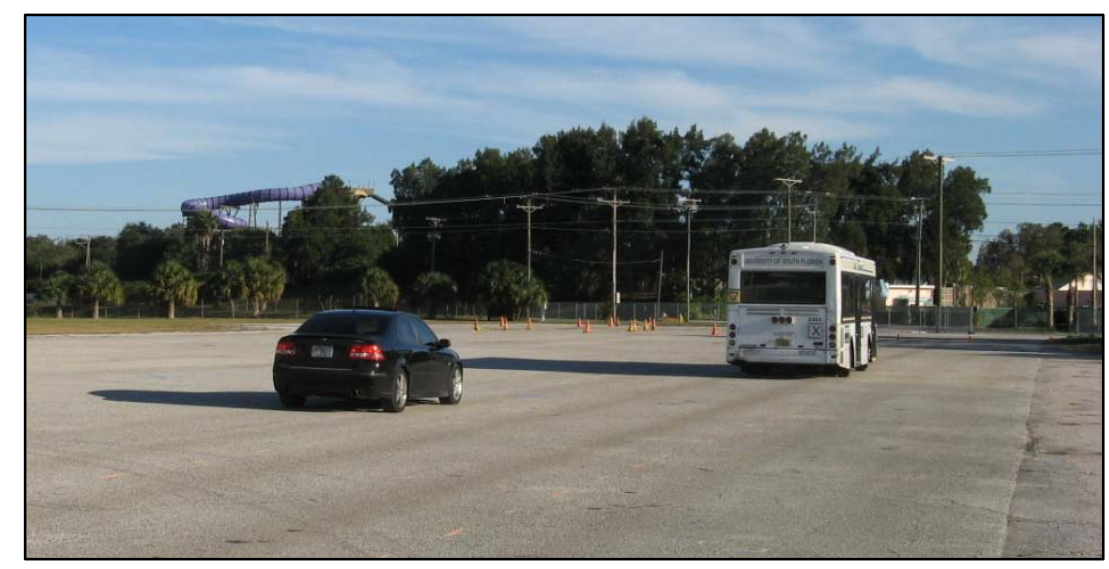

Figure 4-4. “Lane change” maneuver

\section{Sideview Video System FOV under Dynamic Conditions}

The hypothesis of this test was that the drivers would not be able to see a vehicle at all times using mirrors, whereas they would be able to see it while it was next to the bus because of the wide FOV of the cameras. This maneuver required the drivers to drive the bus on the left or right of the three-lane road section while the other vehicle drove in a lane next to the adjacent lane, as shown in Figure 4-5. The purpose of this maneuver was to show the mirror FOV limitations and the advantages of using a video system. The drivers were asked to push the sensor button when they could not see the other vehicle in their mirrors.

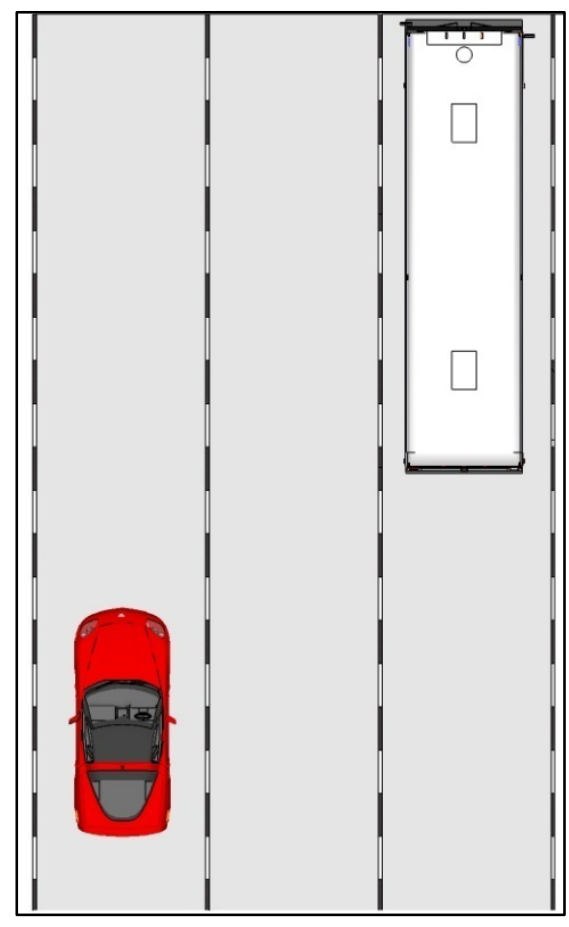

(a) Vehicle to the left of the bus

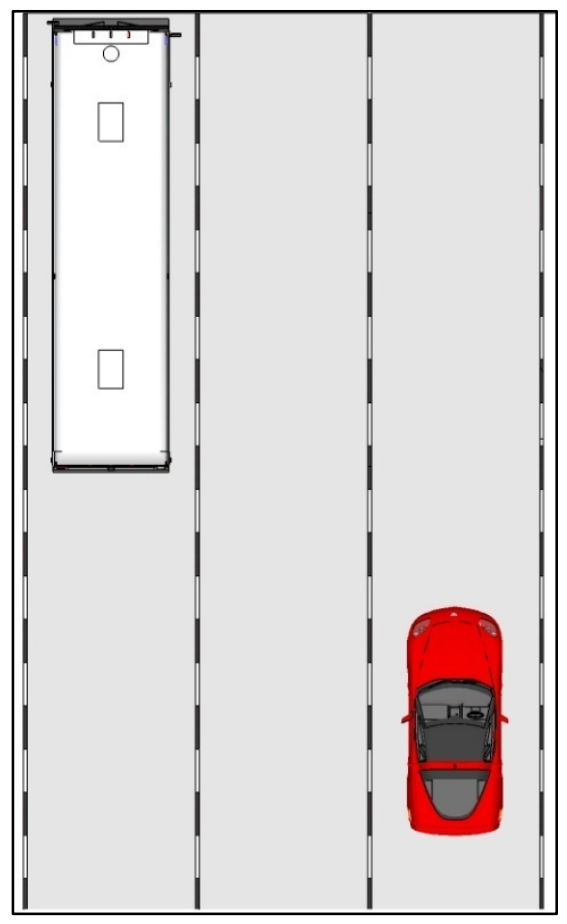

(b) Vehicle to the right of the bus

Figure 4-5. Lane change maneuver with vehicle in next to adjacent lane 
Figure 4-6 shows an example of the situation where the other vehicle is located two lanes away from the bus and is about to change lanes to the left. The shaded area shows the FOV of the mirrors. If the bus driver cannot see the vehicle and changes lanes to the right at the same time, there is potential for a sideswipe collision.

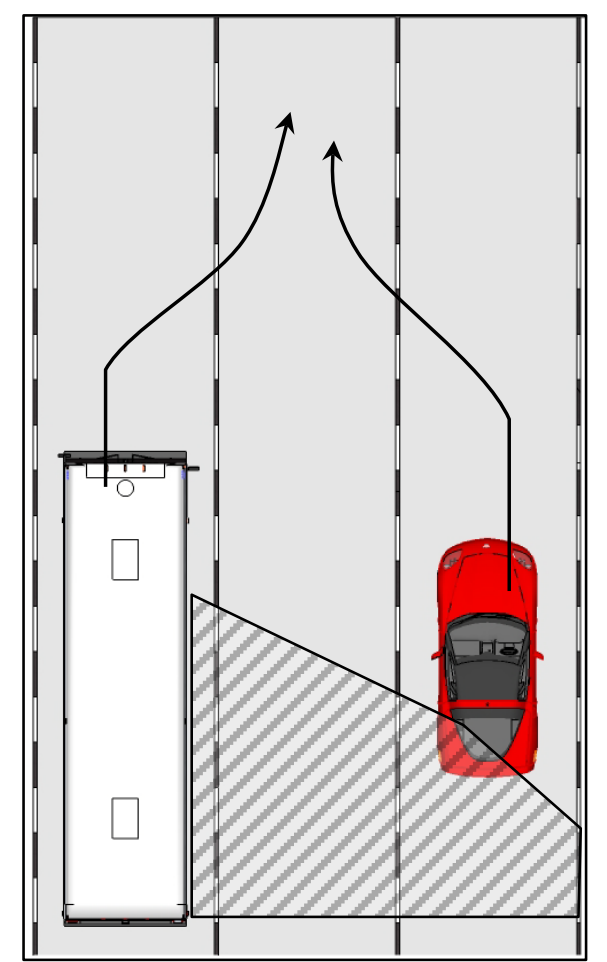

Figure 4-6. Possible side crash scenario

The vehicle is, however, visible using the sideview video system since the FOV of the video system is much wider than that of the mirrors (see Figure 3-12). This situation is dangerous and can potentially cause a crash when the bus is on the outside or inside lane of a three-lane road section. Figure 4-7 shows the vehicle and the bus moving next to each other with one lane spaced between them during this maneuver.

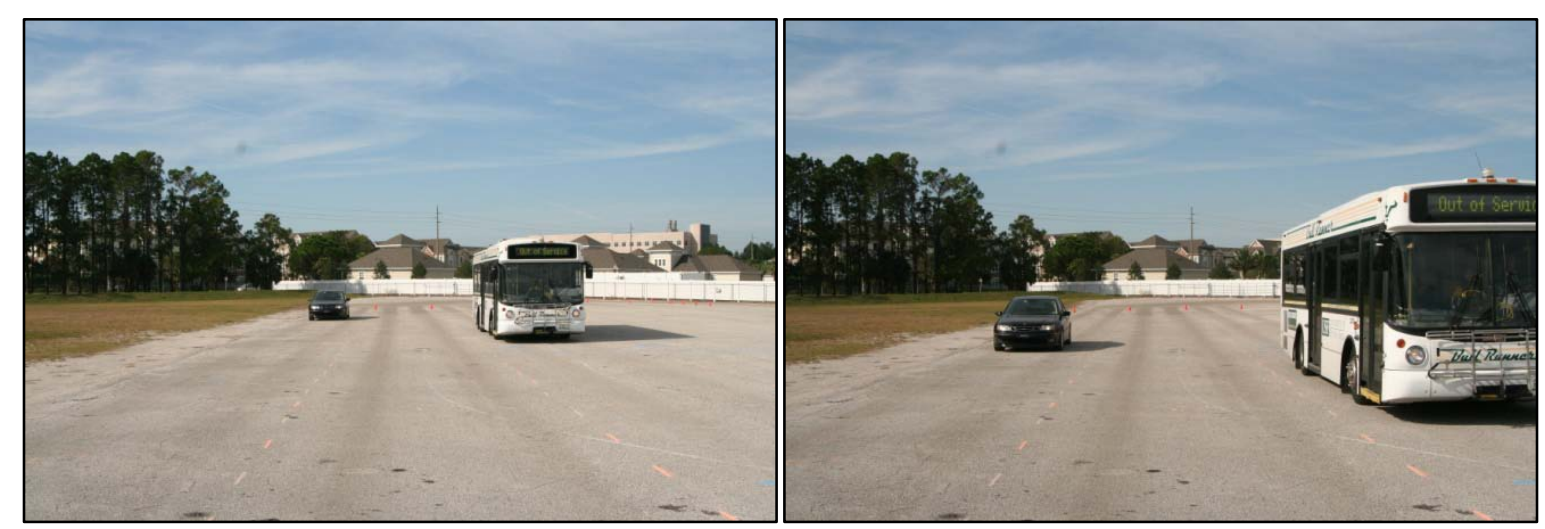

Figure 4-7. Vehicle and bus progress in maneuver 


\subsection{Data Collection}

The data collected during the test were in three forms: 1) responses from drivers to survey questions asked before and after they completed the maneuvers, 2) video recorded during the lane change maneuvers, and 3) distance information collected by research staff during the last perception test. For the video data collection, the bus was equipped with a Data Acquisition System (DAS) able to record multiple video cameras simultaneously and store them for later use.

\section{Data Acquisition System}

During the experiment, the bus was equipped with a DAS to record and store the necessary data for the analysis. The research team designed and assembled this device, incorporating available devices to fit the purposes of the research. Figure 4-8 shows the DAS unit used in the test. The DAS includes a mobile Digital Video Recorder (DVR), a monitor, a Global Positioning System (GPS) antenna, a cooling fan, power switches, and relevant power and video/audio connectors. A schematic diagram of the case wiring is shown in Figure 4-9. The bus was equipped with four cameras. As shown in Figures 4-10 and 4-11, camera (1) was the left-side camera, camera (2) was the right-side camera, camera (3) was a rearview camera, and camera (4) was aimed at the driver's face to observe the drivers' behavior.
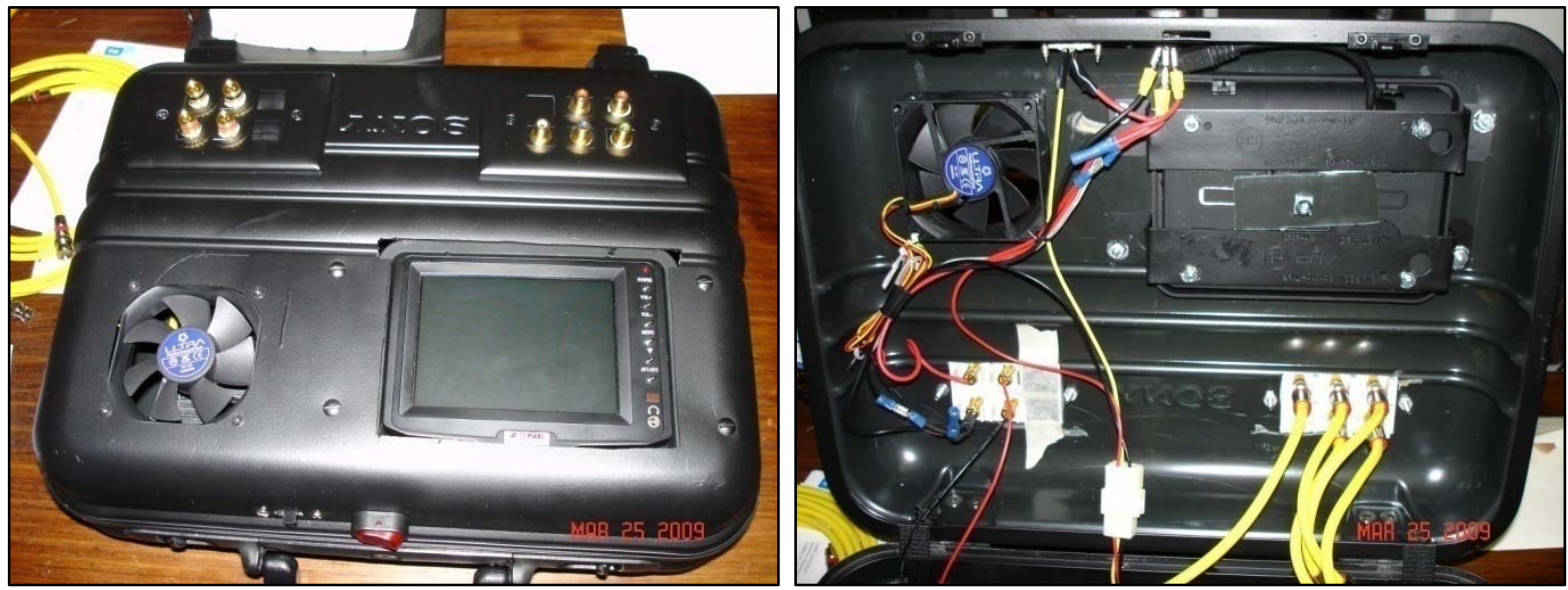

Figure 4-8. DAS unit outside and inside

Figure 4-10 shows photographs from the four cameras, two monitors, the push button, and the DAS unit used to collect data during the test. 


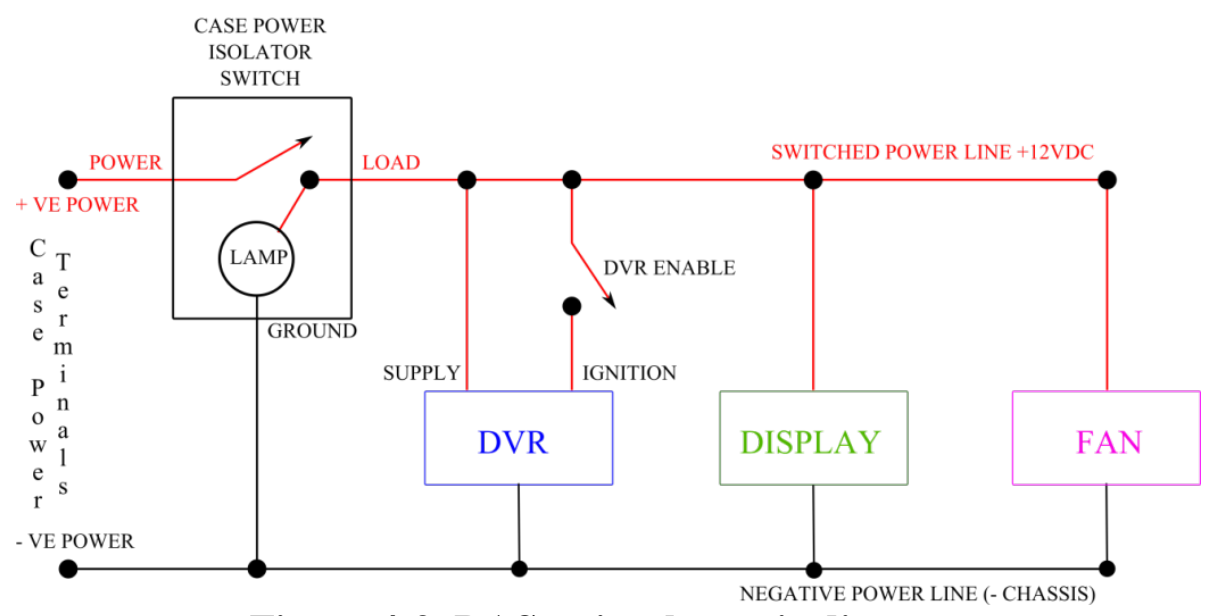

Figure 4-9. DAS unit schematic diagram
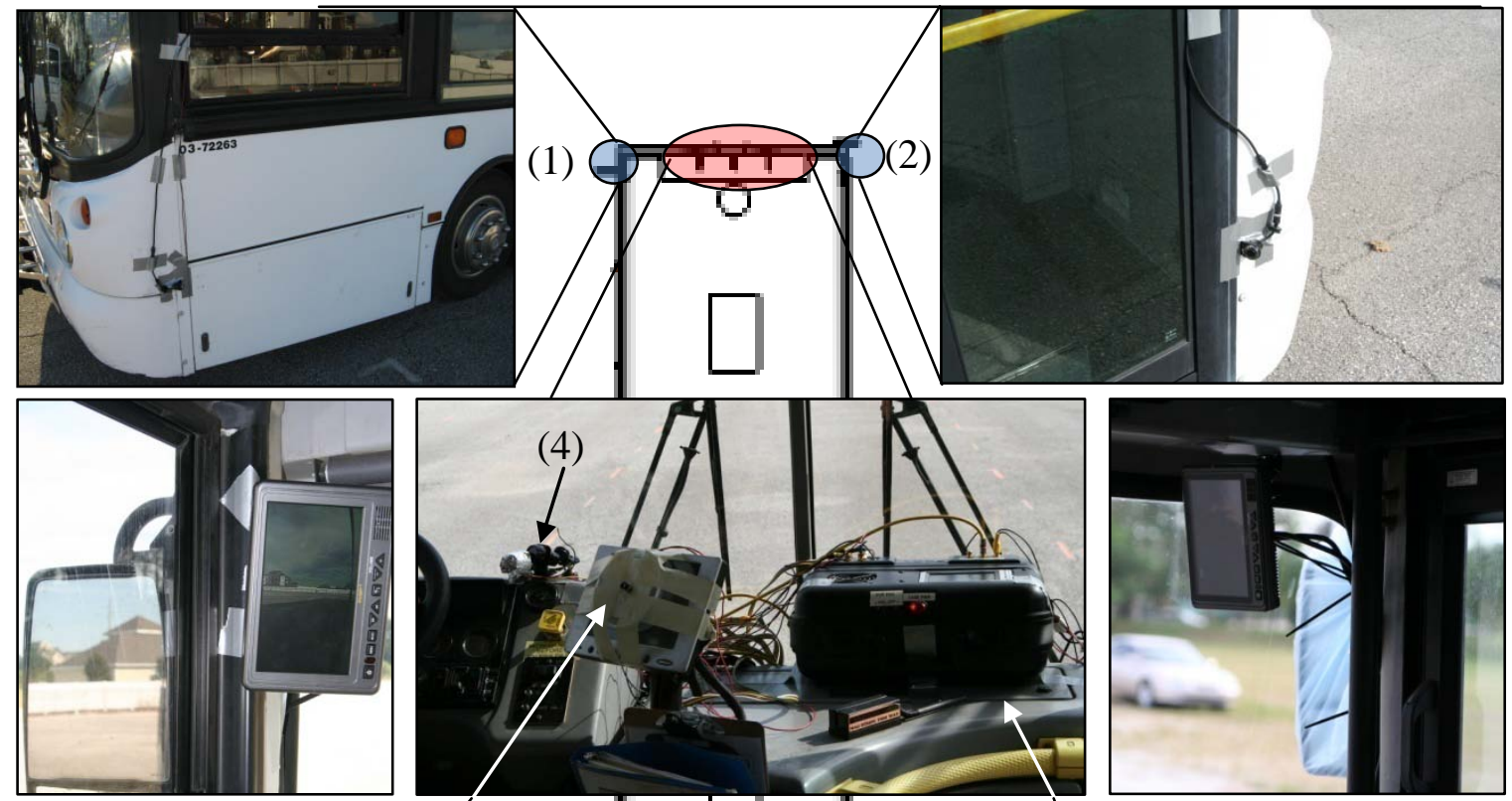

Push button
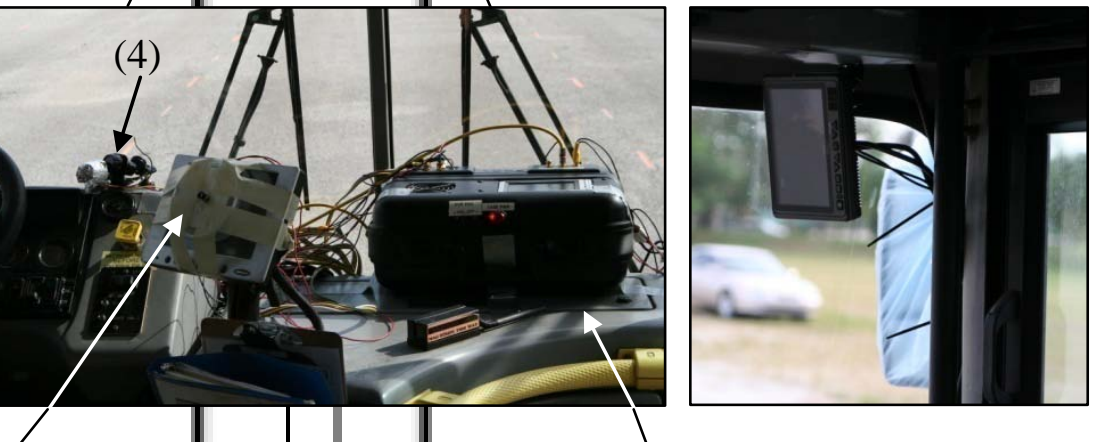

DAS unit

(3)

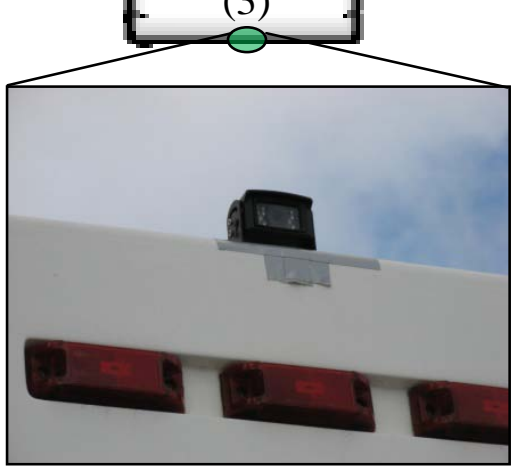

Figure 4-10. Left (1) and right (2) side cameras, left and right side monitors, DAS unit and push button, rearview camera (3) and driver camera (4) 


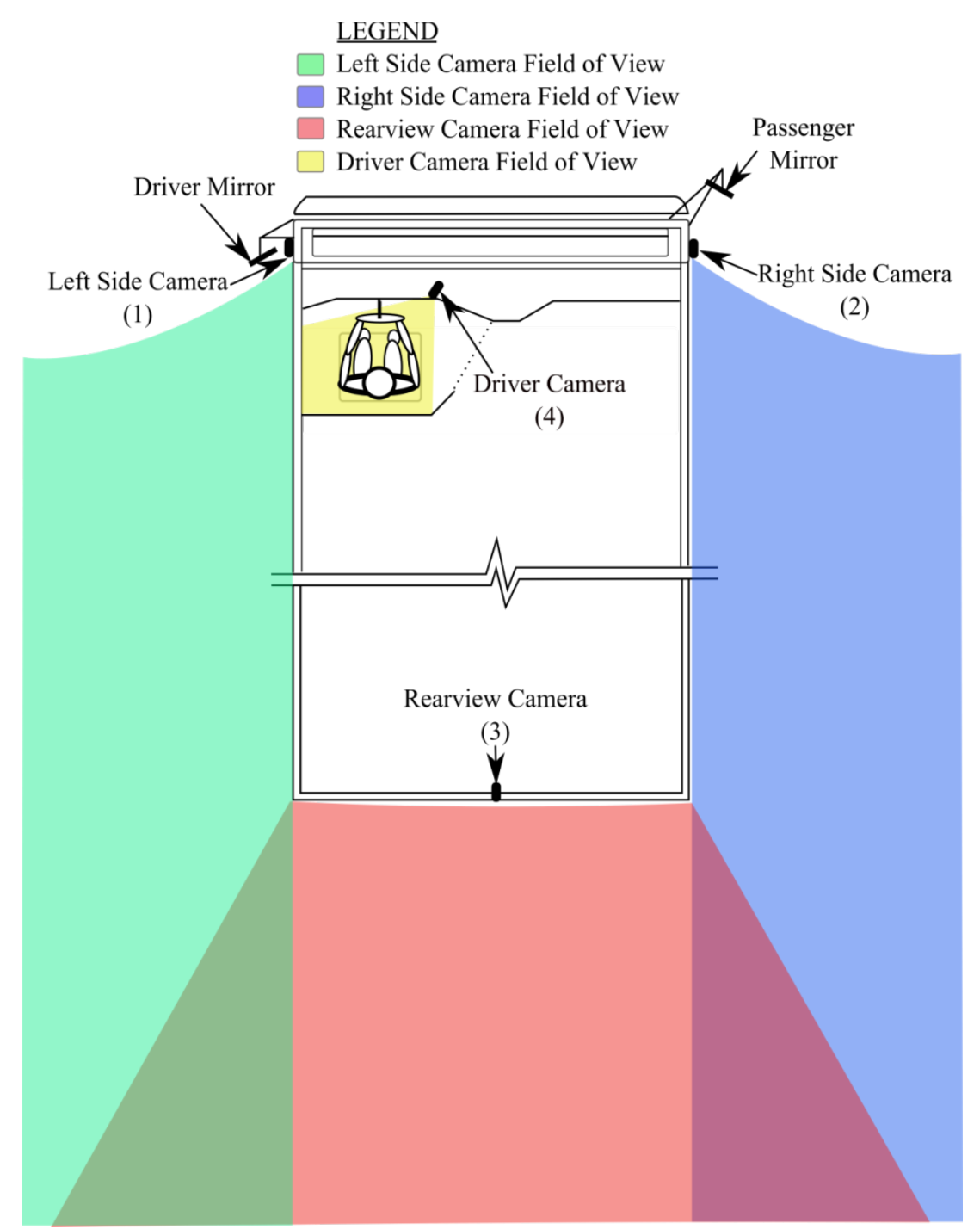

Figure 4-11. Camera locations and fields of view

The method used to record the exact moment the drivers indicated they would change lanes was the push button located at the dashboard, connected to a light emitting diode (LED) in front of camera (4). When the driver pushed the button, the LED would switch on instantly and be recorded with the rest of the video scene. This allowed the research staff to record the exact moment the drivers indicated they would change lanes in front of the oncoming vehicle. All of the video from the cameras was later reviewed using software that multiplexes the videos together in one screen. A screenshot from the software screen is shown in Figure 4-12. The top two images are the left- and right-side cameras, the left bottom image is from the rearview camera, and the right bottom image is from the driver camera, showing that the driver has pressed the button and the LED has lit. 


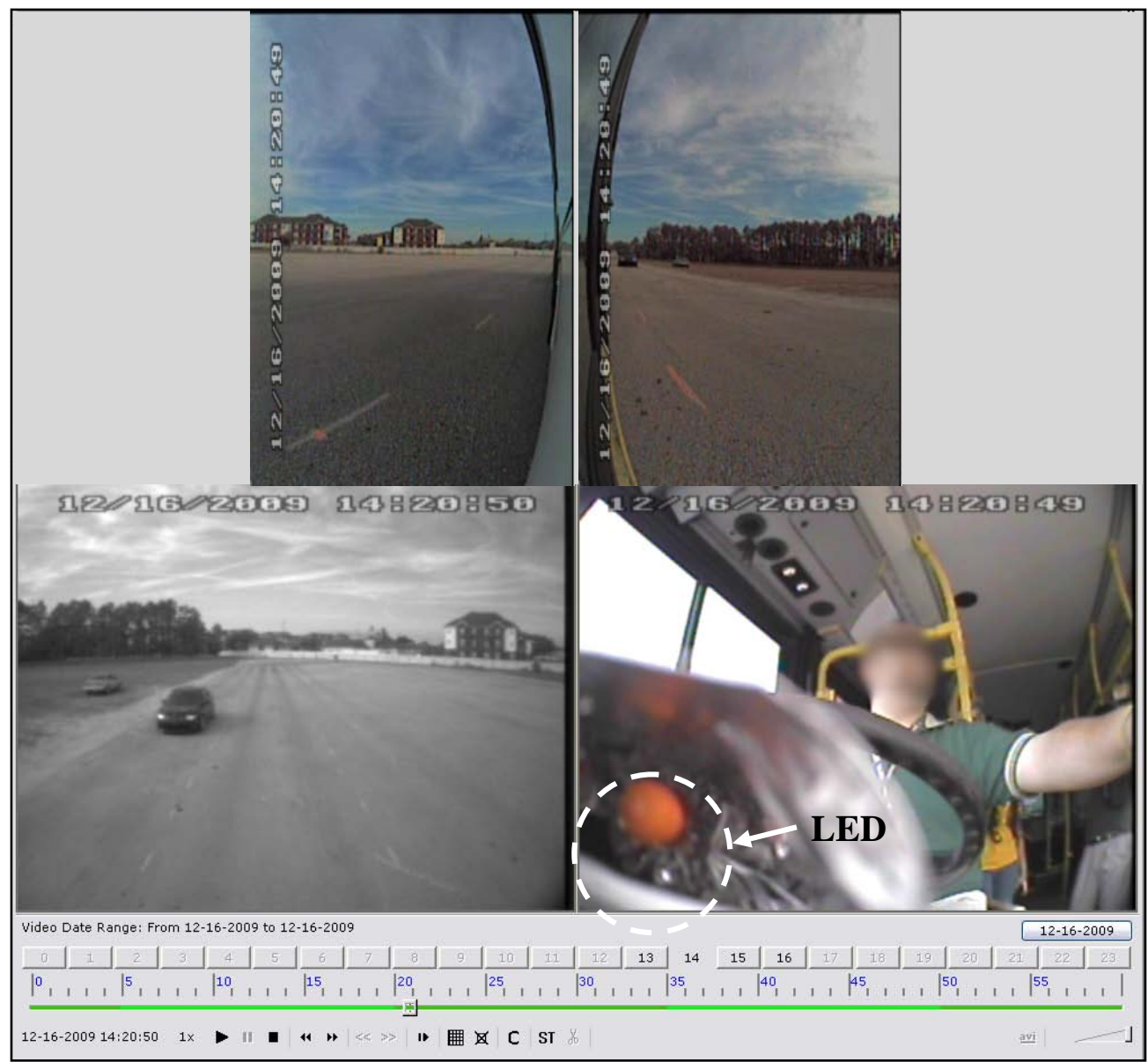

Figure 4-12. Screenshot from the software used for video analysis

The distance data for the lane change maneuver was collected using a virtual scale superimposed on the image from the rearview camera. This was needed because the location of the bus and vehicle would not be constant every time the driver indicated he/she would change lanes. The virtual scale could be introduced later on the video data collected during the test.

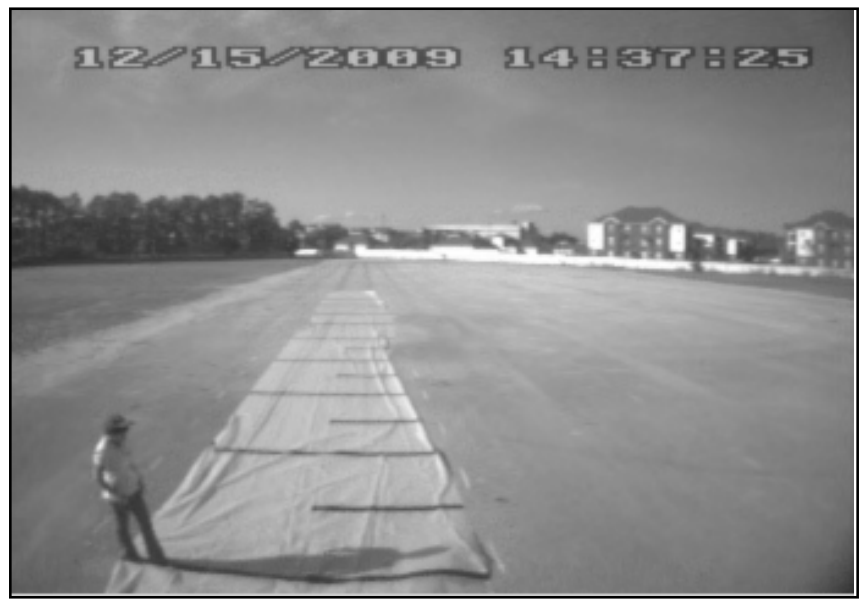

Figure 4-13. The actual scale used for distance measurement 
A scale of $100 \mathrm{ft}$ with increments of $5 \mathrm{ft}$ was laid in the rear of the bus in front of the rearview camera. An image of the actual scale is shown in Figure 4-13. Figure 4-14 shows how the scale was laid starting at the bumper of the bus. Since the camera's view did not start exactly at this point, the first line seen in the image on Figure 4-15 is not the $0 \mathrm{ft}$ line but the $20 \mathrm{ft}$ line. This is why the vehicle located at the second $10 \mathrm{ft}$ line is actually located $30 \mathrm{ft}$ behind the bus. Later, a virtual scale was drawn to match the scale lines, and then superimposed on the video from the rearview camera.

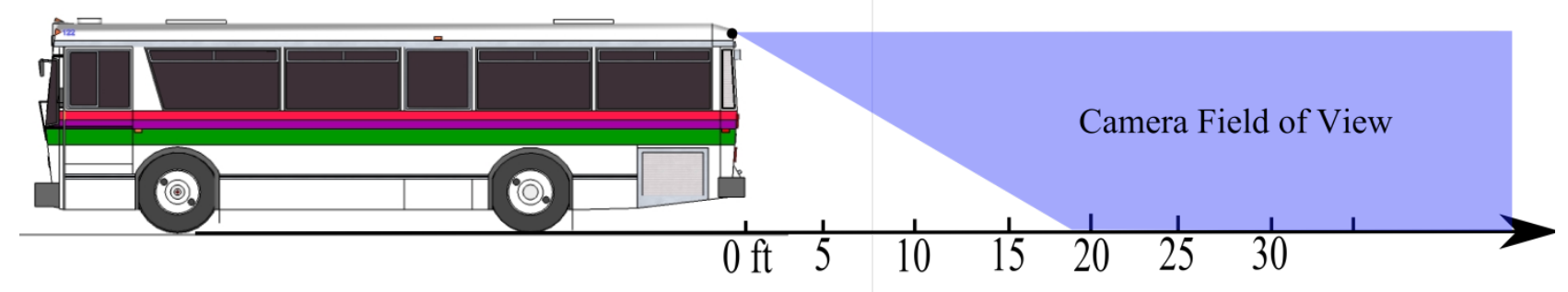

Figure 4-14. Scale placement behind the bus

An example of the outcome is shown in Figure 4-15, where the other vehicle is located at a distance of $30 \mathrm{ft}$ behind the bus when the driver pushed the button.

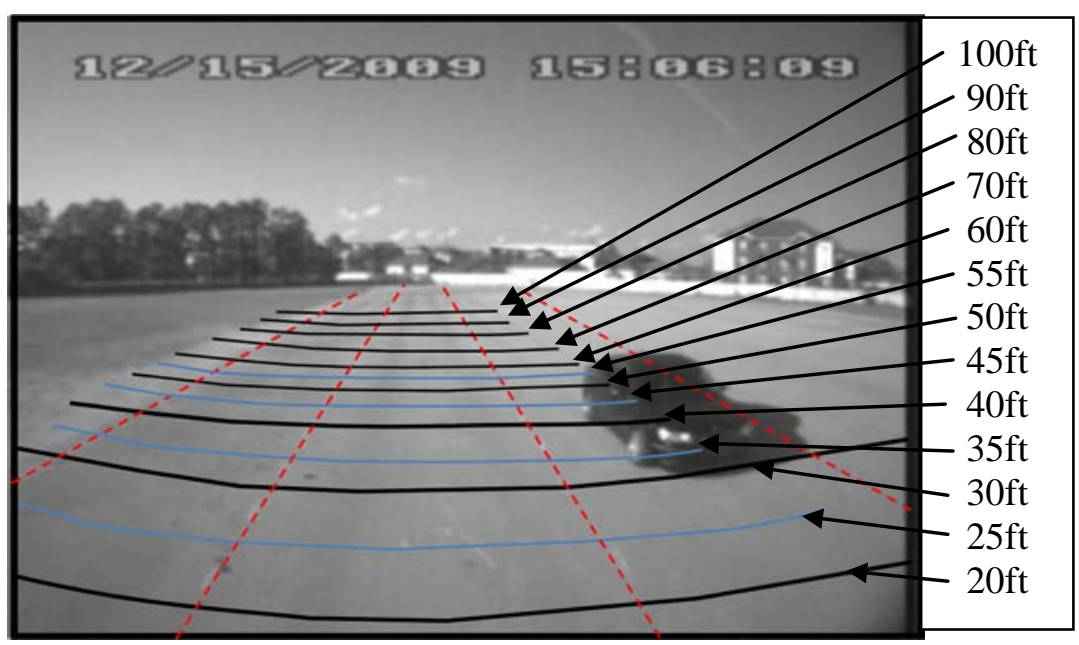

Figure 4-15. Virtual scale used to measure distance

With this method, the location of the two vehicles was not important during the test. Since the rearview video camera was recording continuously, the distance between the vehicles could be obtained later. The next chapter shows the results from the surveys, the distances between the two vehicles, and distance perception exercise. The distance obtain by this exercise is shown in Figure 4-16. 


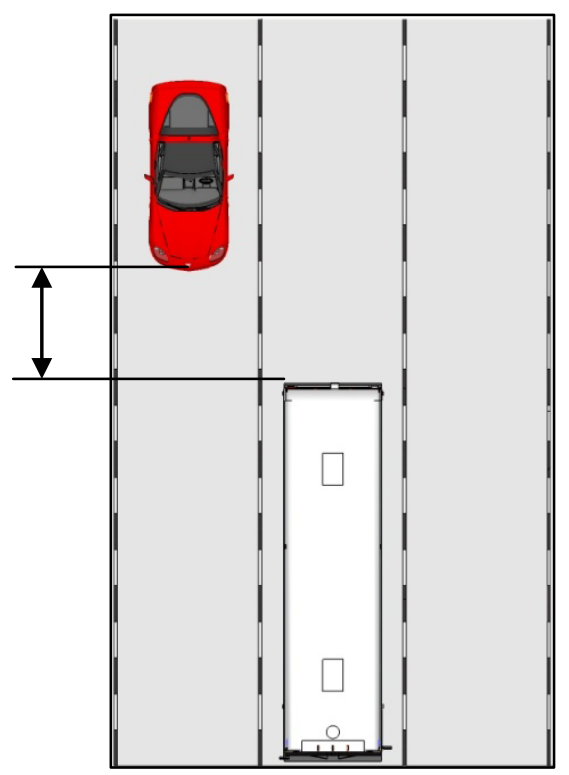

Figure 4-16. Distance measurement during "lane change” maneuver 


\subsection{Results of Controlled Driving Test}

\subsection{Distance/Depth Perception under Static Conditions}

This exercise provided results in distance/depth perception using the video system. As mentioned earlier, the drivers were asked to estimate the distance from the rear of the bus to a person standing behind the bus, using the mirrors and the video system. The bus and person were static (not moving) at the time of the test. As shown in Figure 5-1, the points represent where the drivers said (perceived) the person was standing. The person was actually standing at the locations marked by the two stars. The comparison here is between the points generated by the mirrors, and the points generated by the video system. Both cases have outliers (drivers misjudging by a greater amount than the average), but most drivers exhibited the same errors with the mirrors and camera-based system, which, for the purposes of the test, shows that there is consistency between the two.

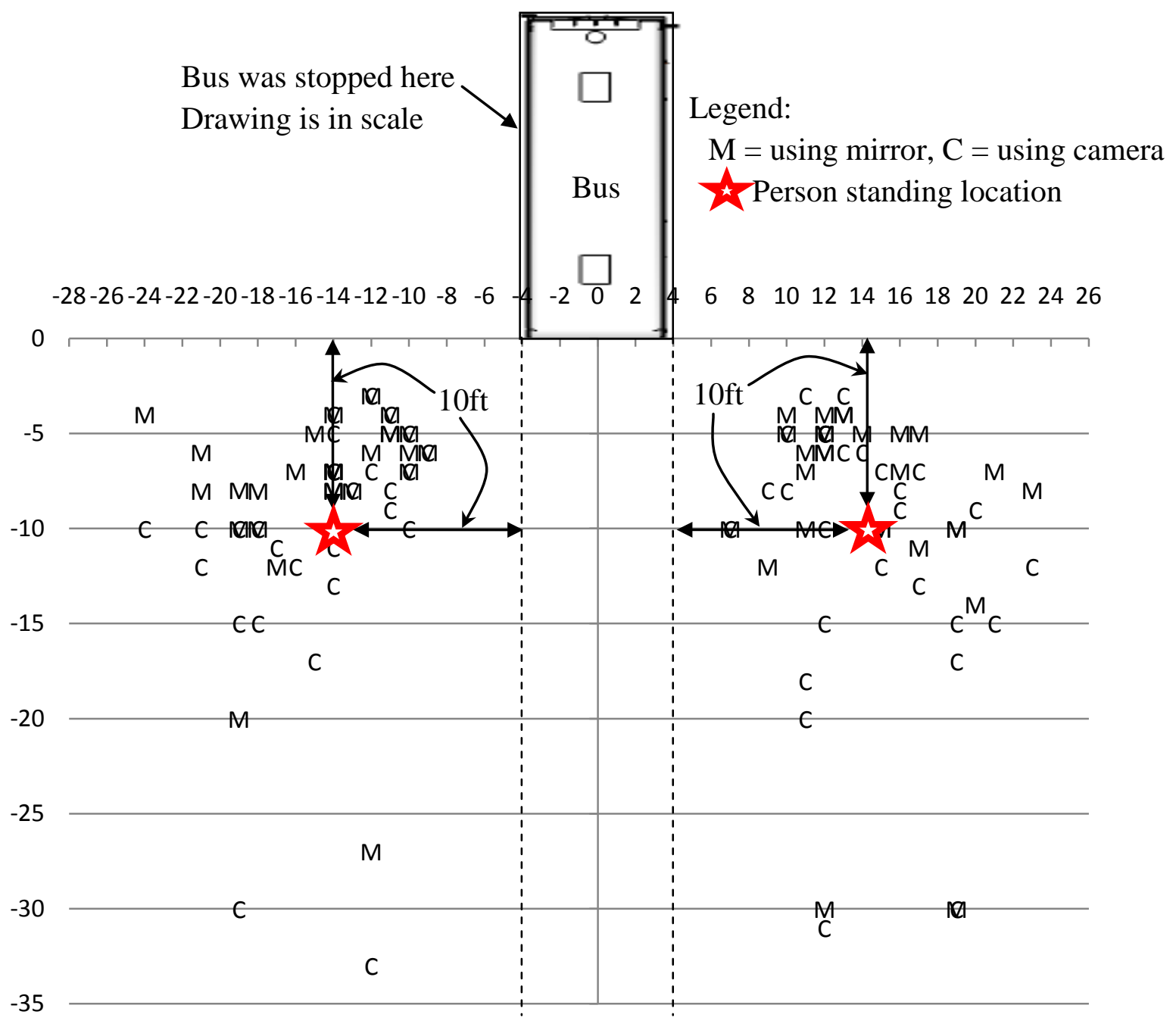

Figure 5-1. Distance perception points 


\subsection{Distance/Depth Perception under Dynamic Conditions}

The lane change maneuvers resulted in the minimum distance at which each driver would change lanes in front of the oncoming vehicle. The goal of this exercise was to obtain the distances using the sideview system and compare those to the distances obtained using the mirrors. Table 5-1 shows the descriptive statistics for the distances. On average, the distances with the video system were about 2-3ft closer than with the mirror. This distance, however, is not statistically significant.

Table 5-1. Descriptive statistics for distances in $\mathbf{f t}$

\begin{tabular}{|c|c|c|c|c|}
\hline Measure & LW & RW & LO & RO \\
\hline Average & 29.11 & 31.29 & 31.18 & 34.11 \\
\hline Max & 80 & 80 & 65 & 75 \\
\hline Min & 10 & 10 & 10 & 10 \\
\hline St. dev. & 14.14 & 16.60 & 13.41 & 15.04 \\
\hline
\end{tabular}

LW = Left side with system, RW = Right side with system, $\mathrm{LO}=$ Left side without system (mirror), $\mathrm{RO}=$ Right side without system (mirror).

All vehicles need to keep a certain distance in front of them in order to safely react or stop in case of an emergency. This distance is called the minimum stopping distance, which consists of the perception reaction distance and the braking distance. It is reasonable to assume that when a vehicle driver changes lanes in front of an oncoming vehicle, the second vehicle might need to adjust its speed by slowly decelerating or braking, depending on the differential speeds between the second and first vehicle, to keep a safe distance between the two vehicles. This distance is called stopping sight distance $\left(\mathrm{d}_{\mathrm{s}}\right)$ and it comprises two components: perception reaction distance $\left(\mathrm{d}_{\mathrm{r}}\right)$ and braking distance $\left(\mathrm{d}_{\mathrm{b}}\right)$, as shown below in Equation 1 .

$$
d_{s}=d_{r}+d_{b}
$$

The perception reaction distance $\left(\mathrm{d}_{\mathrm{r}}\right)$ is the distance travelled while the driver perceives the danger and decides to apply the brakes, and $\mathrm{d}_{\mathrm{b}}$ is the braking distance travelled to physically stop the vehicle. The complete equation of the stopping distance is shown below in Equation 2.

$$
d_{s}=V_{o} t_{r}+\frac{V_{o}^{2}-V_{f}^{2}}{2 g(f \pm G)}
$$

Where:

$V_{o}=$ Initial speed (fps)

$t_{r}=$ Perception reaction time (sec)

$V_{f}=$ Final speed (fps)

$g=$ Acceleration due to gravity (32.2fps ${ }^{2}$ )

$f=$ Coefficient of friction between tires and surface

$G$ = Grade of roadway (+ uphill, - downhill) 
When calculating the stopping distance, the final speed usually is zero. Assuming that in a lane changing maneuver, the driver of the second vehicle does not need to bring the vehicle to a complete stop, but rather decelerate comfortably to keep the distance needed between the two vehicles; the final speed used is the same as that of the first vehicle. In the case of the bus lane changing maneuver during the test, the bus was traveling at a constant $15 \mathrm{mph}$, and the other vehicle was traveling at $18-20 \mathrm{mph}$. With a roadway grade of zero (flat surface); a coefficient of friction of 0.7 between the tires; a clean, dry asphalt surface; an initial speed of $18 \mathrm{mph}$ (26.4 fps); perception reaction time of $1.0 \mathrm{sec}$, and a final speed $15 \mathrm{mph}$ (22 fps), equation (2) becomes:

$$
d_{s}=26.4 * 1.0+\frac{26.4^{2}-22^{2}}{2 * 32.2(0.7 \pm 0)}=32.12 \mathrm{ft}
$$

This distance is a safe distance between the bus and the other vehicle before the bus driver changes lanes in front of the oncoming vehicle. Figures 5-2 and 5-3 show the distances using the mirror and the video system. The two bars on each graph show the left and right sides. The results show that, overall, while using the video system, the drivers can perceive distance similar to the mirrors while the bus is in motion.

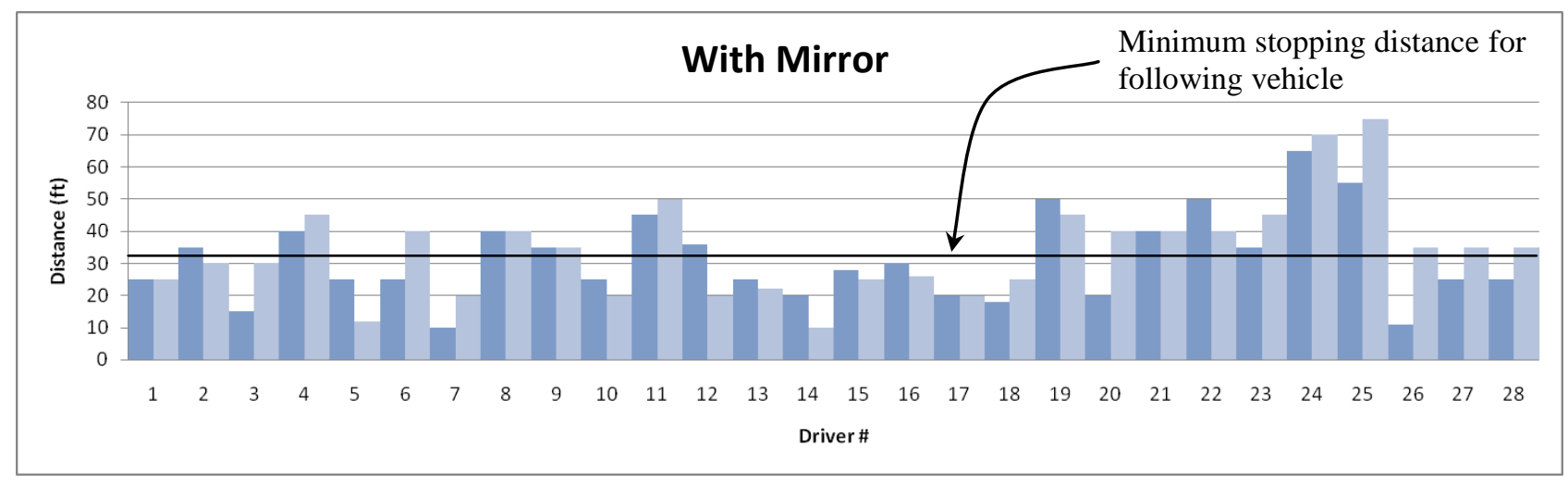

Figure 5-2. Distance measurements for lane change with mirrors

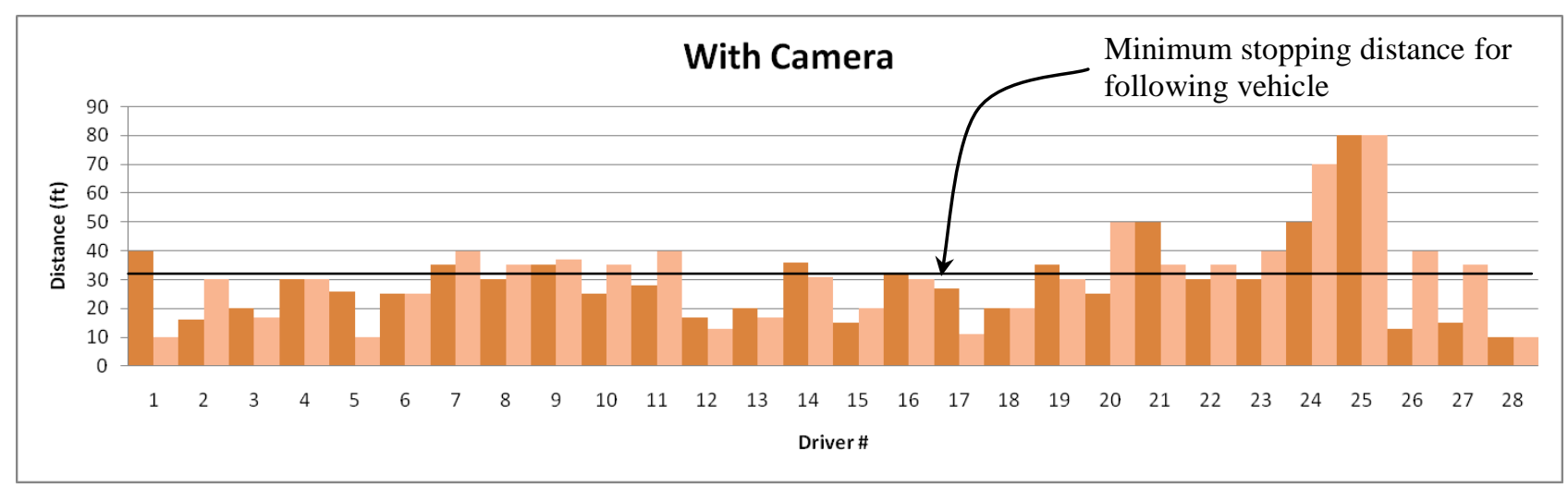

Figure 5-3. Distance measurement for lane change with sideview video system 
The results show that the drivers were able to drive the bus with the sideview system and could perceive another vehicle or person as well as with the mirrors. This is promising, as the system requires training and some time to get used to.

\subsection{Field of View under Dynamic Conditions}

As shown in Figure 5-4, the data obtained during the second maneuver for mirror and camera FOV show that when the other vehicle was located two lanes next to the bus, it could be still seen with the camera-based system at the moment the drivers stated that the view of vehicle was no longer available in the mirrors. Figure 5-4 shows what the drivers could see during the test: the vehicle is no longer visible in the mirror (both flat and convex) but it is clearly visible in the monitor next to the mirror. The maneuver and locations of the vehicle and bus are shown in a diagram and photograph in Figure 5-5.

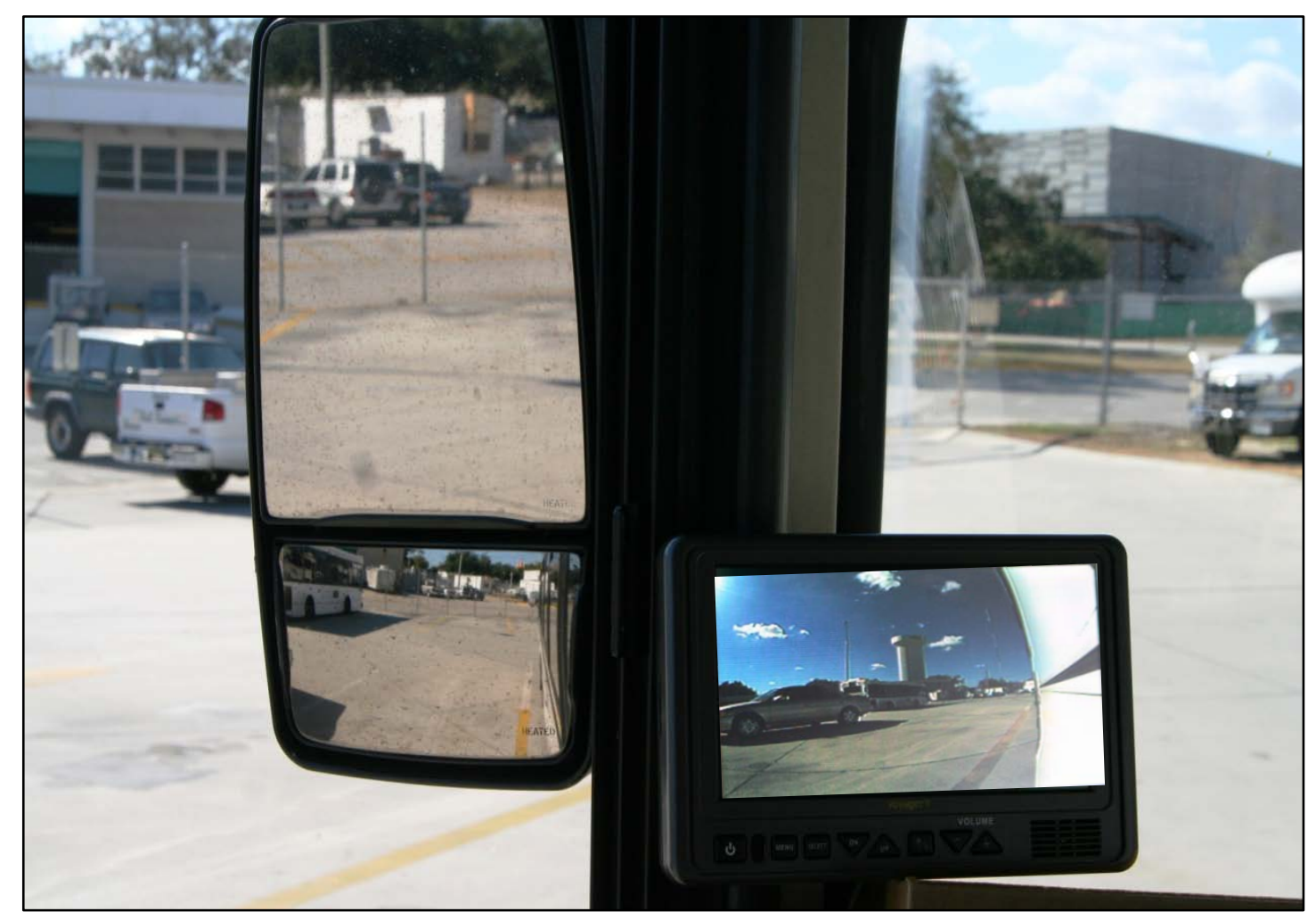

Figure 5-4. Vehicle visible with video system but not with mirrors 


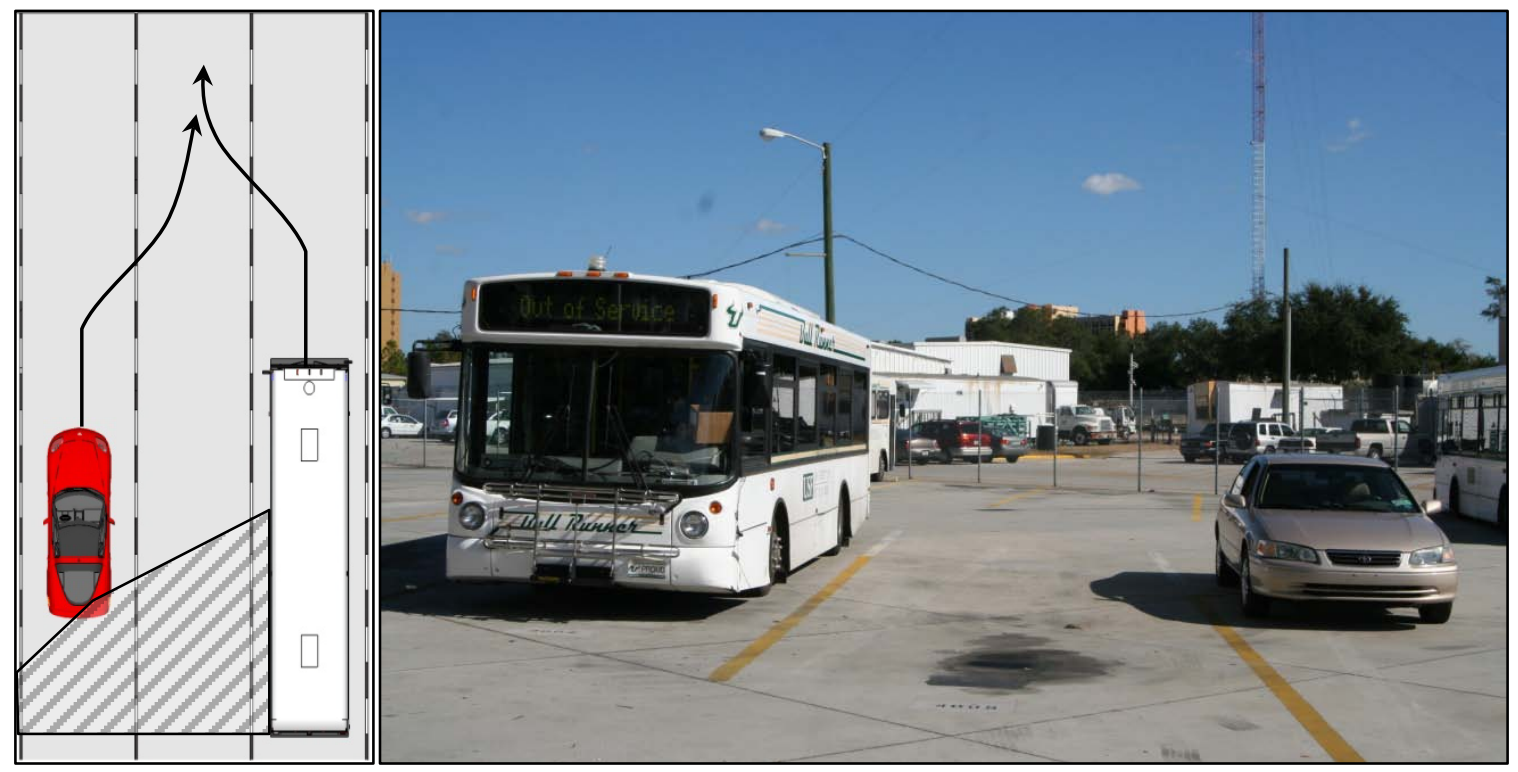

Figure 5-5. Maneuver diagram and location of other vehicle

Figure 5-6 shows an example of the captured camera images (for the left and right sides) of the moment the driver stated he could not see the vehicle in the mirror any longer. The image confirms that the view of the vehicle is still available to drivers through the camera-based system.

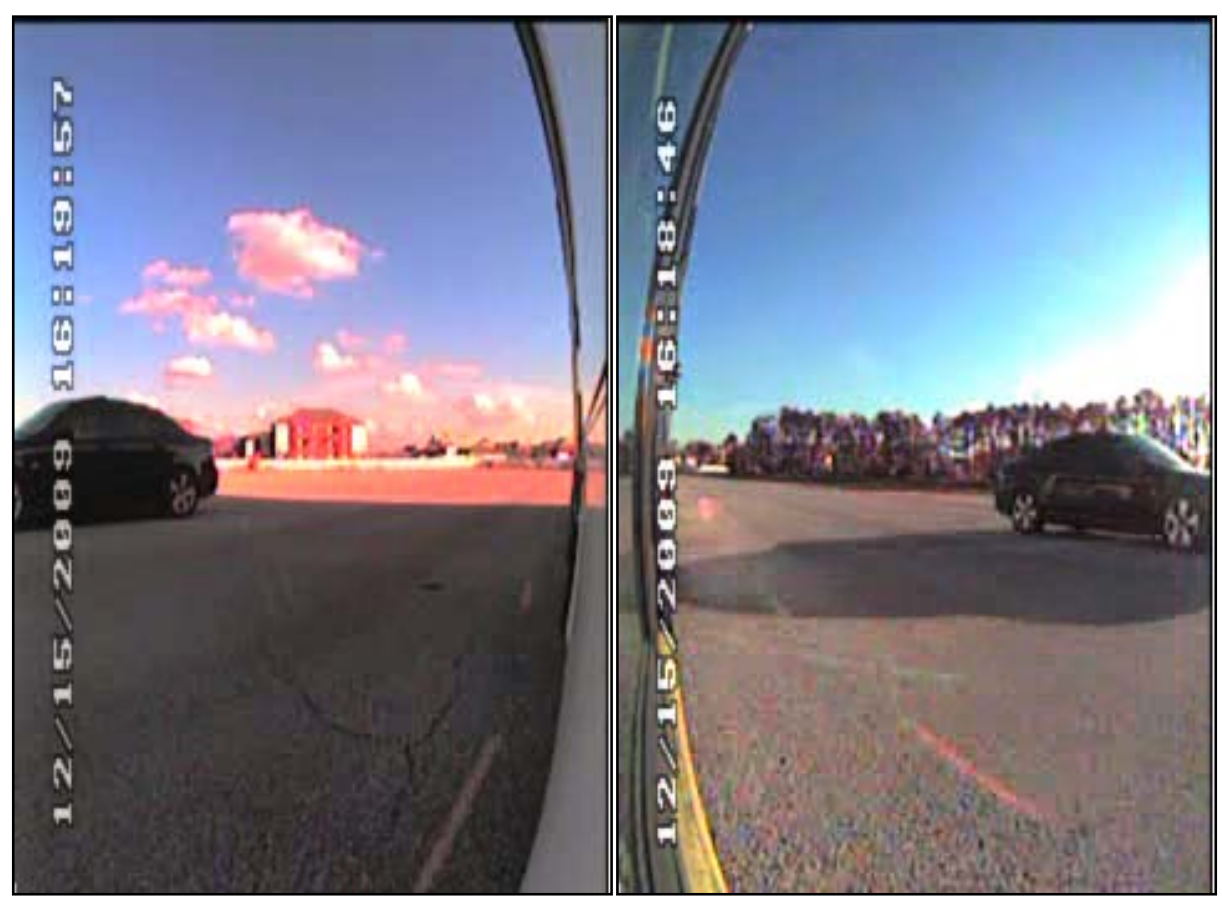

Figure 5-6. Left-and right-side camera images 


\subsection{Driver Survey}

Driver surveys were given to the participating drivers before and after they performed the test maneuvers. A set of questions was asked before and after the drivers took the test so a comparison of before and after responses could be achieved. Of the 28 drivers, 3 experienced incidents where, while turning the bus, the mirrors struck tree branches (for 2 drivers) and a cement pillar (for 1 driver). The sample size was 28 drivers, and their age distribution is shown in Figure 5-7. They had an average of 9.9 years of driving experience, from 0.5 years to 52 years. Eleven drivers had previous experience with a camera-based system (rearview video system) for at least one week. Two drivers experienced a previous side crash. Two bus types were used in the test. The first was the cutaway bus shown in Figure 3-6, and the second was a low floor transit bus shown in Figure 3-2. The responses to the questions are shown separately for each type of bus. The numbers in parentheses show the number of responses for each category.

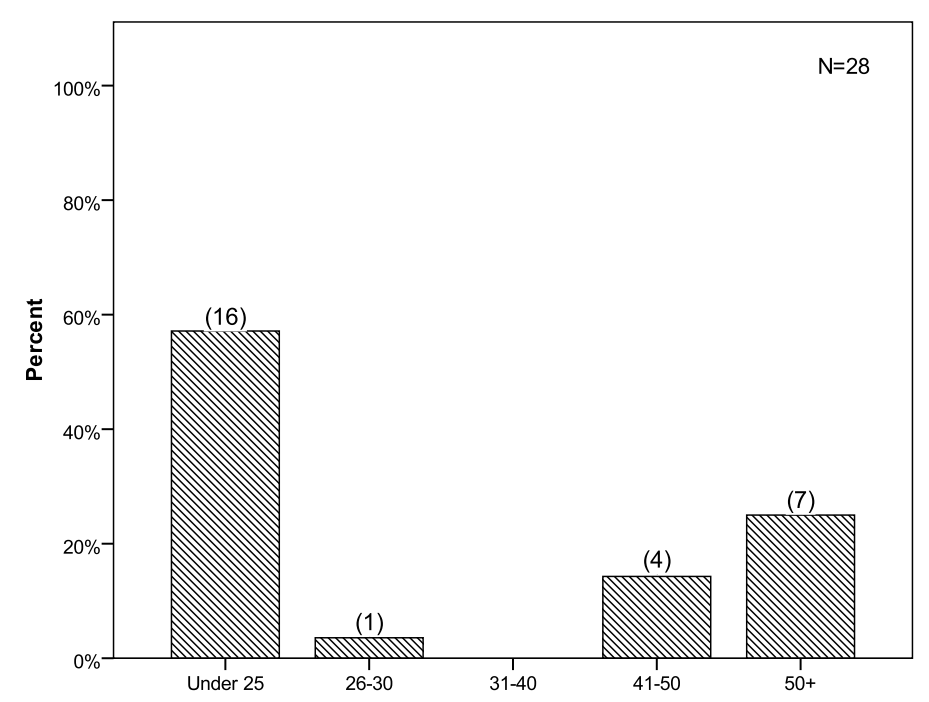

Figure 5-7. Driver age distribution

The following questions were asked before the controlled driving test. 
Q: Do you agree that side mirrors become less effective during rainy weather due to the water droplets on the window glass and mirrors?

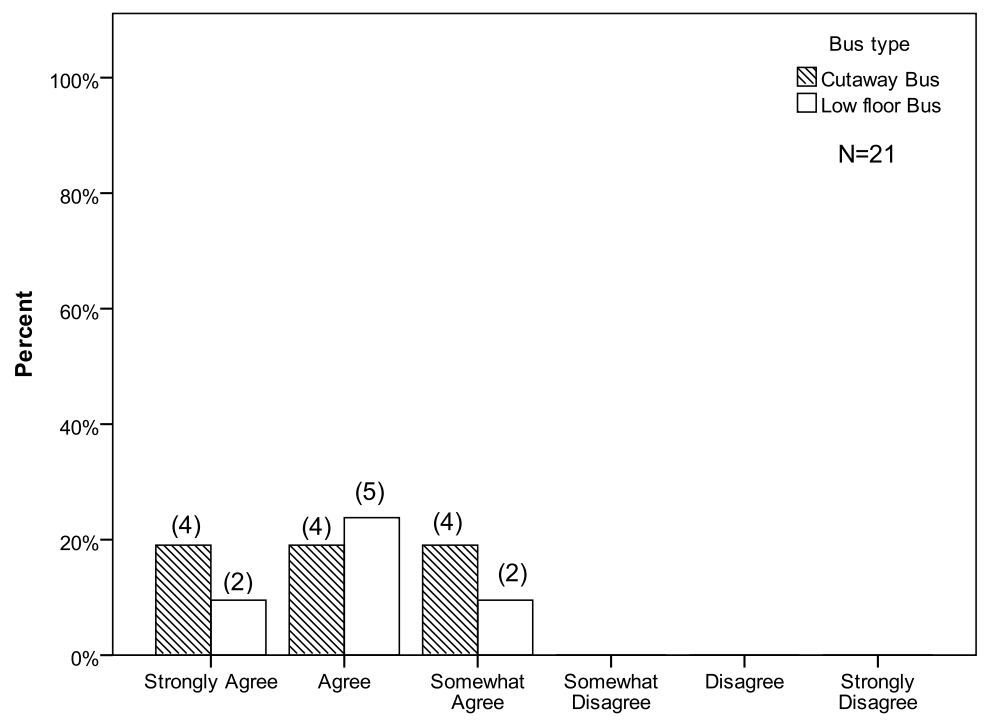

Figure 5-8. Driver responses on survey question: Do you agree that the side mirrors become less effective during rainy weather due to water droplets on the window glass and mirrors?

All drivers agreed that the mirrors become less effective when in rainy weather because the mirror and glass window accumulate water droplets, making it difficult to see through them. The camera-based system, however, is shown to provide a better view, even in rainy weather.

Q: Do you agree that it is difficult to identify an object/person using side mirrors during nighttime?

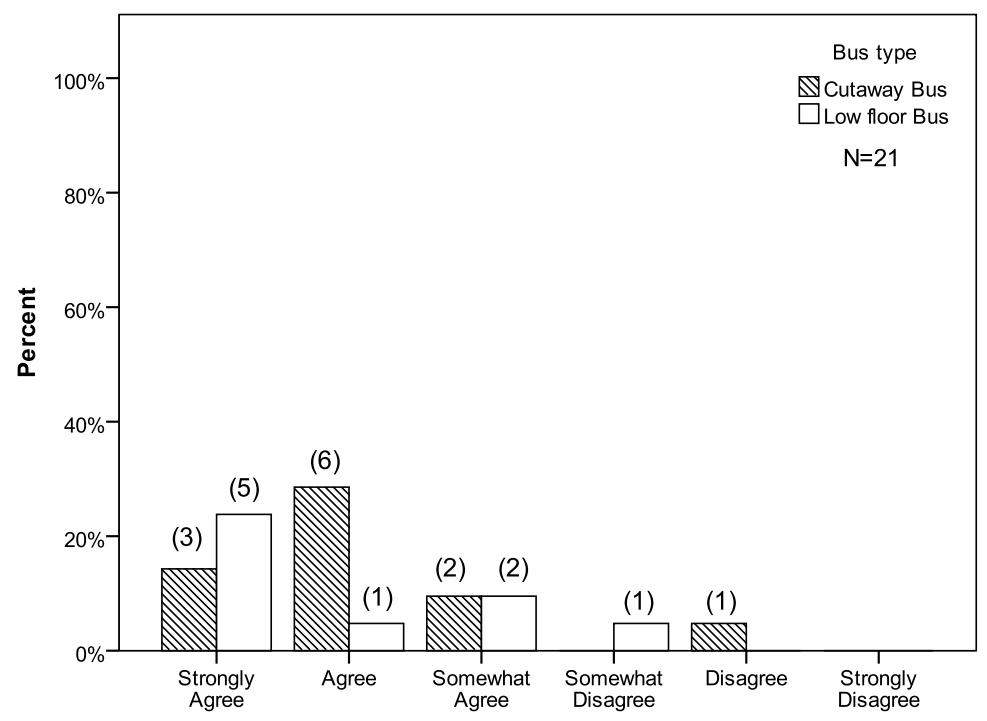

Figure 5-9. Driver responses on survey question: Do you agree that it is difficult to identify an object/person with the side mirrors during nighttime? 
The majority of drivers (90\%) agreed that it is difficult to identify a person or object using the mirrors under nighttime conditions unless it is illuminated (such as a vehicle with headlights). The camera-based system provides a better image under dark conditions, since infrared LEDs illuminate the area so that the camera can provide a better image.

The following questions were asked before and after the controlled driving test to compare the driver's preferences. The two different columns in the graphs represent the two types of buses tested. The striped pattern represents the cutaway bus, whereas the white bar represents the low floor transit bus.

Q: With the sideview video system, are the side blind zones reduced/eliminated compared to conventional mirrors?
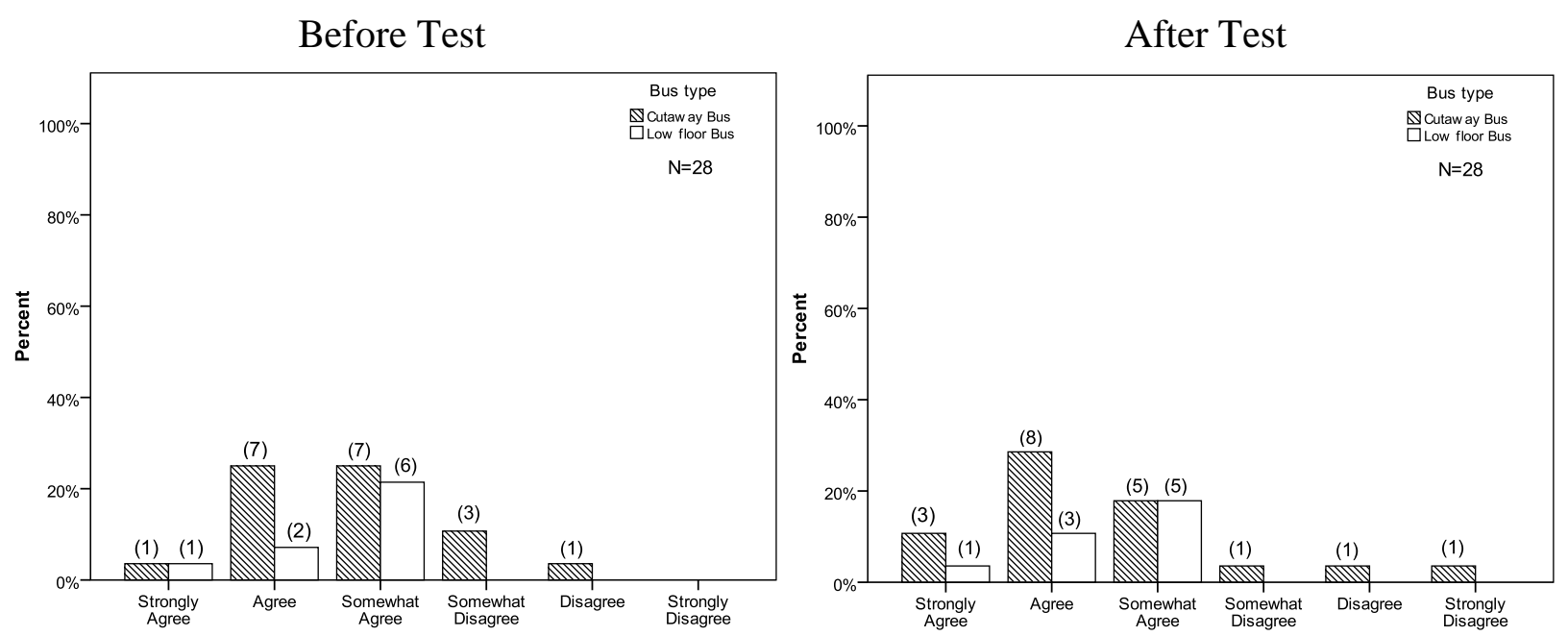

Figure 5-10. Driver responses to survey question: With the sideview video system, the side blind spots are reduced/eliminated compared to conventional mirrors

The majority of drivers (85\%) agreed that the system reduces or eliminates the side blind zones before the test, with an increase (to $90 \%$ ) after the test. 
Q: Can a sideview video system help drivers reduce side crashes (sideswipe, turns, angle crashes) by providing a better view?
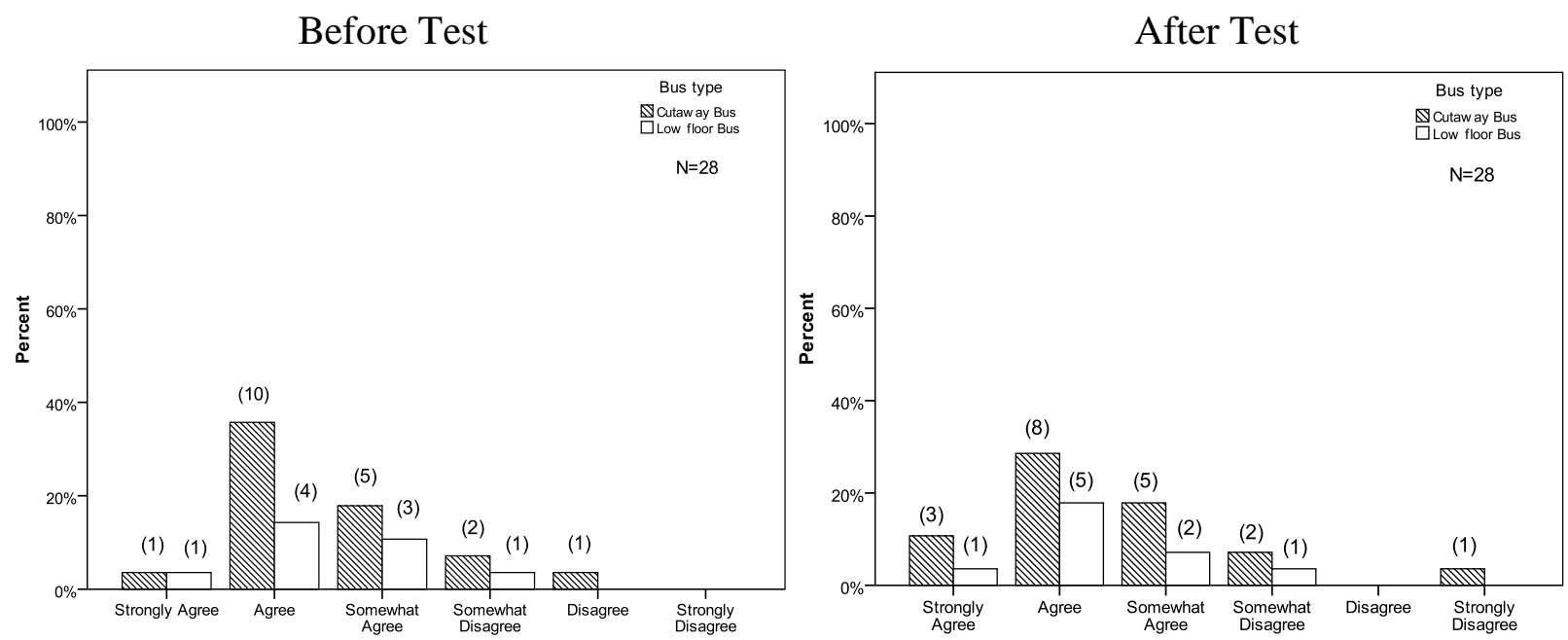

Figure 5-11. Driver responses to survey question: The sideview video system can help drivers to reduce side crashes (sideswipe, turns, angle crashes) by providing a better view

The same results as before are seen for this question as well. The majority of drivers (85\%) agreed that the system can help reduce potential side crashes by providing a better view than the mirrors before the test, and 90 percent agreed after they took the test.

Q: In general, can a sideview video system improve bus safety?
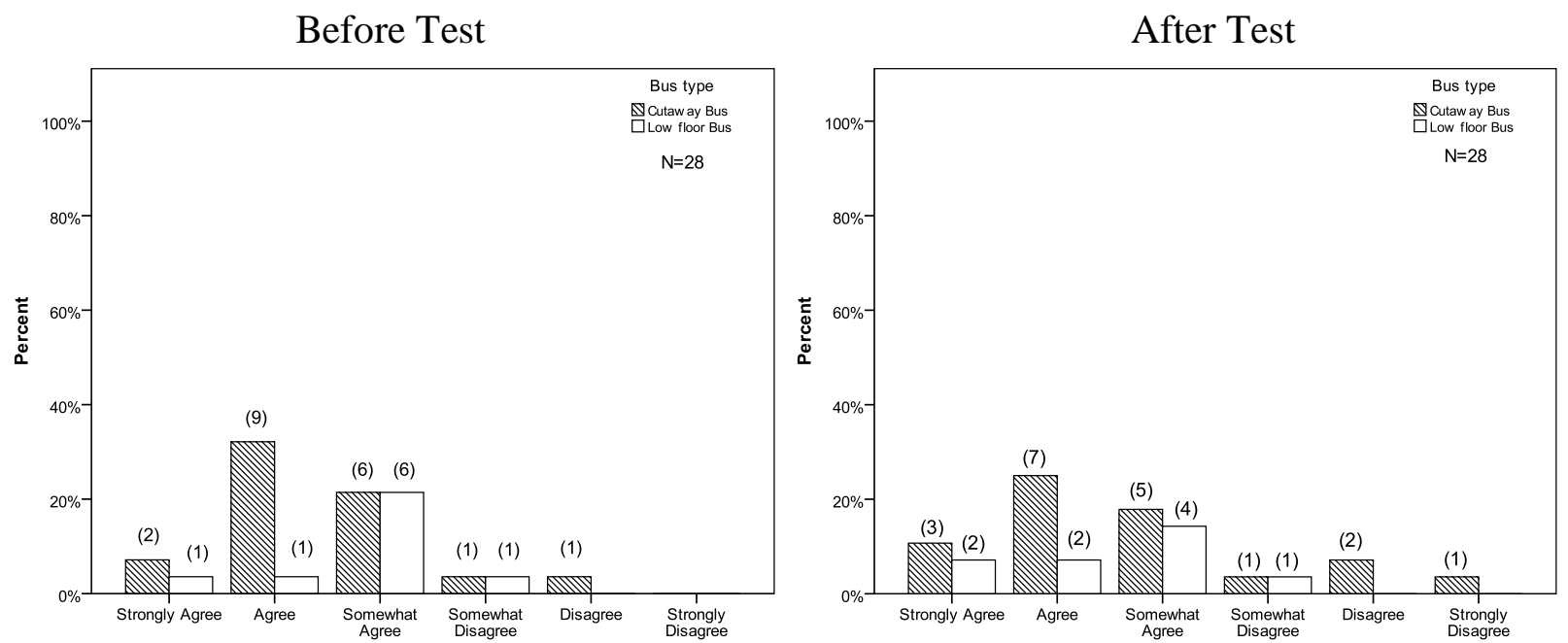

Figure 5-12. Driver responses to survey question: In general, the sideview video system can improve bus safety

A total of 89 percent of the drivers agreed before the test, and 82 percent agreed after. 
Q: Is the use of a sideview video system easy and can it be adopted quickly?
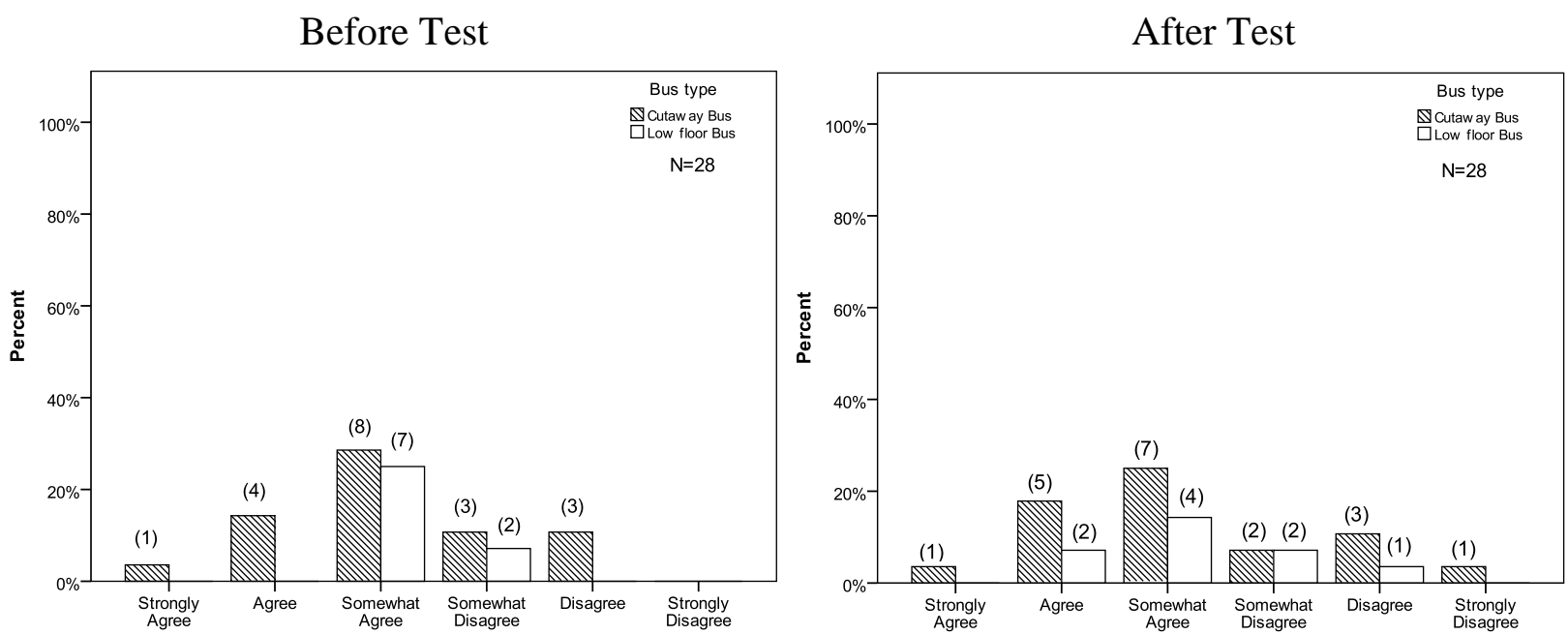

Figure 5-13. Driver responses to survey question: The use of the sideview video system is easy and can be adopted quickly

Most of the drivers (71\%) agreed with this statement before the test, and 68 percent agreed after the test. Most drivers mentioned that it was difficult to answer this question before they could use the system, and even after they had some exposure, it was still very difficult for them to respond with certainty because the time spent with the system was not enough.

Q: Would you agree to replace mirrors with a sideview video system?
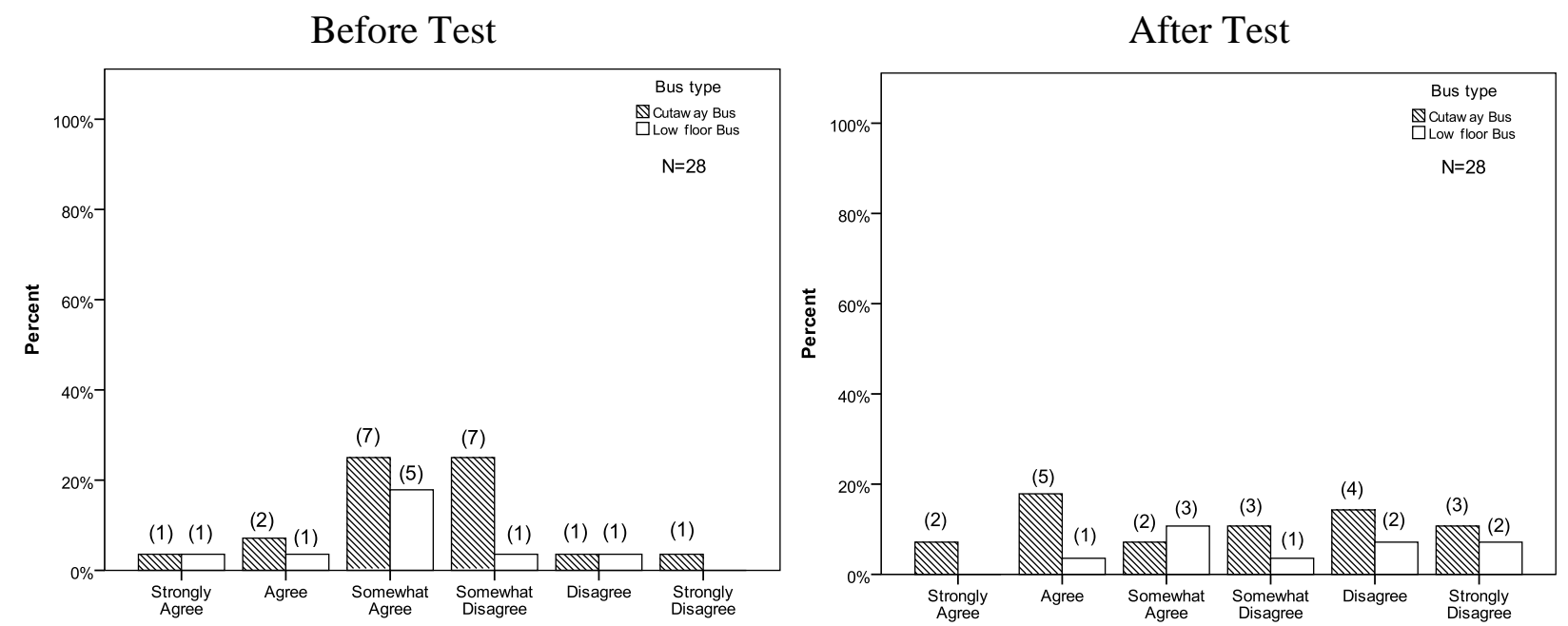

Figure 5-14. Driver responses to survey question: Would you agree to replace the mirrors with the sideview video system?

The responses for this question were somewhat mixed and the drivers did not seem to form a specific opinion, even after they took the test. In absolute numbers, 60 percent agreed before the test and 46 percent agreed after the test. This shows that the drivers do not seem to agree on replacing mirrors with a sideview video system. 
The above five questions were asked before and after the test to assess if the drivers changed their opinions based on their exposure to the system. A statistical paired t-test was performed to identify if the changes to the responses were attributed to the system. The test shows that there is no evidence to show that the changes are attributed to the system even if there is high correlation between some pairs.

Table 5-2. Questions correlation matrix

\begin{tabular}{|c|c|c|c|}
\hline & N & Correlation & Sig. \\
\hline Pair 1 & 28 & 0.446 & 0.017 \\
\hline Pair 2 & 28 & 0.510 & 0.006 \\
\hline Pair 3 & 28 & 0.462 & 0.013 \\
\hline Pair 4 & 28 & 0.456 & 0.015 \\
\hline Pair 5 & 28 & 0.551 & 0.002 \\
\hline
\end{tabular}

Table 5-3. Paired t-test

\begin{tabular}{|c|c|c|c|c|c|c|c|c|}
\hline & \multicolumn{5}{|c|}{ Paired Differences } & \multirow{3}{*}{$\mathbf{t}$} & \multirow{3}{*}{ df } & \multirow{3}{*}{ Sig. (2-tailed) } \\
\hline & \multirow[b]{2}{*}{ Mean } & \multirow[b]{2}{*}{ Std. Dev } & \multirow[b]{2}{*}{ Std. Error Mean } & \multicolumn{2}{|c|}{$\begin{array}{l}\text { 95\% Confidence } \\
\text { Interval of the } \\
\text { Difference }\end{array}$} & & & \\
\hline & & & & Lower & Upper & & & \\
\hline Pair 1 & 0.179 & 1.090 & 0.206 & -0.244 & 0.601 & 0.867 & 27 & 0.394 \\
\hline Pair 2 & 0.071 & 1.016 & 0.192 & -0.322 & 0.465 & 0.372 & 27 & 0.713 \\
\hline Pair 3 & -0.071 & 1.184 & 0.224 & -0.531 & 0.388 & -0.319 & 27 & 0.752 \\
\hline Pair 4 & -0.036 & 1.138 & 0.215 & -0.477 & 0.406 & -0.166 & 27 & 0.869 \\
\hline Pair 5 & -0.464 & 1.374 & 0.260 & -0.997 & 0.068 & -1.788 & 27 & 0.085 \\
\hline
\end{tabular}

Table 5-4. Descriptive statistics for t-test

\begin{tabular}{|c|c|c|c|c|}
\hline & Mean & $\mathbf{N}$ & Std. Deviation & Std. Error Mean \\
\hline \multirow{2}{*}{ Pair 1 } & 2.71 & 28 & 0.897 & 0.169 \\
\cline { 2 - 5 } & 2.54 & 28 & 1.138 & 0.215 \\
\hline \multirow{2}{*}{ Pair 2 } & 2.54 & 28 & 0.922 & 0.174 \\
\cline { 2 - 5 } & 2.46 & 28 & 1.105 & 0.209 \\
\hline \multirow{2}{*}{ Pair 3 } & 2.57 & 28 & 0.920 & 0.174 \\
\cline { 2 - 5 } & 2.64 & 28 & 1.283 & 0.242 \\
\hline \multirow{2}{*}{ Pair 4 } & 3.18 & 28 & 0.945 & 0.179 \\
\cline { 2 - 5 } & 3.21 & 28 & 1.197 & 0.226 \\
\hline \multirow{2}{*}{ Pair 5 } & 3.29 & 28 & 1.117 & 0.211 \\
\cline { 2 - 5 } & 3.75 & 28 & 1.624 & 0.307 \\
\hline
\end{tabular}


The following questions were asked after the drivers completed the test maneuvers and had some exposure with the system. The responses for these questions show the drivers' final opinions and represent how they felt about the system's performance after the test.

Q: Do you agree that, with a sideview video system, you can observe the boarding and late arriving passengers better than with a side mirror?

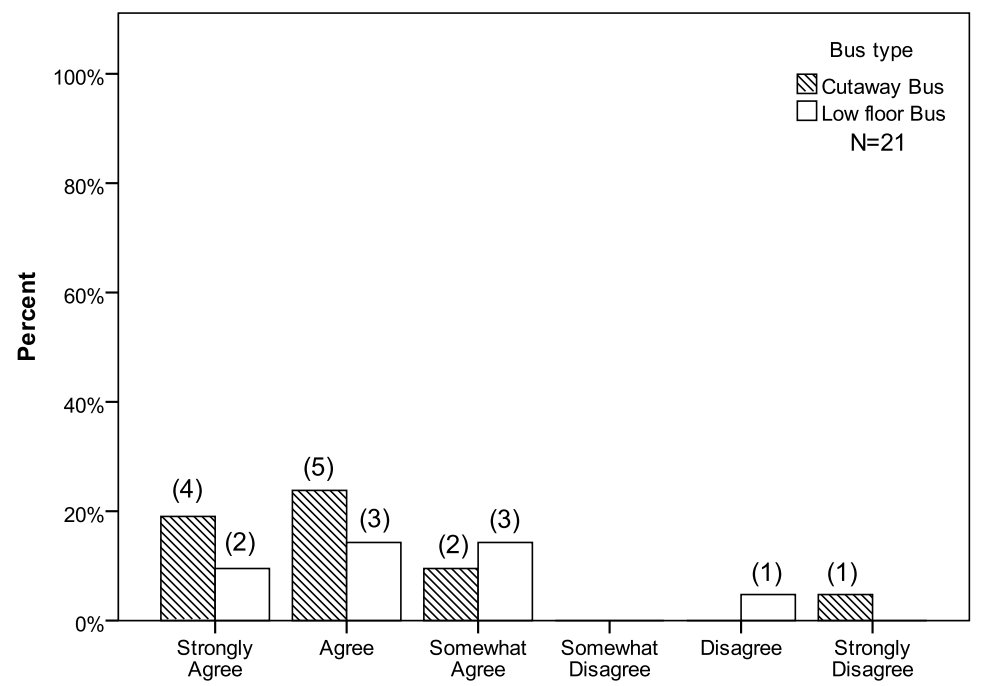

Figure 5-15. Driver responses to survey question: Do you agree that with the sideview video system you can observe the boarding and late arriving passengers better than with the mirror?

The majority of drivers (90\%) agreed that with the video system they can better observe late arriving passengers running towards the door.

Q: Did the sideview video system provide a better view than mirrors?

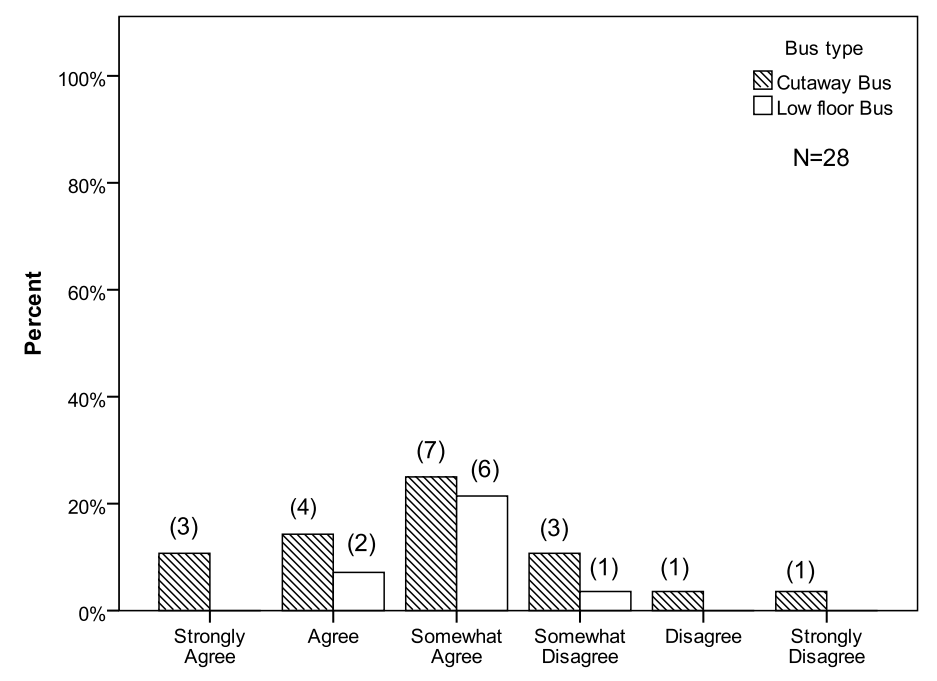

Figure 5-16. Driver responses to survey question: The sideview video system provides a better side view than the mirrors 
The majority of drivers (79\%) agreed that the video system provided a better view than the mirrors.

Q: Could you comfortably drive a bus with a sideview video system alone?

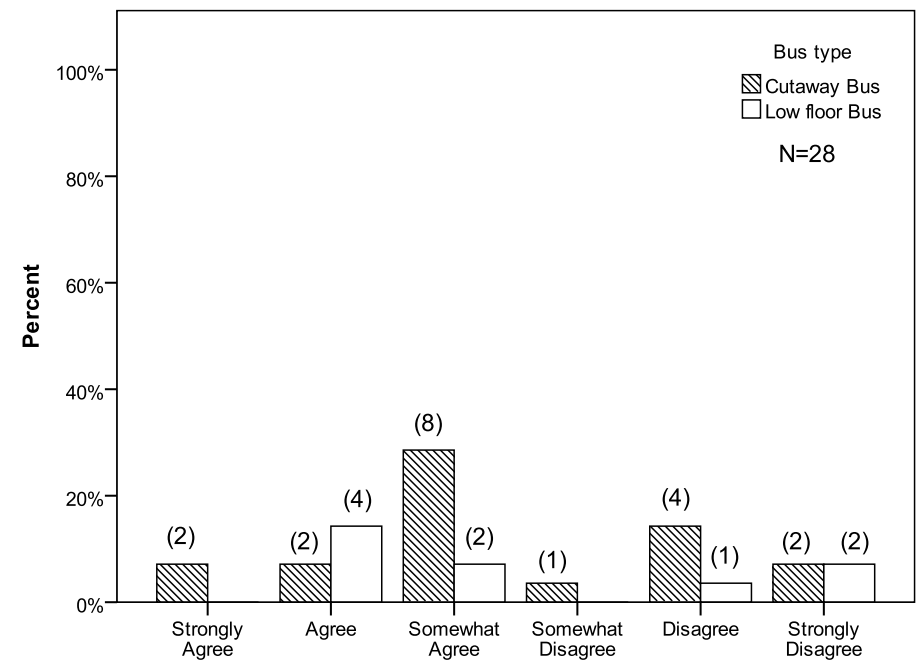

Figure 5-17. Driver responses to survey question: Do you agree that you can comfortably driver the bus with the sideview video system alone (without mirrors)?

A total of 64 percent of the drivers agreed that they think they could comfortably drive a bus with a sideview system alone. The fact that the exposure time was limited is one of the reasons more drivers did not respond positively.

Q: Would you like to have a sideview video system on the bus you drive every day?

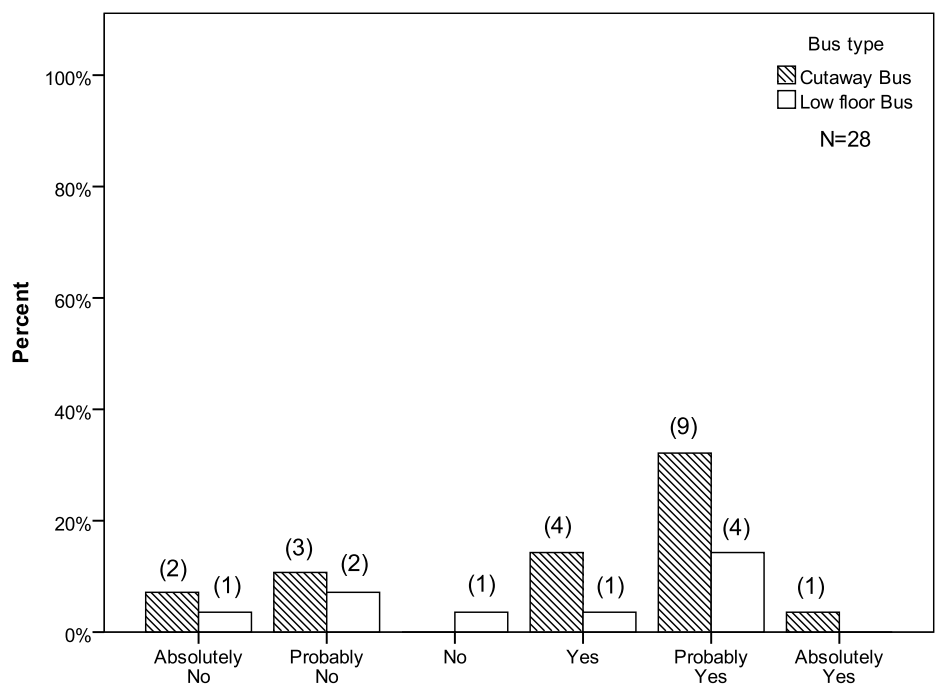

Figure 5-18. Driver responses to survey question: Would you like to have the sideview video system in the bus you driver every day?

The majority of drivers (68\%) said they would like to have a video system in their bus. This is an indirect measure of the drivers' acceptance of the system. 
Q: With the sideview video system, did you feel comfortable performing a lane change maneuver?

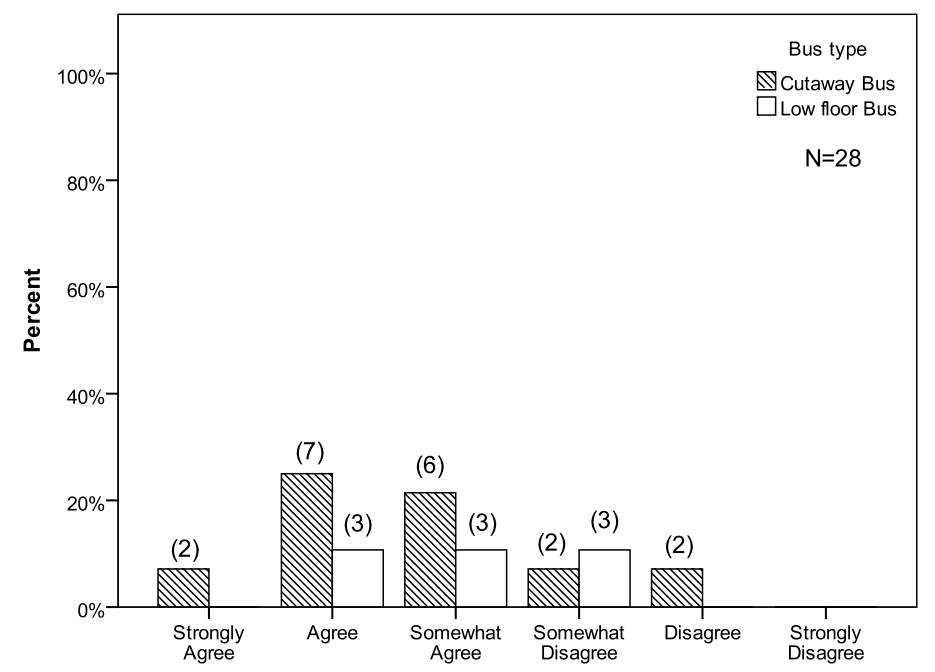

Figure 5-19. Driver responses to survey question: With the sideview video system, you felt comfortable performing a lane change maneuver

The majority of drivers (75\%) agreed that they felt comfortable performing a lane change maneuver with the system.

Q: Does the sideview video system have the potential to help reduce side crashes during a lane change maneuver?

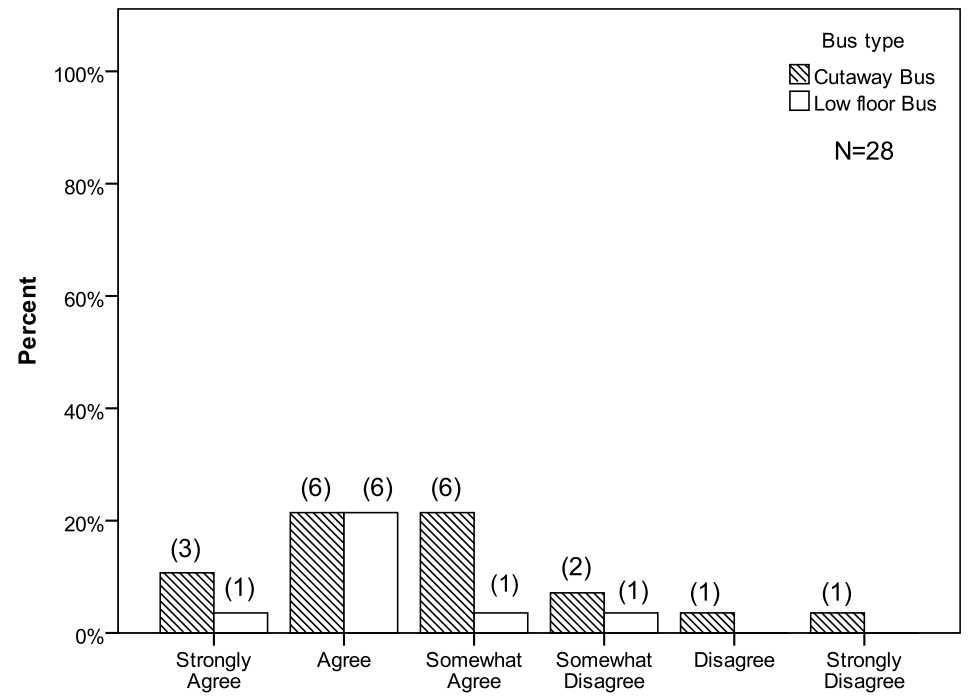

Figure 5-20. Driver responses to survey question: The sideview video system has the potential to help reduce side crashes during a lane change maneuver

The majority of drivers (82\%) agreed that the video system has the potential to help reduce side crashes during a lane change maneuver. 
Q: Can a sideview video system minimize or eliminate the side blind zones of a bus?

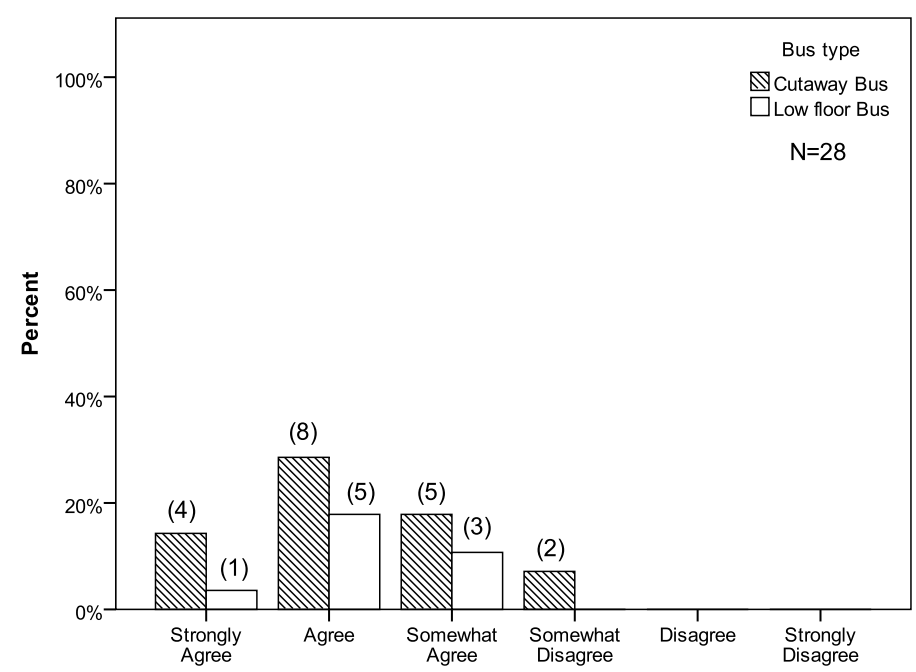

Figure 5-21. Driver responses to survey question: The sideview video system can minimize or eliminate the side blind zones of the bus

The majority of drivers (93\%) agreed that a video system can minimize or eliminate the side blind zones of the bus.

\section{Monitor Orientation, Location and Size}

The drivers also were asked questions about monitor orientation, location, and size. One of the advantages of the system is that the monitors can be installed at a variety of locations and can be different sizes and orientations. The drivers were asked their opinion on these matters, based on the setup during the test. Figure 5-23 shows the orientation of the monitor.

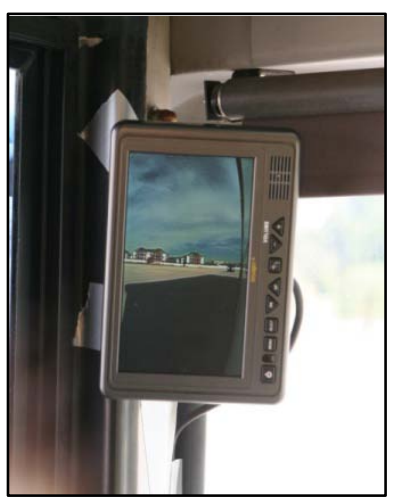

a) Portrait orientation

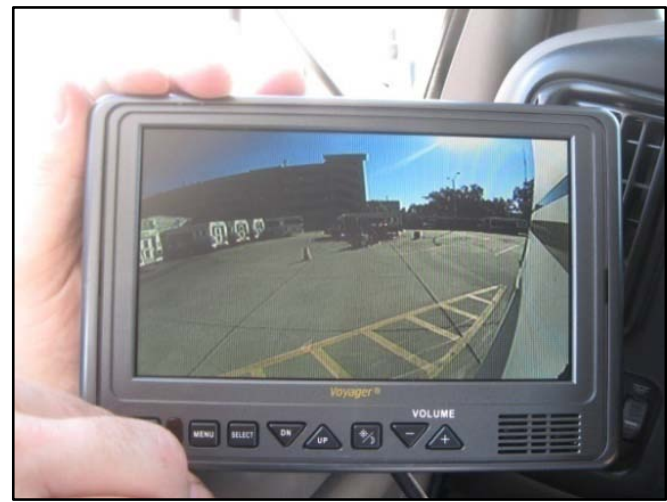

b) Landscape orientation

Figure 5-22. Monitor orientation 
Q: How would you prefer to have the monitors oriented - portrait (like in the controlled driving test) or landscape?

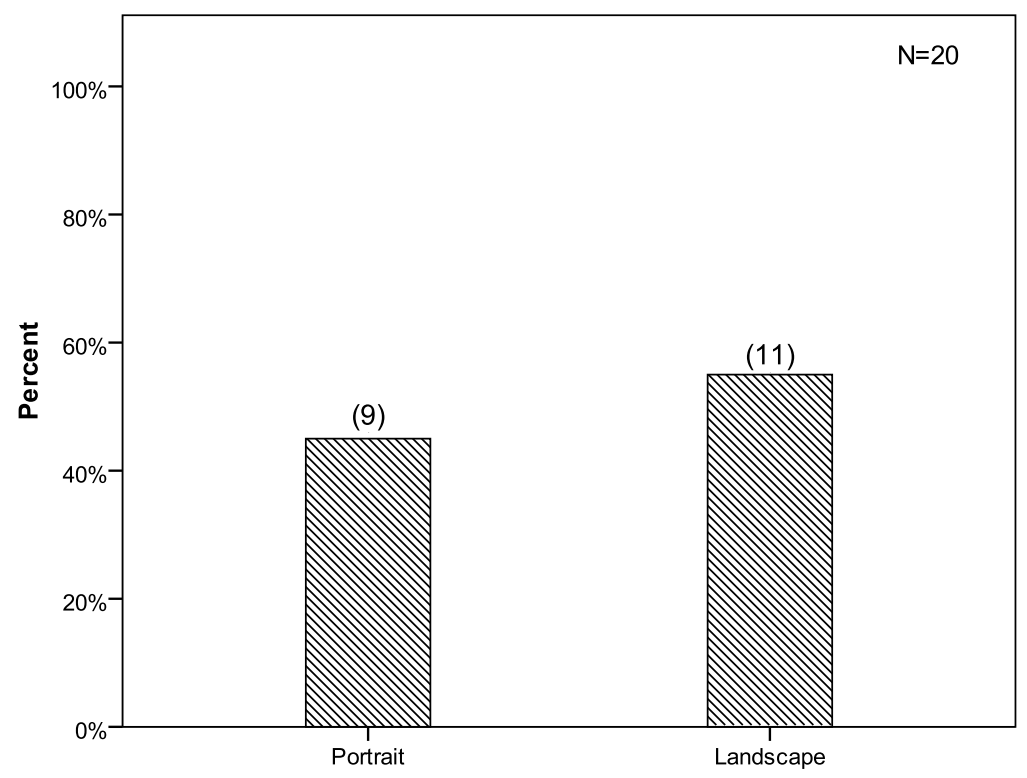

Figure 5-23. Driver responses to survey question: How would you prefer to have the monitors oriented - portrait or landscape?

When the monitor is oriented in a portrait setup, there is a certain distortion that occurs because of the scene being presented in less space. During the test, both monitors were installed in a portrait orientation in order to resemble the mirror's size and orientation. From the responses of this question, more than half of the drivers would prefer it in a landscape orientation. This is categorized as driver preference and can be changed from driver to driver. Figure 5-24 shows the monitors installed during the test (left and right side). 

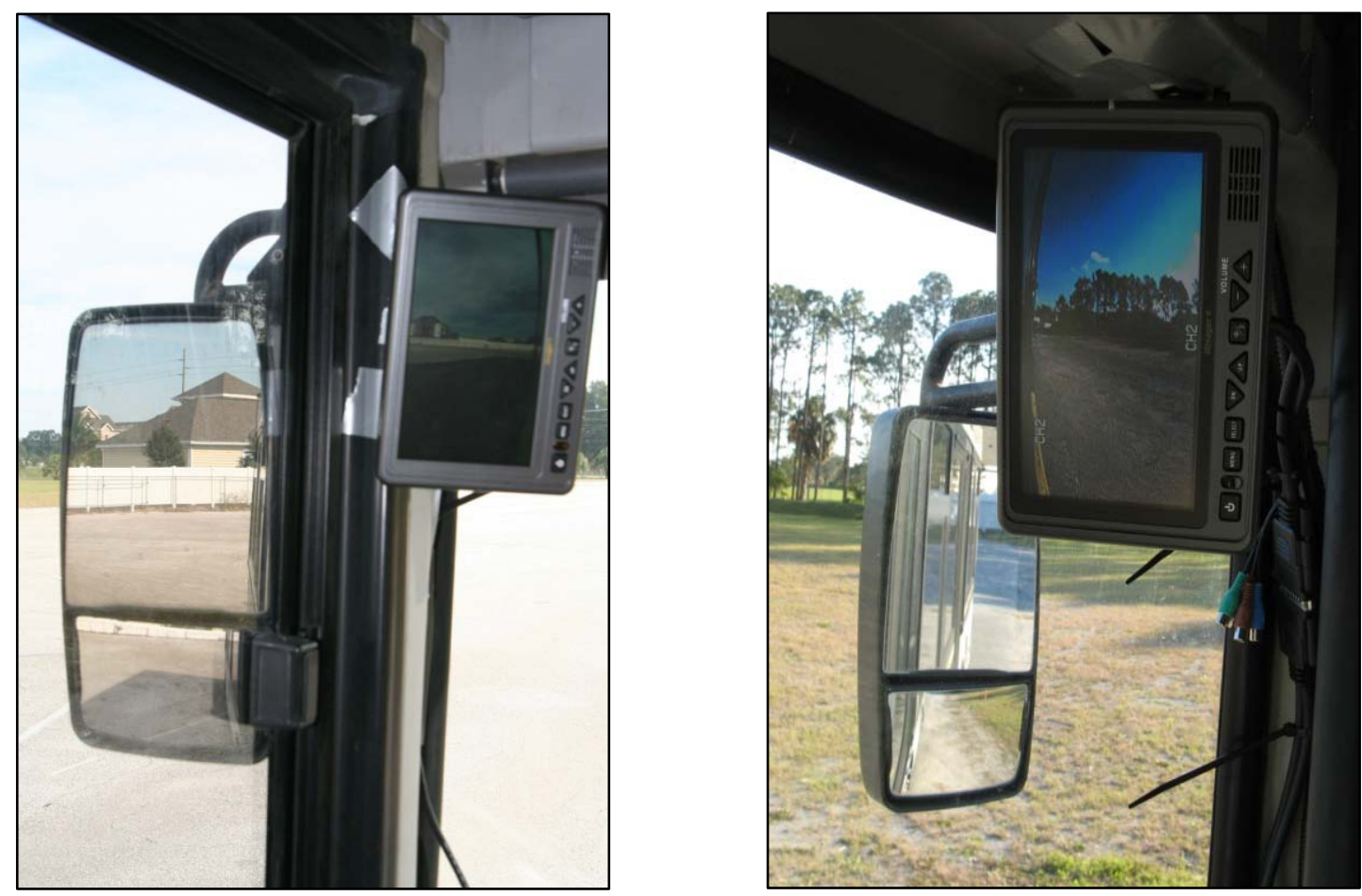

Figure 5-24. Left and right monitor installed next to mirror in portrait orientation

Q: Considering the same monitors present during the controlled driving test, where would you place the monitors of the sideview camera-based system? Please indicate by selecting one of the four setup scenarios.
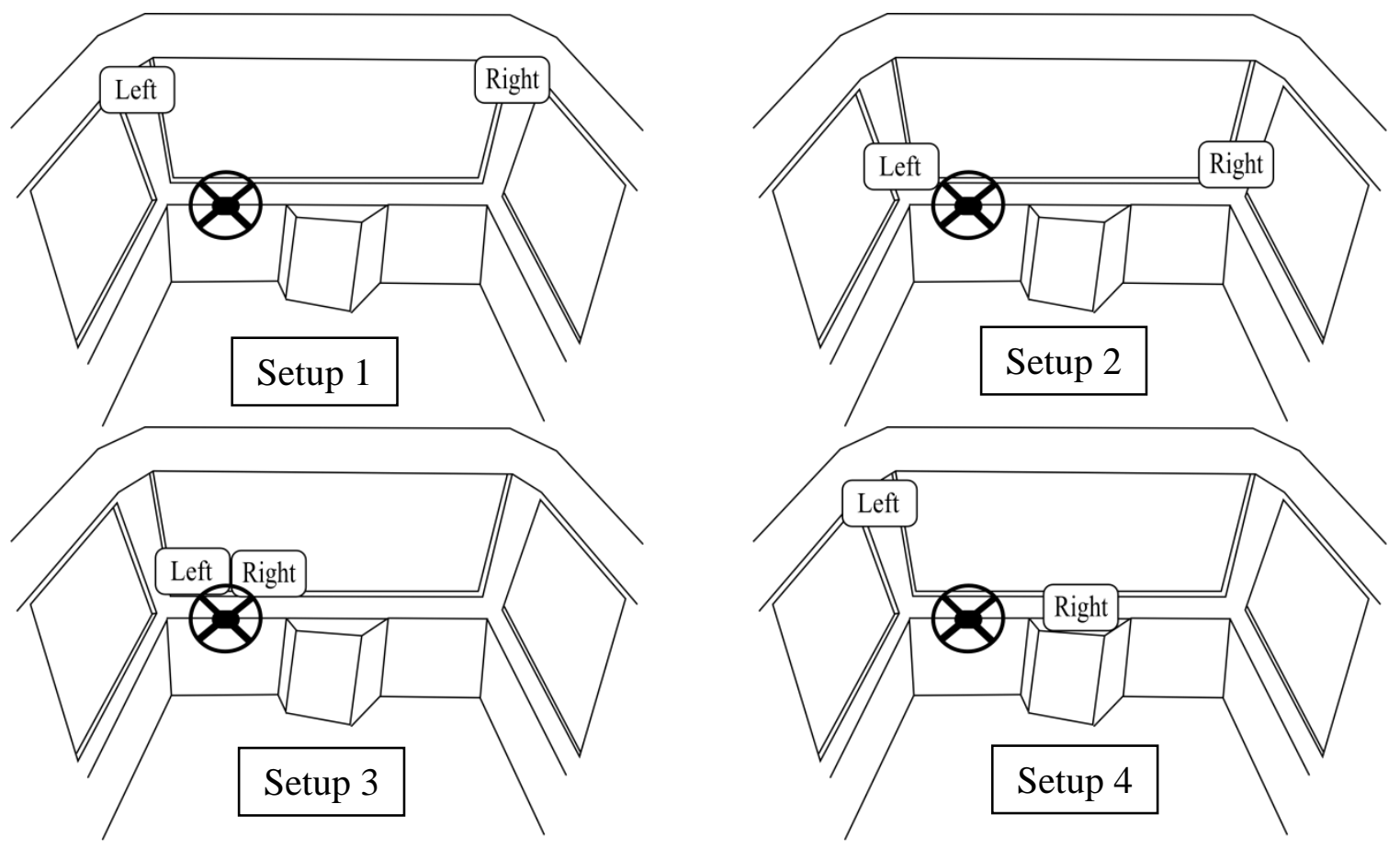


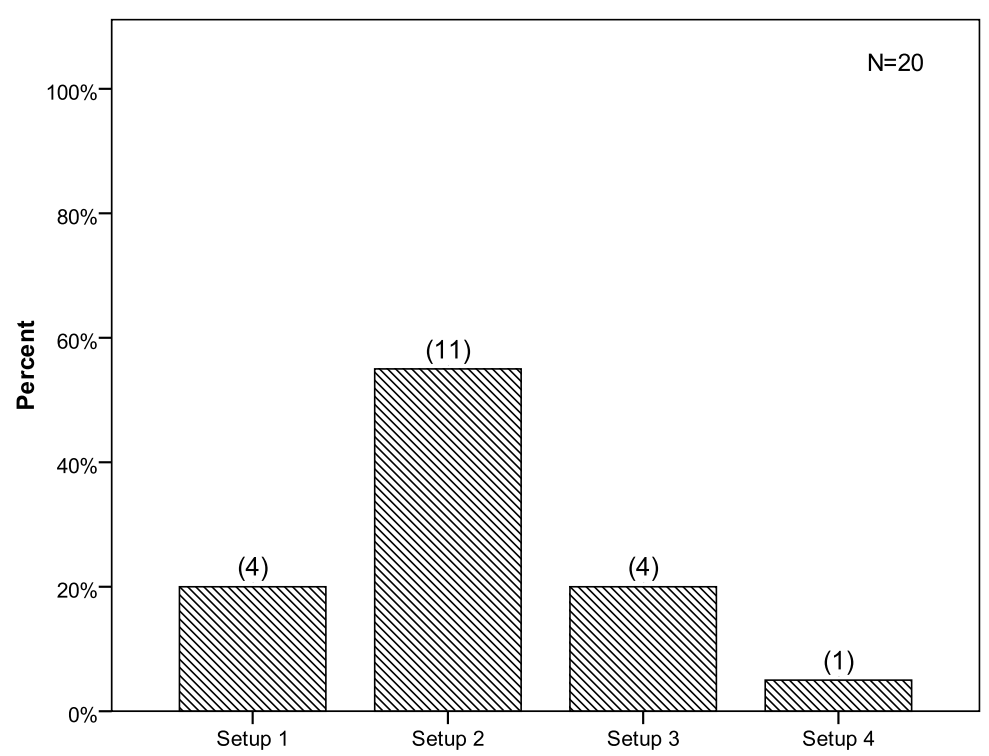

Figure 5-25. Driver responses to survey question about setup scenario

The majority of drivers agreed with the second setup, which represents the testing conditions. The location of the monitors, however, is another personal preference of the drivers and can be changed.

Q: Considering the same monitor location as during the controlled driving test, which size of monitor would you prefer for left and right side?

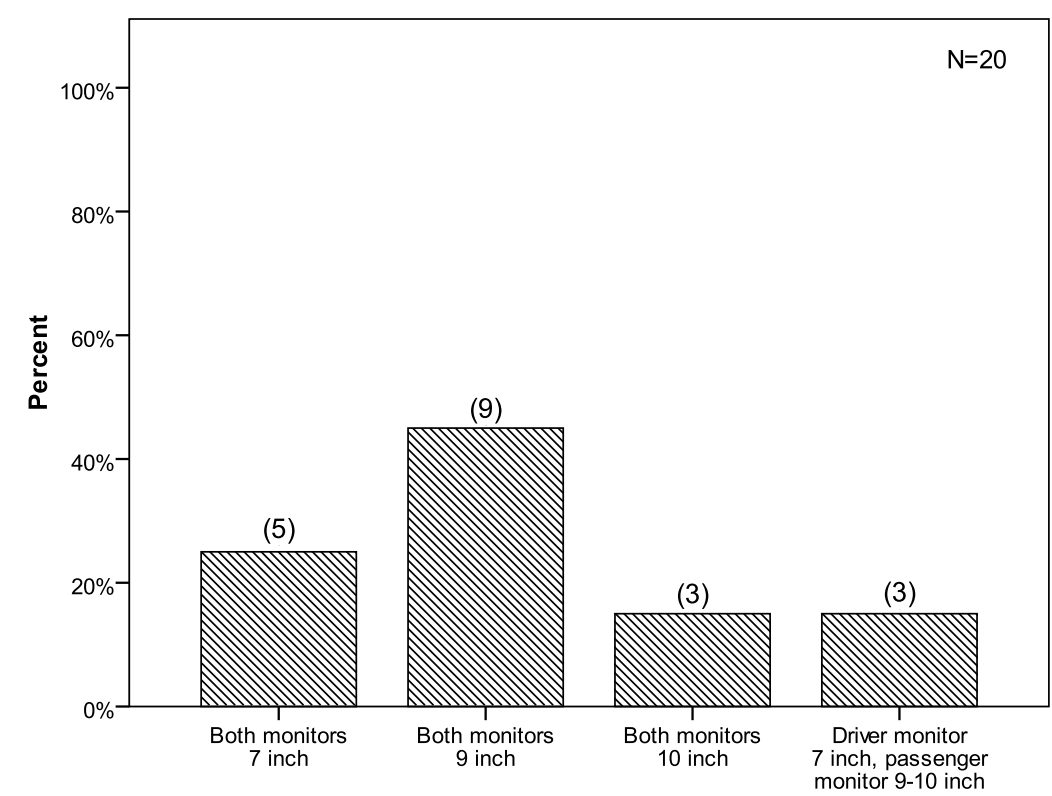

Figure 5-26. Driver responses to survey question about monitor size

The majority of drivers preferred slightly bigger monitors than the ones used in the controlled driving test $\left(7^{\prime \prime}\right)$. 


\subsection{Sideview Video System Benefits}

During the testing of the system, several advantages of the camera over the mirrors became clear. The first and most foremost is that the cameras have a wide angle view; thus, the FOV captured is much more than that of the mirrors. This allows the drivers to see more area next to the bus, whereas before, things disappeared in the blind zones. Furthermore, if the system is equipped with infrared LEDs, it can provide a much better view in low light or dark conditions. The infrared LEDs illuminate the area in infrared waves that the camera can capture, thus providing a better image than viewed with the naked eye using the mirrors. Figure 5-27 shows the image of the camera-based system at night. Note that the image in the monitor is similar to daytime conditions, whereas the rest of the area is dark. In this way, the drivers can see much more around the vehicle, even people who are not illuminated. For comparison purposes, Figure 5-28 presents the mirror image under the same conditions. From the survey, it was evident that some drivers liked the fact that they could see much better using the sideview video system at night.

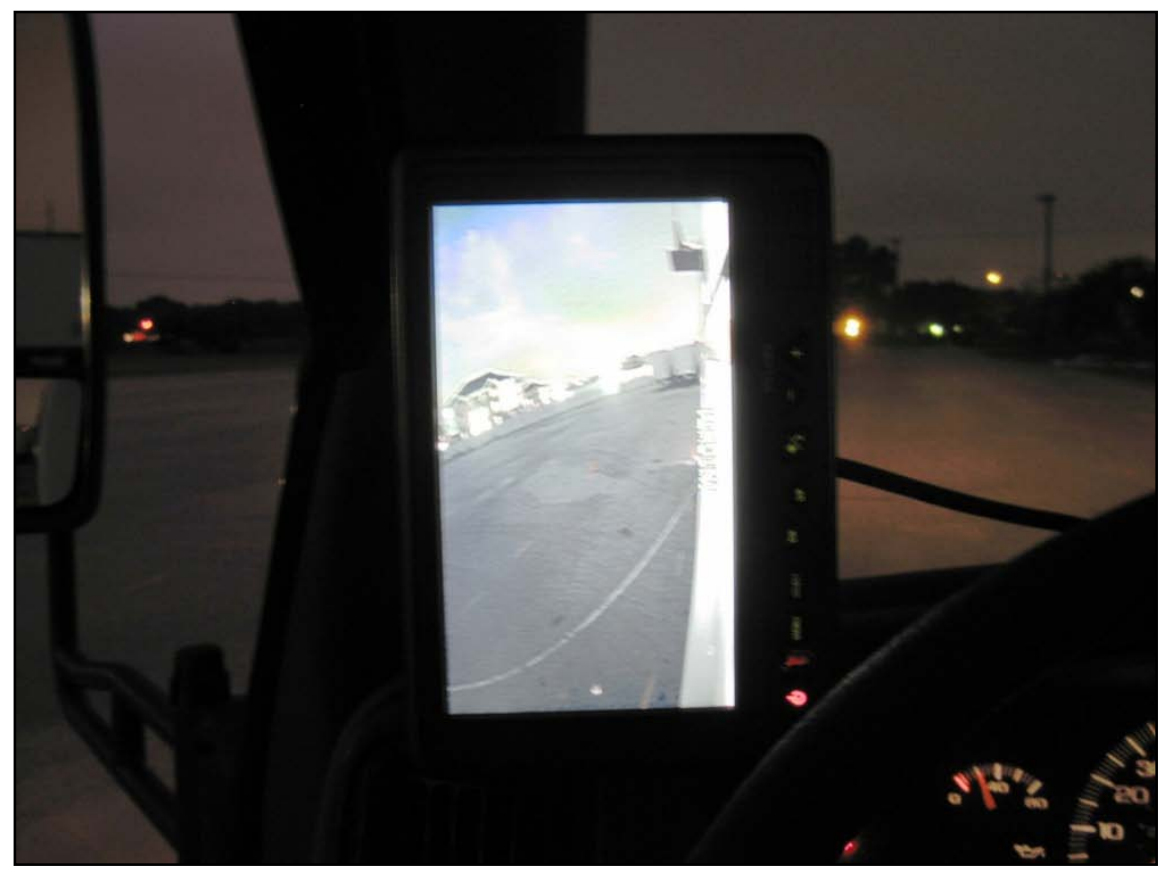

Figure 5-27. Image from camera-based system during nighttime 


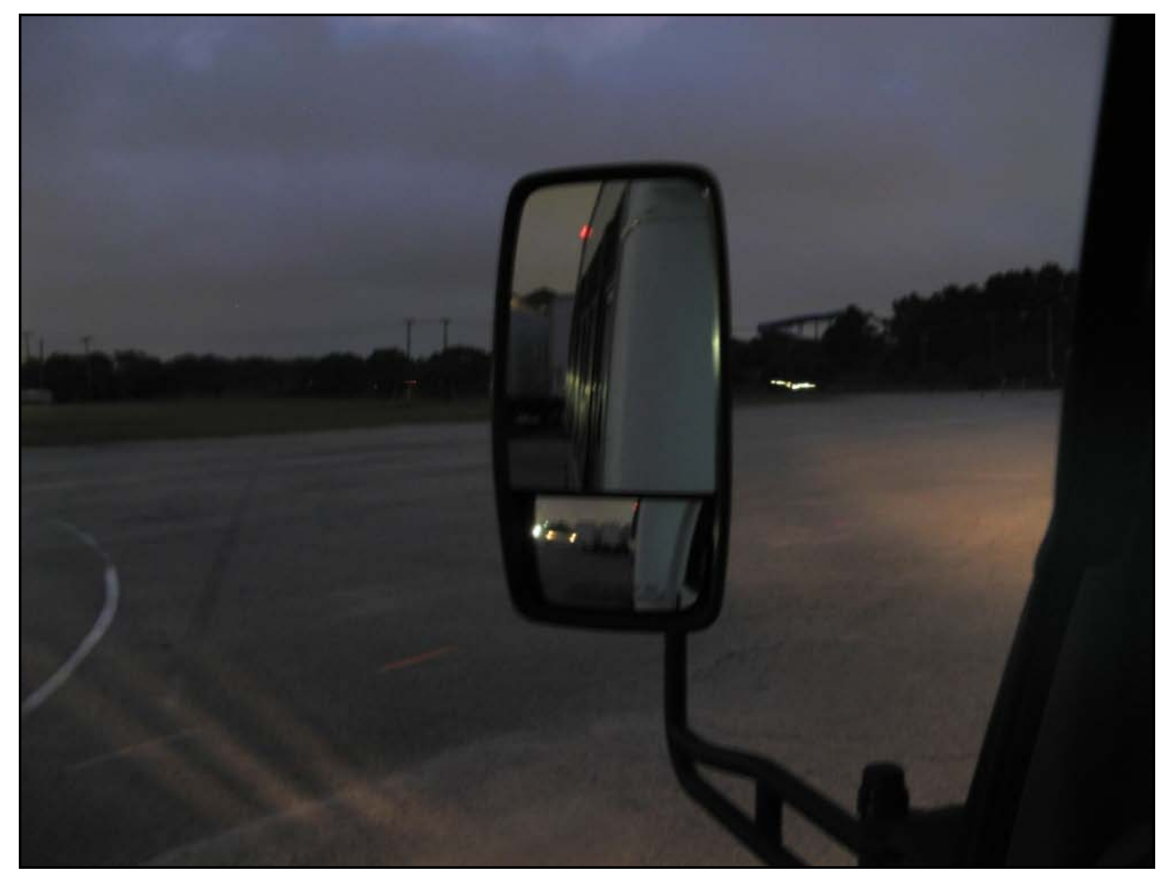

Figure 5-28. Image from mirror during nighttime

Another benefit of the system is that it provides a better view in rainy conditions. Since the camera is small, it is easier to clean. When raining, the window and mirrors have water droplets on the surface, making it much more difficult to see through them, as shown in Figure 5-29. In comparison, Figure 5-30 shows the image of the camera under the same weather conditions.

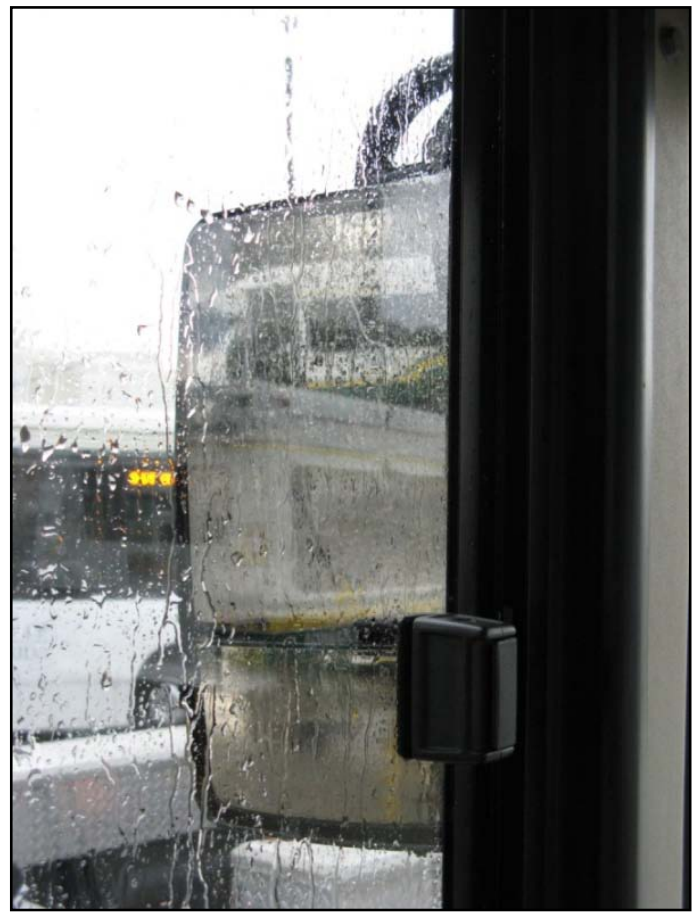

Figure 5-29. Image from mirror through driver's window while raining 


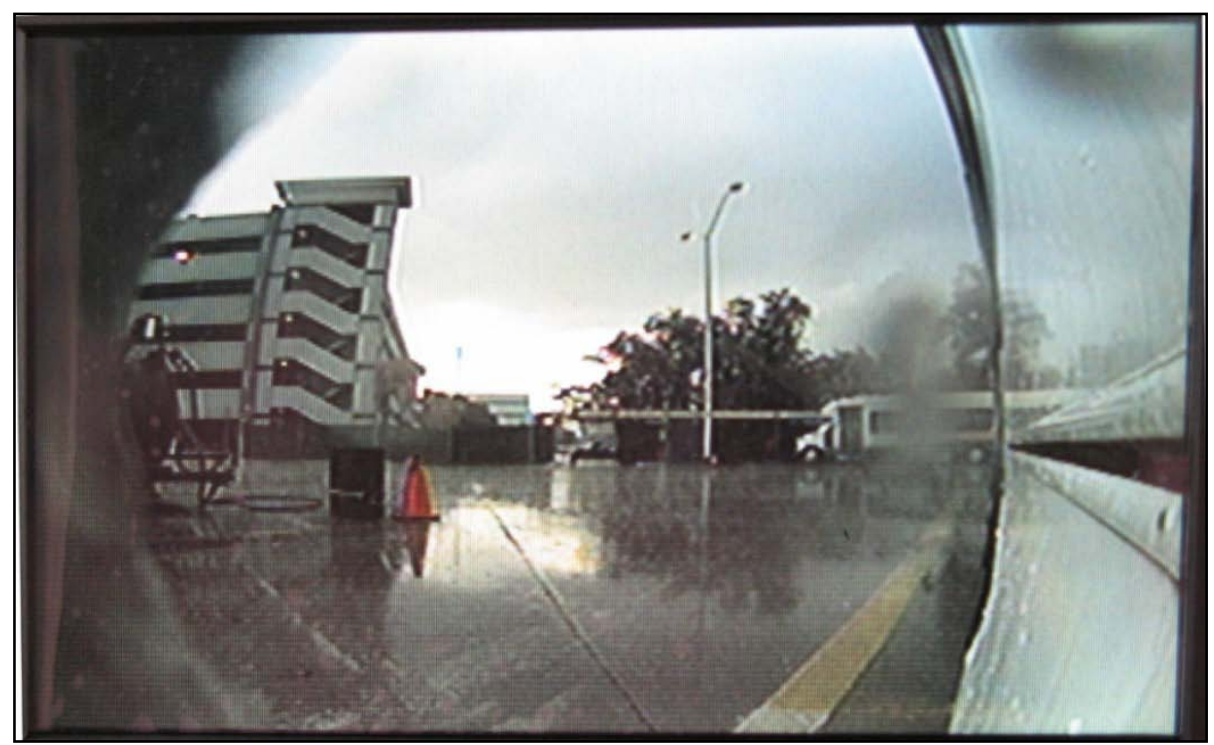

Figure 5-30. Image from sideview while raining

Another benefit of having the sideview video system is that it has a fixed FOV. When using the mirrors, each driver has to adjust the mirror for his/her height so that they get an adequate FOV. After interviewing the drivers and training officers from the participating agency, it became clear that most drivers do not readjust the mirrors when they get into the bus and, thus, drive the bus without the optimum FOV. This situation is shown in Figure 5-31, where the first mirror image is not adjusted properly for the driver and the vehicle is not visible in the flat mirror. In the second image the mirror is properly adjusted, and the vehicle is visible in both flat and convex mirrors. In comparison, the image from the sideview system is the same for all drivers, thus eliminating the need to make any adjustments providing the optimum FOV.
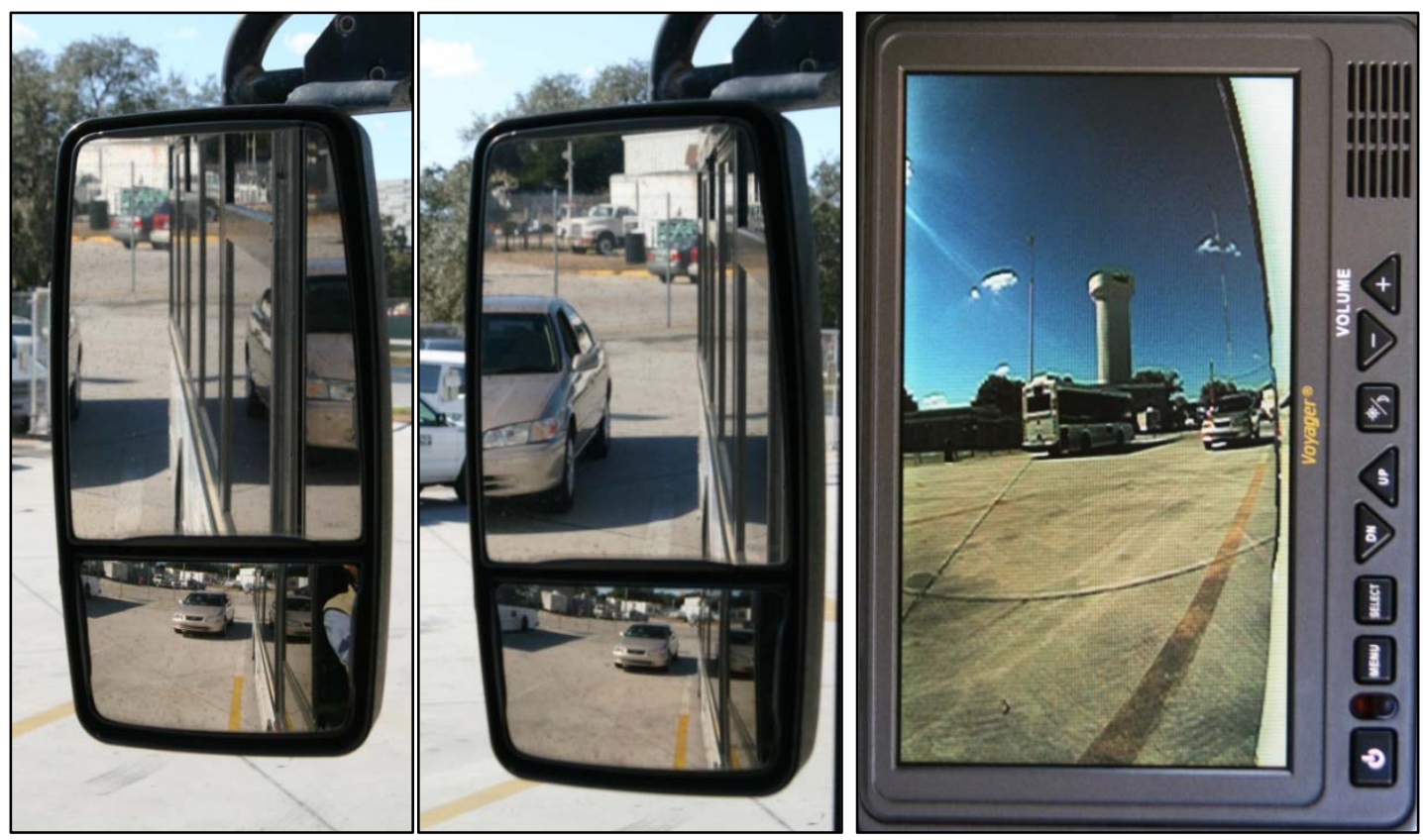

Figure 5-31. Mirror views for vehicle located behind the length of the bus 
Another benefit of the sideview video system is that the physical dimensions of the cameras are much less than that of the mirrors. In the case of the cutaway bus, the right side mirror is installed on the quarter panel or bumper. The height of the mirror is 5-6ft or lower. The mirror and bracket extend out of the wall of the bus, so it is dangerous because standing pedestrians or passengers could be hit if the driver is not careful. A few cases were actually reported of exactly this problem. By installing a sideview camera, the problem is eliminated because the camera does not extend more than 3" from the side wall of the bus. Figure 5-32 shows the side camera and mirror of the cutaway bus. Clearly, the camera is safer because it is not extending out nearly as much as the mirror.

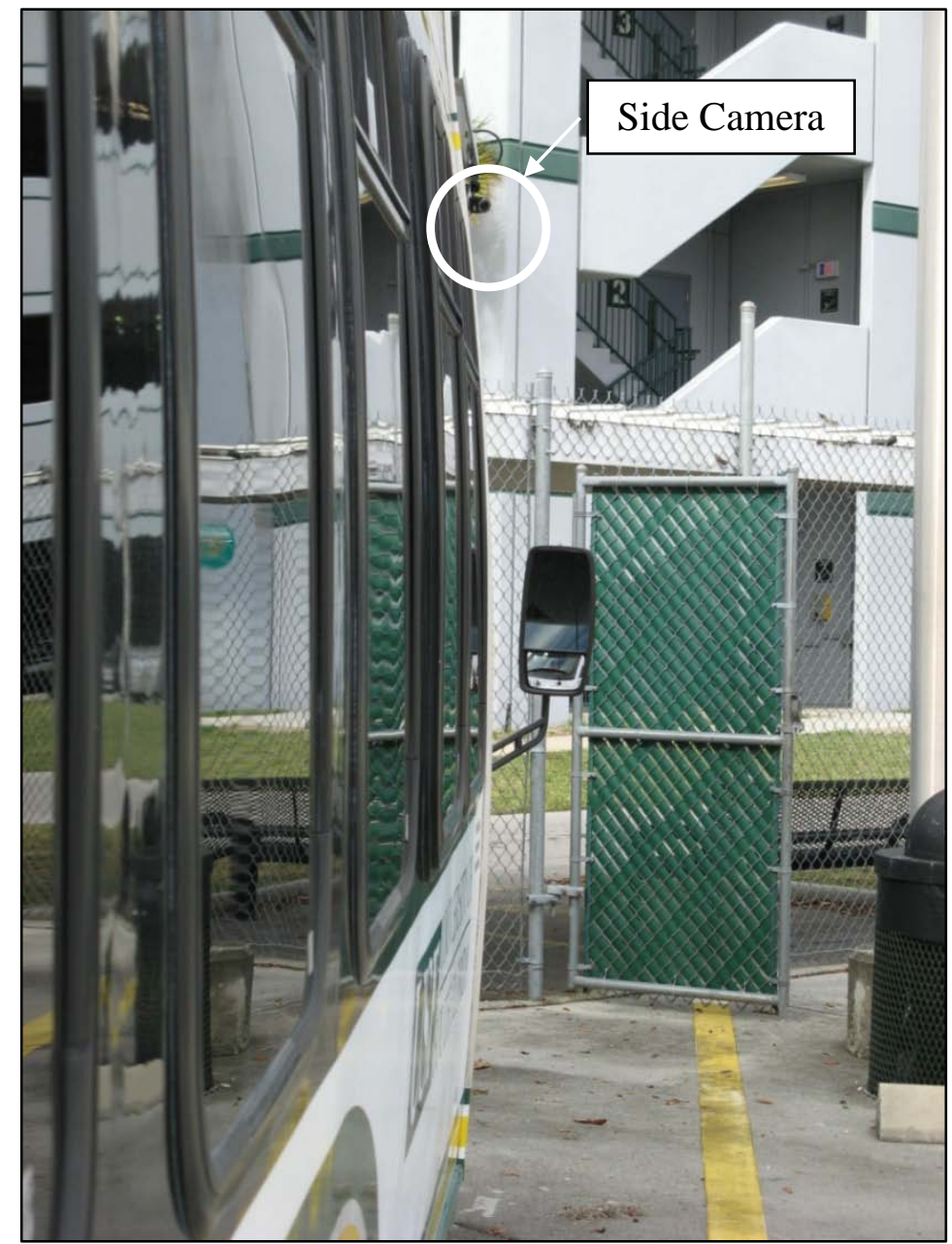

Figure 5-32. Side camera location on cutaway bus

A final benefit is that the video feed from the cameras can be recorded for insurance and claims documentation. Many transit agencies already use side cameras on the right side to record boarding and waiting passengers for evidence in case of a lawsuit. This provides the agencies with a good option in cases where passengers falsely claim that they were harmed by the bus driver's actions. 


\subsection{Conclusions and Recommendations}

This study was designed to evaluate the effectiveness of camera-based systems to reduce transit bus side crashes through measuring the reduction of blind zones and analyzing the results of controlled driving tests using sideview video systems. The proposed system incorporates video cameras installed on the outside walls of the bus aimed at the left and right rear sides of the bus, and two monitors inside the bus to provide the driver with images from the cameras. The sideview video system was closely evaluated using a controlled driving test that simulated reality scenarios. The controlled driving test was designed to establish if the transit bus drivers could drive using the sideview video system instead of mirrors, and if they value the benefits of having such a system. Also, the test was used to obtain feedback from the drivers about possible setup locations, monitor sizes, and orientation, as well as enhancements to make the sideview video system more attractive for use. From this study, the following conclusions were reached:

- In comparison with the sensor-based systems, camera-based systems provide an image to the driver that is simpler to process and requires less time. Available sensor-based systems have been evaluated in the past, and detection reliability and false alarms were the major concerns of the studies.

- The side blind zones that exist due to the mirrors' inability to cover the area were greatly reduced or eliminated when using the sideview video system with wide-angle cameras. Volumetric measurements of the field of view showed that the sideview video system provided greater coverage than the mirrors. The bus drivers could see at least two lanes next to the bus, providing them the opportunity to avoid situations where a lane change maneuver would potentially result in a sideswipe crash.

- The sideview video system was used in driver tests under controlled conditions to analyze the system's effectiveness. The drivers were able to adapt to the system and perceive distances similar to mirrors. This shows that the drivers can potentially drive a bus equipped with the system in the future.

- Driver surveys provided valuable feedback on the system. The majority of the participating drivers stated that they liked the sideview video system but were not confident about replacing the mirrors with the system used in the controlled driving test without further enhancement.

- The sideview video system has many benefits. The system can perform better than the mirrors in dark conditions and in rain. Also, the wide field of view provides drivers with a much better sideview, thus creating great potential for avoiding vehicles during lane changing maneuvers.

- The sideview video systems have minor limitations in certain lighting conditions, which can be further improved in the future. Also, the size and location of the monitors can vary, providing an optimum viewing experience. 
It is also important to note that the systems tested are available as aftermarket systems designed and manufactured to provide additional side views of the vehicle, but are not perfect and were not designed to be used in place of mirrors. Therefore, the sideview video system has great potential to be enhanced for use in the field.

This study has successfully completed the initial step of evaluating sideview video systems for transit buses. A sideview video system was installed and tested under controlled conditions with a sample of 28 bus drivers, who provided valuable feedback on the system. The study found that the system has great potential to improve the safety of bus operations in Florida.

Potential issues with the system's reliability under normal working conditions still need to be examined in a more realistic and longer field study. For this system to progress into an industryaccepted safety device, it will need further testing under real working conditions. CUTR proposes the following as future field deployments in phase II to further enhance the sideview video system for transit buses:

- Cameras are able to provide a wider view than mirrors, so there is a need to identify how much more view is needed or if the view provided by the wide-angle cameras is adequate.

- Based on the observation from the controlled driving test and feedback from the driver survey, sideview video systems can be further enhanced in the areas of camera view, camera location, monitor size, and monitor settings.

- It will be very beneficial to install an enhanced sideview video system on a number of buses from one or many transit agencies for field deployments and collect naturalistic and behavioral driver data in order to assess the actual effectiveness of the system under real working conditions as well as any potential interference with driving tasks. This will also provide the opportunity for the participating transit agencies to provide their insights on the system's design improvements.

- A variety of transit drivers from different driving environments will provide a more representative platform on which to base the results of the study.

- More technical specifications need to be drawn to identify specific locations, size, image contrast/brightness for monitors, lens angle, and field of view for the cameras for uniformity among transit agencies. 


\section{References}

1. Sando, T., G. Mbatta, D. Chimba, and R. Moses. The Influence of Narrower Lanes on Bus Sideswipe Crashes. In TRB Annual Meeting 2009 Compendium of Papers. DVD. Transportation Research Board of the National Academies, Washington D.C., 2009.

2. Rephlo, J., S. Miller, R. Haas, H. Saporta, D. Stock, D. Miller, L. Feast, and B. Brown. Side Object Detection System Evaluation: Final Evaluation Report. Contract DTFH61-02-C00061. ITS Joint Program Office, U.S. Department of Transportation, 2008.

3. National Highway Traffic Safety Administration. Traffic Safety Facts Reports 2003-2006. http://www.nhtsa.dot.gov/. Accessed Nov. 10, 2009.

4. Dunn, T., R. Laver, D. Skorupski, and D. Zyrowski. Assessing the Business Case for Integrated Collision Avoidance Systems on Transit Buses. Publication FTA-OMB No. 07040188. FTA, U.S. Department of Transportation, 2007.

5. Wierwille, W. W., W. A. Schaudt, S. K. Gupta, J. M. Spaulding, and R.J. Hanowski. Development of a Performance Specification for Camera-Video Imaging Systems on Heavy Trucks. Publication NHTSA-DOT-HS-810-958. NHTSA, U.S. Department of Transportation, 2008.

6. McNeil, S., C. Thorpe, and C. Mertz. A New Focus for Side Collision Warning Systems for Transit Buses. In Intelligent Transportation Society of America's Tenth Annual Meeting and Exposition. CD-ROM. Intelligent Transportation Society of America, Washington D.C., 1999.

7. Mazzae, E. N., and R. W. Garrott. Experimental Evaluation of the Performance of Available Backover Prevention Technologies for Medium Straight Trucks. Publication NHTSA-DOTHS-810-865. NHTSA, U.S. Department of Transportation, 2007. 


\section{Appendix}

\section{Controlled Driving Test for Sideview Video System}

\section{Driver Packet:}

- Driver Informed Consent Form

- Survey "Before” Test

- Survey “After” Test 


\section{Informed Consent to Participate in Research Information to Consider Before Taking Part in this Research Study}

\section{IRB Study \# 107658 I}

Researchers at the Center for Urban Transportation Research (CUTR) in the University of South Florida (USF) study many topics. For some studies, we need the help of people who agree to participate. This form will discuss this specific research study.

We are asking you to take part in a research study that is called:

"Evaluation of Camera-Based Systems to Reduce Transit Bus Side Collisions”

Your participation will help the research team to evaluate whether the sideview camera-based system has the potential to effectively assist transit bus drivers to reduce side collisions.

Dr. Pei-Sung Lin, Director of ITS, Traffic Operations and Safety Program at CUTR, is the Principal Investigator of this research study. With Dr. Lin's permission, his research staff involved in the study can act on his behalf.

The person explaining the research to you may be someone other than the Principal Investigator. Other research personnel who you may be involved with include Dr. Chanyoung Lee and Dr. Achilleas Kourtellis.

The research study will be done at the USF Bullrunner training facility in Tampa, Florida.

This research is sponsored by National Center of Transit Research and the Florida Department of Transportation.

\section{Purpose of the Study}

The purpose of this study is to:

- Evaluate the effectiveness of camera-based systems in reducing side collisions under a controlled condition. This will be done through a variety of different methods, including a controlled driving test and driver surveys. All tests will be conducted in a laboratory environment not on actual roads.

\section{Study Procedures}

If you take part in this study, you will be asked to:

- Participate in a controlled driving test, which will involve performing driving tasks using mirrors and a sideview video system. This will allow researchers to evaluate the difference between using the mirrors and a camera-based system. The test will last one hour per participant. Recordings from the camera will be used to note behavioral changes with drivers while using the system. The videos will be used only for completing the research, and personal driver identification information will be confidential. This test will be performed at the bus driver training facility located in Tampa, Florida. 
- Complete driver surveys for the use of the system.

\section{Alternatives}

You have the alternative to choose not to participate in this research study.

\section{Benefits}

Drivers who participate in this study will have a better knowledge of "no zone" areas and understand lane changing maneuvers. In addition, you will be given an appreciation certificate to recognize your contribution to the study.

\section{Risks or Discomfort}

There is no known risk or discomfort.

\section{Compensation}

For your participation in this study, you will be compensated at your hourly wage with USF Parking and Transportation Services.

\section{Confidentiality}

We must keep your study records as confidential as possible. The study requires that we record the video from all cameras while you are driving the bus for observation and analysis at a later time. The digital video will be kept confidential and will not be released without your written consent. The videos will be stored on computers located in CUTR at the University of South Florida with no access by outside sources. After obtaining your written consent, some parts of the videos might be used in presentations in research conferences to share insights from the project. Your personal information will never be released to, presented to, or shared with any party. However, certain people may need to see your study records. By law, anyone who looks at your records must keep them completely confidential. The only people who will be allowed to see these records are:

- The research team, including the Principal Investigator, study coordinator, and all other research staff.

- Certain government and university people who need to know more about the study. For example, individuals who provide oversight on this study may need to look at your records. This is done to make sure that we are doing the study in the right way. They also need to make sure that we are protecting your rights and your safety. These include:

o The University of South Florida Institutional Review Board (IRB) and the staff who work for the IRB. Other individuals who work for USF that provide other kinds of oversight may also need to look at your records.

o The Department of Health and Human Services (DHHS).

o People at the agency who paid for this study, the Florida Department of Transportation, may look at the study records.

We may publish what we learn from this study. If we do, we will not reveal identifying information. We will not publish anything that would let people know who you are. 


\section{Voluntary Participation / Withdrawal}

You should take part in this study only if you want to volunteer. You should not feel that there is any pressure to take part in the study to please the investigator or the research staff. You are free to participate in this research or withdraw at any time. There will be no penalty or loss of benefits you are entitled to receive if you stop taking part in this study.

\section{Questions, Concerns, or Complaints}

If you have any questions, concerns or complaints about this study, call Dr. Pei-Sung Lin at 813974-4910. If you have questions about your rights as a participant in this study, general questions, or if you have complaints, concerns, or issues you want to discuss with someone outside the research, call the Division of Research Integrity and Compliance of the University of South Florida at (813) 974-9343.

If you experience an unanticipated problems related to the research, call Dr. Pei-Sung Lin at 813974-4910.

\section{Consent to Take Part in this Research Study}

It is up to you to decide whether you want to take part in this study. If you want to take part, please sign the form if the following statements are true.

I freely give my consent to take part in this study. I understand that by signing this form I am agreeing to take part in research. I have received a copy of this form to take with me.

Signature of Person Taking Part in Study

Date

Printed Name of Person Taking Part in Study

\section{Statement of Person Obtaining Informed Consent}

I have carefully explained to the person taking part in the study what he or she can expect.

I hereby certify that when this person signs this form, to the best of my knowledge, he or she understands:

- What the study is about.

- What procedures/interventions/investigational drugs or devices will be used.

- What the potential benefits might be.

- What the known risks might be.

Signature of Person Obtaining Informed Consent

Date

Printed Name of Person Obtaining Informed Consent 


\section{Controlled Driving Test}

\section{Sideview Video System}

This system has two cameras and two monitors, one for each side of the bus. It can potentially replace the sideview mirrors. Instead of having the sideview mirrors, you will have two monitors inside the bus to show you each side of the bus. The monitors will be mounted as shown below:

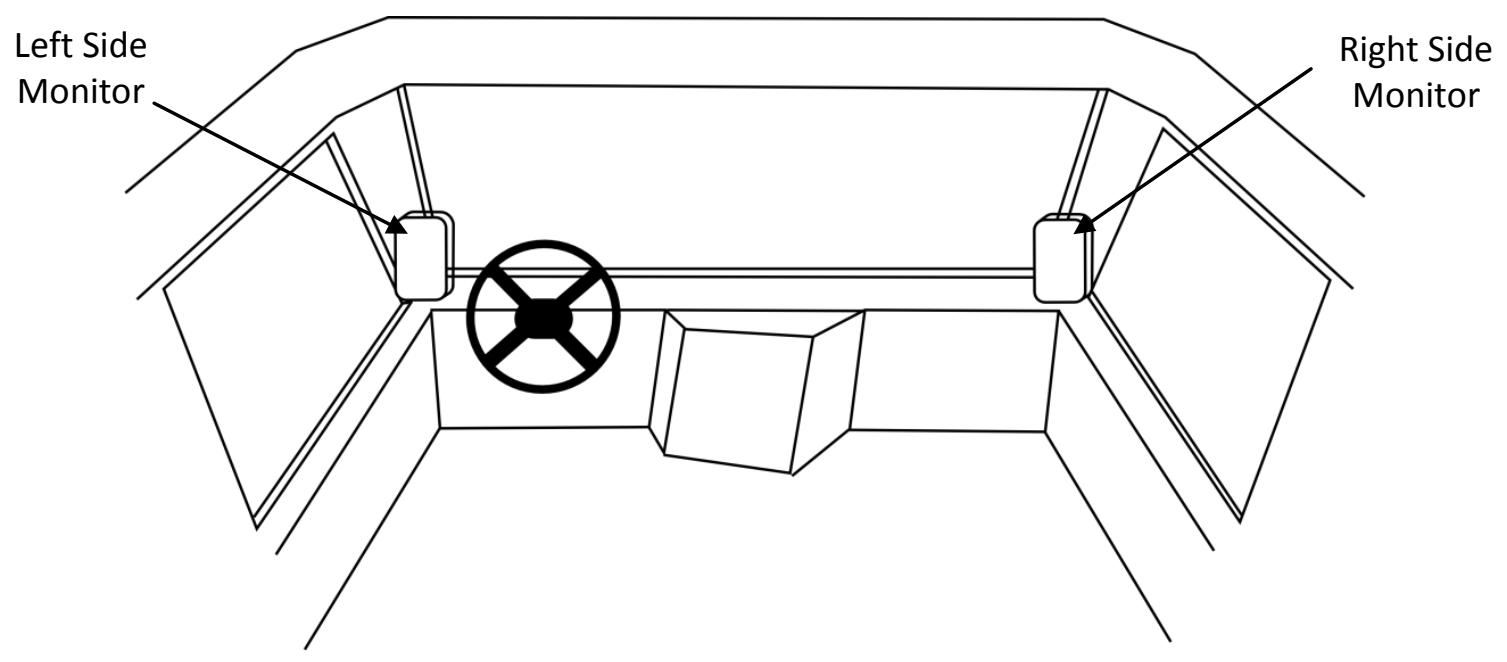

The diagram below shows the Field of View of the mirrors and camera system:

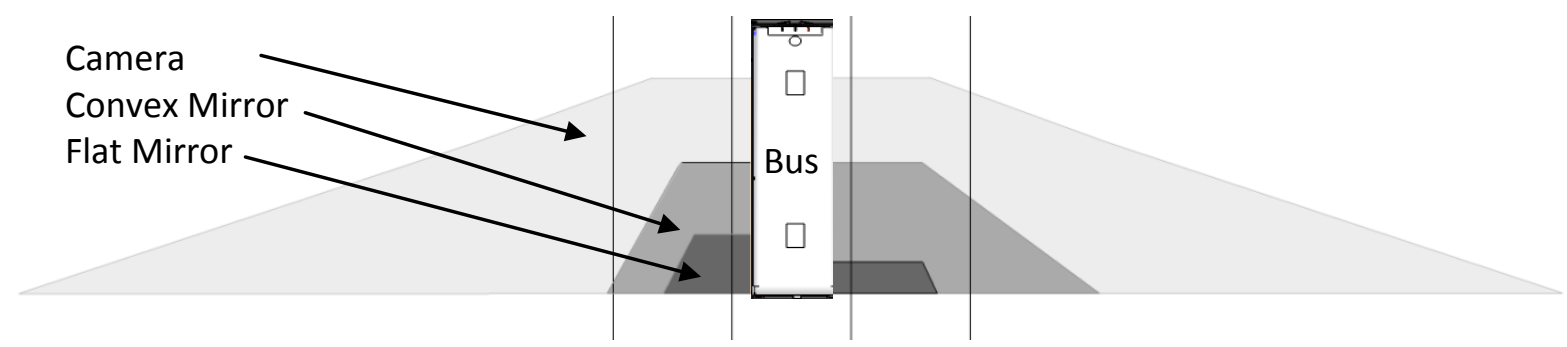

Based on your perception for the system, please fill out the "before" test survey. 


\section{“Before” Test Survey}

1. Have you experienced an incident where the side mirrors struck a person or an object?
A) Yes I have.
B) No I have not.

(If Yes, please elaborate.)

2. Do you agree that the side mirrors become less effective during rainy weather due to the water droplets on the window glass and mirrors?

\begin{tabular}{|c|c|c|c|c|c|}
1 & 2 & 3 & 4 & 5 & 6 \\
\hline $\begin{array}{c}\text { Strongly } \\
\text { Agree }\end{array}$ & Agree & $\begin{array}{c}\text { Somewhat } \\
\text { Agree }\end{array}$ & $\begin{array}{c}\text { Somewhat } \\
\text { Disagree }\end{array}$ & Disagree & $\begin{array}{c}\text { Strongly } \\
\text { Disagree }\end{array}$
\end{tabular}

3. Do you agree that it is difficult to identify an object/person with the side mirrors during nighttime?

\begin{tabular}{|c|c|c|c|c|c|}
1 & 2 & 3 & 4 & 5 & 6 \\
\hline $\begin{array}{c}\text { Strongly } \\
\text { Agree }\end{array}$ & Agree & $\begin{array}{c}\text { Somewhat } \\
\text { Agree }\end{array}$ & $\begin{array}{c}\text { Somewhat } \\
\text { Disagree }\end{array}$ & Disagree & $\begin{array}{c}\text { Strongly } \\
\text { Disagree }\end{array}$
\end{tabular}

4. With the sideview video system, are the side blind zones reduced/eliminated compared to conventional mirrors?

\begin{tabular}{|c|c|c|c|c|c|}
1 & 2 & 3 & 4 & 5 & 6 \\
\hline $\begin{array}{c}\text { Strongly } \\
\text { Agree }\end{array}$ & Agree & $\begin{array}{c}\text { Somewhat } \\
\text { Agree }\end{array}$ & $\begin{array}{c}\text { Somewhat } \\
\text { Disagree }\end{array}$ & Disagree & $\begin{array}{c}\text { Strongly } \\
\text { Disagree }\end{array}$
\end{tabular}

5. Can the sideview video system help drivers to reduce side crashes (sideswipe, turns, angle crashes) by providing a better view?

\begin{tabular}{|c|c|c|c|c|c|}
1 & 2 & 3 & 4 & 5 & 6 \\
\hline $\begin{array}{c}\text { Strongly } \\
\text { Agree }\end{array}$ & Agree & $\begin{array}{c}\text { Somewhat } \\
\text { Agree }\end{array}$ & $\begin{array}{c}\text { Somewhat } \\
\text { Disagree }\end{array}$ & Disagree & $\begin{array}{c}\text { Strongly } \\
\text { Disagree }\end{array}$
\end{tabular}

6. In general, can the sideview video system improve bus safety?

\begin{tabular}{|c|c|c|c|c|c|}
1 & 2 & 3 & 4 & 5 & 6 \\
\hline $\begin{array}{c}\text { Strongly } \\
\text { Agree }\end{array}$ & Agree & $\begin{array}{c}\text { Somewhat } \\
\text { Agree }\end{array}$ & $\begin{array}{c}\text { Somewhat } \\
\text { Disagree }\end{array}$ & Disagree & $\begin{array}{c}\text { Strongly } \\
\text { Disagree }\end{array}$
\end{tabular}

7. Is the use of the sideview video system easy and can it be adopted quickly?

\begin{tabular}{|c|c|c|c|c|c|}
1 & 2 & 3 & 4 & 5 & 6 \\
\hline $\begin{array}{c}\text { Strongly } \\
\text { Agree }\end{array}$ & Agree & $\begin{array}{c}\text { Somewhat } \\
\text { Agree }\end{array}$ & $\begin{array}{c}\text { Somewhat } \\
\text { Disagree }\end{array}$ & Disagree & $\begin{array}{c}\text { Strongly } \\
\text { Disagree }\end{array}$
\end{tabular}


8. Would you agree to replace the mirrors with the sideview video system?

\begin{tabular}{|c|c|c|c|c|c|}
1 & 2 & 3 & 4 & 5 & 6 \\
\hline $\begin{array}{c}\text { Strongly } \\
\text { Agree }\end{array}$ & Agree & $\begin{array}{c}\text { Somewhat } \\
\text { Agree }\end{array}$ & $\begin{array}{c}\text { Somewhat } \\
\text { Disagree }\end{array}$ & Disagree & $\begin{array}{c}\text { Strongly } \\
\text { Disagree }\end{array}$
\end{tabular}

\section{Driving Test Procedure}

You will now go over the test with one of the test administrators. First, you will go through a course using the camera-based system only to get familiar with the system. The course will look like the diagram in the next picture.

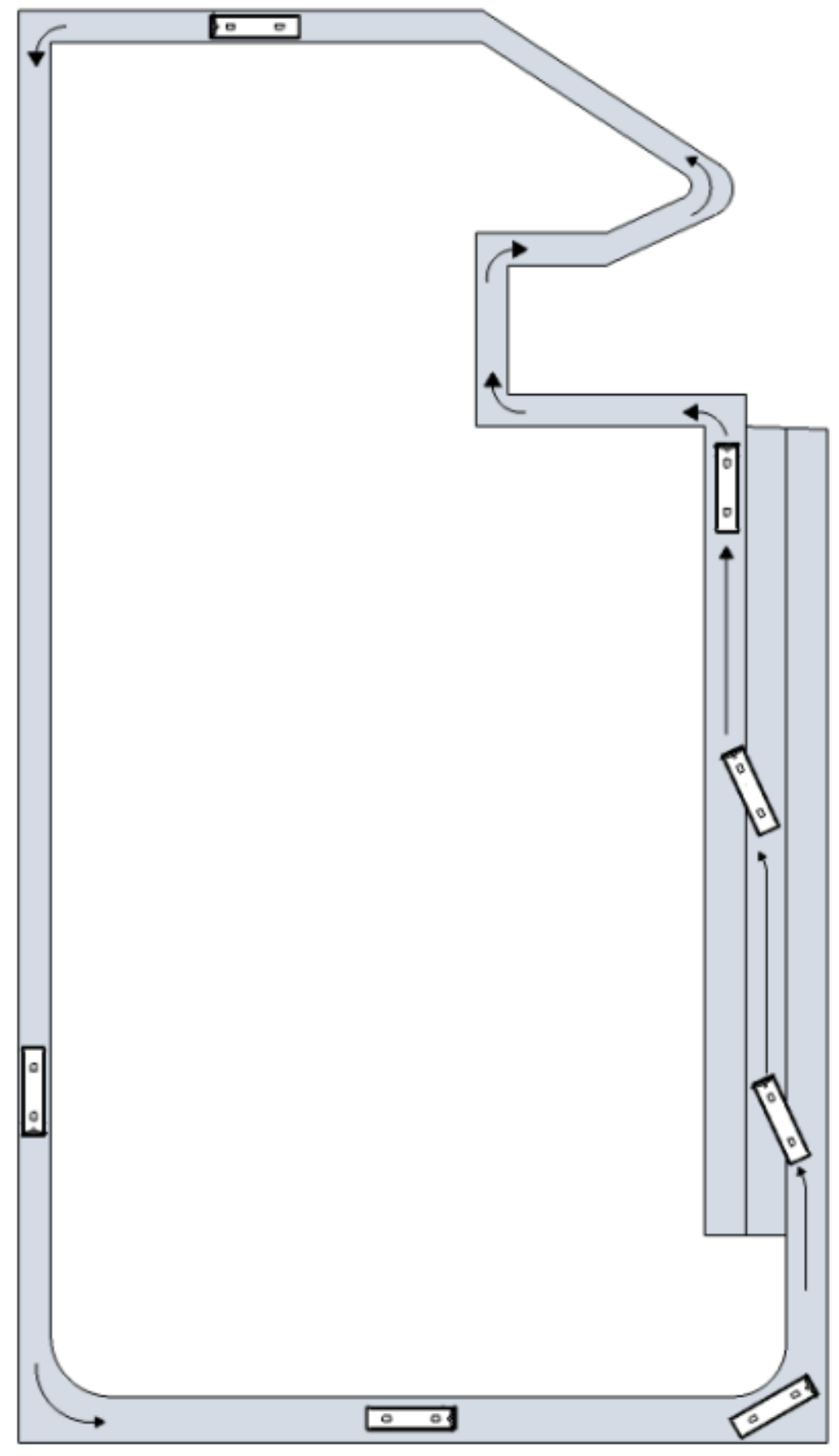


You will then perform the maneuvers shown next.

Lane change (car next lane)
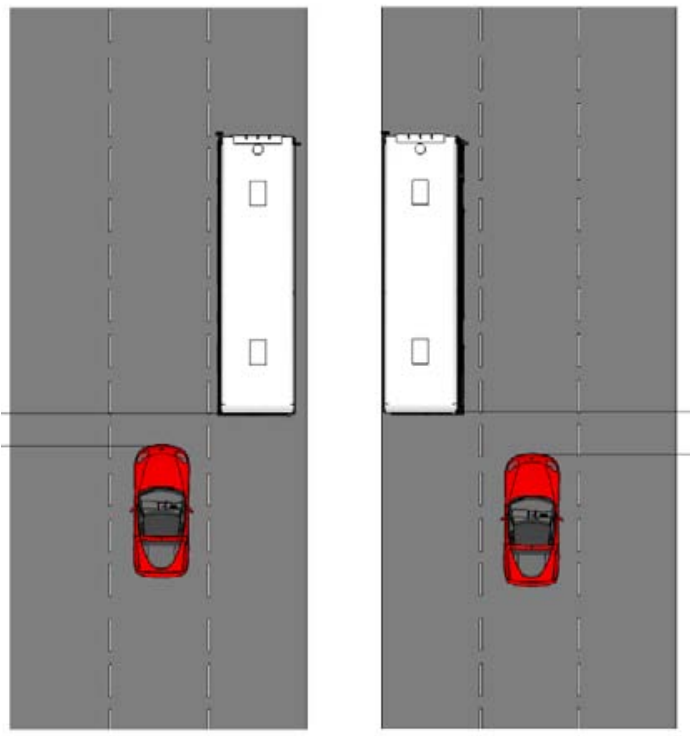

Lane change (car one lane over)
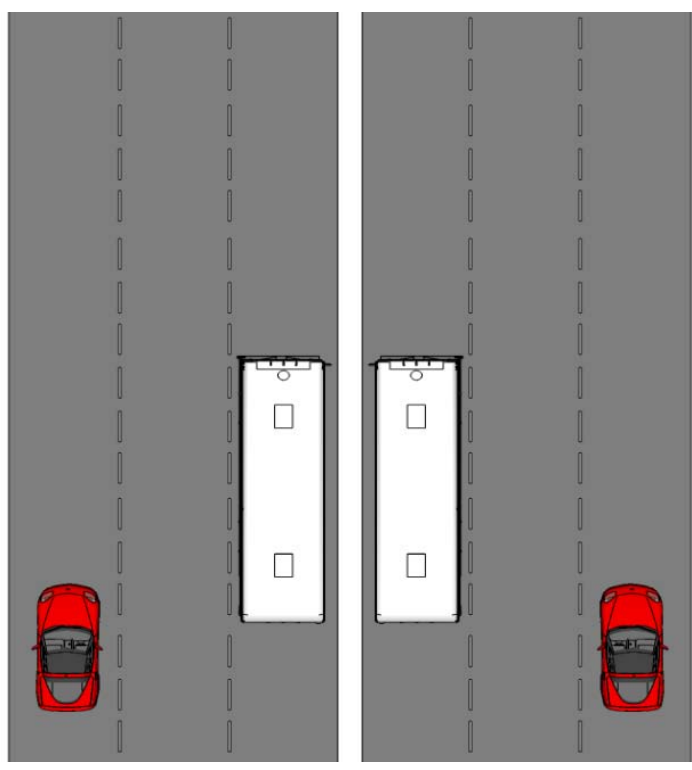


\section{After Test Survey}

9. With the sideview video system, are the side blind zones reduced/eliminated compared to conventional mirrors?

\begin{tabular}{|c|c|c|c|c|c|}
1 & 2 & 3 & 4 & 5 & 6 \\
\hline $\begin{array}{c}\text { Strongly } \\
\text { Agree }\end{array}$ & Agree & $\begin{array}{c}\text { Somewhat } \\
\text { Agree }\end{array}$ & $\begin{array}{c}\text { Somewhat } \\
\text { Disagree }\end{array}$ & Disagree & $\begin{array}{c}\text { Strongly } \\
\text { Disagree }\end{array}$
\end{tabular}

10. Can the sideview video system help drivers to reduce side crashes (sideswipe, turns, angle crashes) by providing a better view?

\begin{tabular}{|c|c|c|c|c|c|}
1 & 2 & 3 & 4 & 5 & 6 \\
\hline $\begin{array}{c}\text { Strongly } \\
\text { Agree }\end{array}$ & Agree & $\begin{array}{c}\text { Somewhat } \\
\text { Agree }\end{array}$ & $\begin{array}{c}\text { Somewhat } \\
\text { Disagree }\end{array}$ & Disagree & $\begin{array}{c}\text { Strongly } \\
\text { Disagree }\end{array}$
\end{tabular}

11. In general, can the sideview video system improve bus safety?

\begin{tabular}{|c|c|c|c|c|c|}
1 & 2 & 3 & 4 & 5 & 6 \\
\hline $\begin{array}{c}\text { Strongly } \\
\text { Agree }\end{array}$ & Agree & $\begin{array}{c}\text { Somewhat } \\
\text { Agree }\end{array}$ & $\begin{array}{c}\text { Somewhat } \\
\text { Disagree }\end{array}$ & Disagree & $\begin{array}{c}\text { Strongly } \\
\text { Disagree }\end{array}$
\end{tabular}

12. Is the use of the sideview video system easy and can it be adopted quickly?

\begin{tabular}{|c|c|c|c|c|c|}
1 & 2 & 3 & 4 & 5 & 6 \\
\hline $\begin{array}{c}\text { Strongly } \\
\text { Agree }\end{array}$ & Agree & $\begin{array}{c}\text { Somewhat } \\
\text { Agree }\end{array}$ & $\begin{array}{c}\text { Somewhat } \\
\text { Disagree }\end{array}$ & Disagree & $\begin{array}{c}\text { Strongly } \\
\text { Disagree }\end{array}$
\end{tabular}

13. Would you agree to replace the mirrors with the sideview video system?

\begin{tabular}{|c|c|c|c|c|c|}
1 & 2 & 3 & 4 & 5 & 6 \\
\hline $\begin{array}{c}\text { Strongly } \\
\text { Agree }\end{array}$ & Agree & $\begin{array}{c}\text { Somewhat } \\
\text { Agree }\end{array}$ & $\begin{array}{c}\text { Somewhat } \\
\text { Disagree }\end{array}$ & Disagree & $\begin{array}{c}\text { Strongly } \\
\text { Disagree }\end{array}$
\end{tabular}

14. Do you agree that with the sideview camera-based system you can observe the boarding and late arriving passengers better than with the side mirror?

\begin{tabular}{|c|c|c|c|c|c|}
1 & 2 & 3 & 4 & 5 & 6 \\
\hline $\begin{array}{c}\text { Strongly } \\
\text { Agree }\end{array}$ & Agree & $\begin{array}{c}\text { Somewhat } \\
\text { Agree }\end{array}$ & $\begin{array}{c}\text { Somewhat } \\
\text { Disagree }\end{array}$ & Disagree & $\begin{array}{c}\text { Strongly } \\
\text { Disagree }\end{array}$
\end{tabular}
15. Your Age:
A) Under 25
B) $26-30$
C) 31 to 40
D) 41 to 50
E) $50+$

16. Years of bus driving experience: yrs 
17. Previous experience with any camera aid systems (backup, rear view, side or otherwise)?
A) YES
B) $\mathrm{NO}$

a. If YES above:

Duration of experience with camera-based system:
A) 1 week
B) 1-2 weeks
C) 3-4 weeks
D) 1-2 months
E) 3-4 months
F) Never

18. Ever had side crashes during bus driving? YES NO

19. Does the sideview video system provide a better sideview than the mirrors?

\begin{tabular}{|c|c|c|c|c|c|}
1 & 2 & 3 & 4 & 5 & 6 \\
\hline $\begin{array}{c}\text { Strongly } \\
\text { Agree }\end{array}$ & Agree & $\begin{array}{c}\text { Somewhat } \\
\text { Agree }\end{array}$ & $\begin{array}{c}\text { Somewhat } \\
\text { Disagree }\end{array}$ & Disagree & $\begin{array}{c}\text { Strongly } \\
\text { Disagree }\end{array}$
\end{tabular}

20. Do you agree that you can comfortably drive the bus with the sideview video system alone (without mirrors)?

\begin{tabular}{|c|c|c|c|c|c|}
1 & 2 & 3 & 4 & 5 & 6 \\
\hline $\begin{array}{c}\text { Strongly } \\
\text { Agree }\end{array}$ & Agree & $\begin{array}{c}\text { Somewhat } \\
\text { Agree }\end{array}$ & $\begin{array}{c}\text { Somewhat } \\
\text { Disagree }\end{array}$ & Disagree & $\begin{array}{c}\text { Strongly } \\
\text { Disagree }\end{array}$
\end{tabular}

21. Would you like to have a sideview video system in the bus you drive every day?

\begin{tabular}{|c|c|c|c|c|c|}
1 & 2 & 3 & 4 & 5 & 6 \\
\hline Absolutely No & Probably No & No & Yes & Probably Yes & $\begin{array}{c}\text { Absolutely } \\
\text { Yes }\end{array}$
\end{tabular}

If you answered NO above, please indicate why not.

22. With the sideview video, did you feel comfortable performing a lane change maneuver?

\begin{tabular}{|c|c|c|c|c|c|}
1 & 2 & 3 & 4 & 5 & 6 \\
\hline $\begin{array}{c}\text { Strongly } \\
\text { Agree }\end{array}$ & Agree & $\begin{array}{c}\text { Somewhat } \\
\text { Agree }\end{array}$ & $\begin{array}{c}\text { Somewhat } \\
\text { Disagree }\end{array}$ & Disagree & $\begin{array}{c}\text { Strongly } \\
\text { Disagree }\end{array}$
\end{tabular}

23. Does the sideview video system have the potential to help reduce side crashes during a lane change maneuver?

\begin{tabular}{|c|c|c|c|c|c|}
1 & 2 & 3 & 4 & 5 & 6 \\
\hline $\begin{array}{c}\text { Strongly } \\
\text { Agree }\end{array}$ & Agree & $\begin{array}{c}\text { Somewhat } \\
\text { Agree }\end{array}$ & $\begin{array}{c}\text { Somewhat } \\
\text { Disagree }\end{array}$ & Disagree & $\begin{array}{c}\text { Strongly } \\
\text { Disagree }\end{array}$
\end{tabular}


24. Can the sideview video system minimize or eliminate the side blind zones of the bus?

\begin{tabular}{|c|c|c|c|c|c|}
1 & 2 & 3 & 4 & 5 & 6 \\
\hline $\begin{array}{c}\text { Strongly } \\
\text { Agree }\end{array}$ & Agree & $\begin{array}{c}\text { Somewhat } \\
\text { Agree }\end{array}$ & $\begin{array}{c}\text { Somewhat } \\
\text { Disagree }\end{array}$ & Disagree & $\begin{array}{c}\text { Strongly } \\
\text { Disagree }\end{array}$
\end{tabular}

\section{Additional Comments}

Are there any additional comments or recommendations you would like to make regarding the sideview video system (likes, dislikes, monitor-camera locations, system configuration, etc.)? 